Daniele Cristina Bosco Aprile

\title{
Efeito agudo do exercício físico aeróbio na atividade nervosa simpática periférica de pacientes portadores de doença renal crônica - estágio III
}

Dissertação apresentada à Faculdade de Medicina da Universidade de São Paulo para obtenção do título de Mestre em Ciências

Área de concentração: Nefrologia Orientadora: Profa. Dra.Taís Tinucci 
Dedicatória

Dedico esse trabalho a meus pais Sandra e Tarcílio, pelo amor incondicional e por estarem ao meu lado, em todas as minhas escolhas...

Aos meus irmãos Nando, João e Alexandre, pela cumplicidade e amizade, mesmo distantes...

Ao meu porto seguro, Alex, pela paciência e compreensão, por ser minha razão nos momentos em que eu era somente emoção. 


\section{Agradecimentos}

Agradeço primeiramente a Deus por colocar em minha vida saúde, persistência e oportunidades que me possibilitaram a chegar até aqui...

À Taís Tinucci, minha orientadora, pela confiança e amizade em todos os momentos e especialmente durante a elaboração deste trabalho...

Ao Dr. Décio Mion Jr., pela disponibilização do Laboratório de Hipertensão...

À Cláudia Forjaz, e aos colegas do LAHAM pela amizade e pelo auxílio sempre, especialmente ao Dr. Luiz Augusto Riane...

À Josiane Gusmão e Silvana, pela paciência, disponibilidade, auxílio e bom humor nos momentos críticos, especialmente durante a realização dos experimentos...

À Eliana e Pedro, da secretaria de pós-graduação, por serem solícitos, sempre...

A todos os meus amigos que ajudaram, das mais variadas formas, a realizar este trabalho, especialmente: Desire Coelho, Daniel Sanches, Tatiana Yago, Pedro Berseli, Vívian Gitti, Gustavo Vinciprova, Viviane Yamamoto, Oswaldo Jr, Carla Rossetto, Sílvia Novaes, Edson Blefari, Luciano Russo, Milena Araújo, Aline Araújo, Carolina Cagnacci, Vanessa Zambelli, Rochele Aquino, Fabiana Benatti, Fabiana Okagawa, Mônica Saião, Marinella Burgos, Larissa Jardini, Maria Paula, Daniane Friedl, Cassio Marques, Antonio Alonso, Lazuli Akimura.

A todos os voluntários que viabilizaram este trabalho...

Aos meus familiares sempre acreditaram em mim e torceram por meu sucesso...

A Marinalva, funcionária da biblioteca central, por sua empatia...

E especialmente à Bruna Oneda, pelo auxílio, paciência, bom humor, disponibilidade e conhecimento. Por ser sempre tão solícita, amiga e contribuir imensamente para realização deste trabalho! 


\section{SUMÁRIO}

Página

Lista de abreviaturas................................................................. i

Lista de Figuras................................................................................. ii

Lista de Tabelas............................................................................ iv

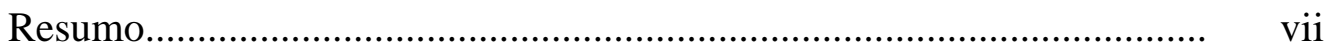

Summary .............................................................................. viii

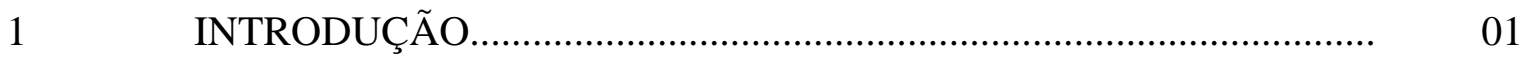

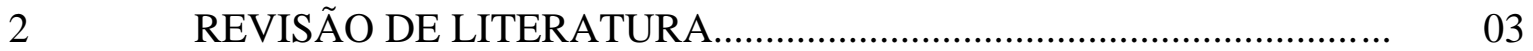

2.1 Doença Renal Crônica........................................................................... 03

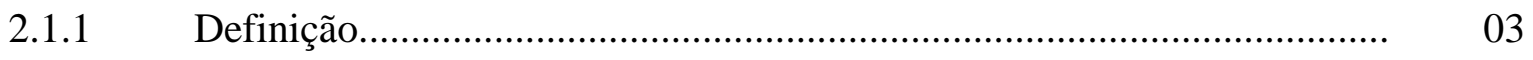

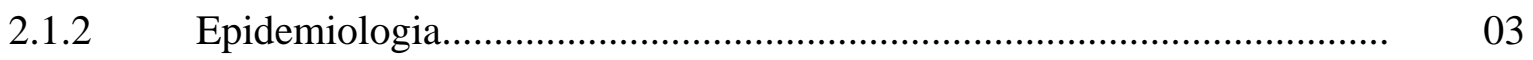

2.1.3 Estágios, progressão e classificação da doença......................................... 04

2.1.4 Diagnóstico da DRC e marcadores da lesão renal..................................... 06

2.1.5 Complicações e fatores de risco associados............................................... 07

2.1.5.1 Doenças cardiovasculares..................................................................... 07

2.1.5.2 Hiperatividade do sistema nervoso simpático........................................... 11

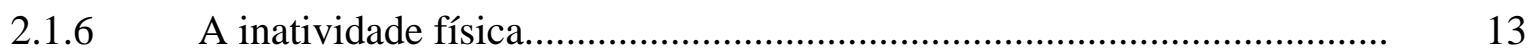

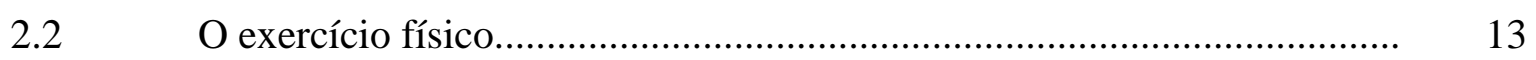

2.2.1 Classificação do exercício físico.............................................................. 14

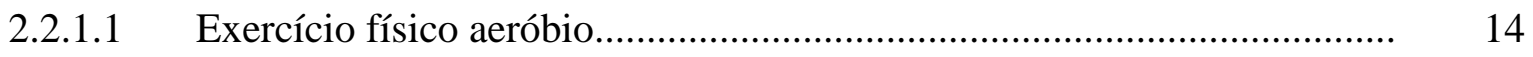

2.2.1.2 Efeitos agudos do exercício físico aeróbio............................................... 15

2.3 Controle neural da atividade cardiovascular no exercício......................... 16

2.3.1 O controle reflexo da circulação durante o exercício................................ 17

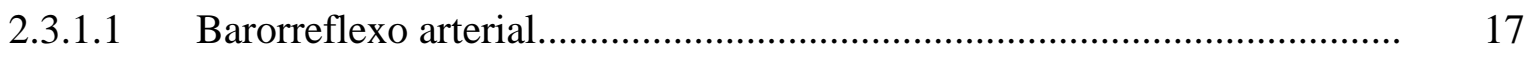

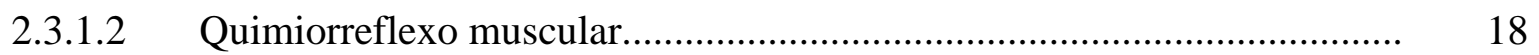


2.3.1.3 Mecanorreflexo muscular.

2.4 A função renal e o exercício físico.......................................................... 19

2.5 A doença renal crônica e o exercício físico................................................. 22

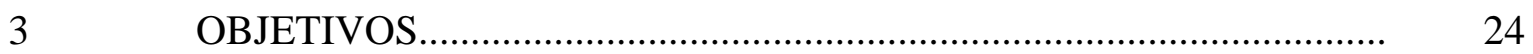

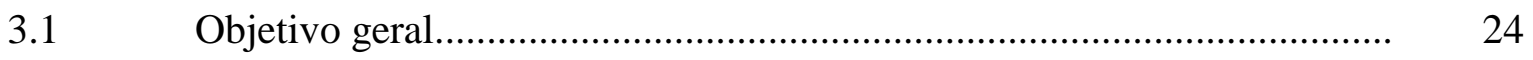

Objetivos específicos.................................................................. 24

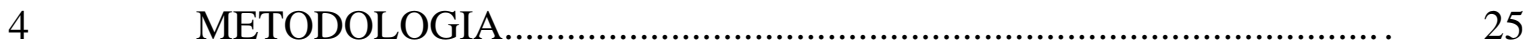

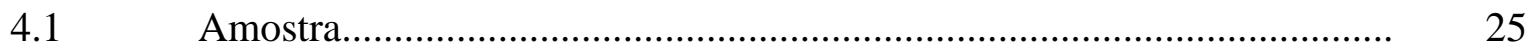

Critérios de inclusão....................................................................... 25

Exames Preliminares..................................................................... 26

4.3.1 Diagnóstico de Hipertensão.................................................................... 26

4.3.2 Diagnóstico de Obesidade ........................................................................ 26

4.3.3 Exames laboratoriais........................................................................... 27

4.3.4 Avaliação do condicionamento físico (Capacidade aeróbia máxima)....... 27

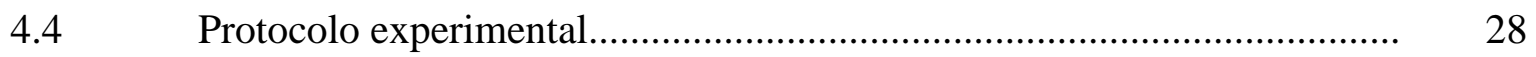

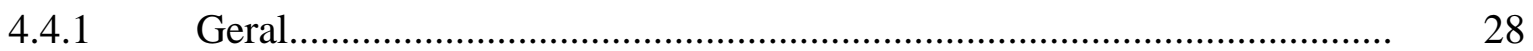

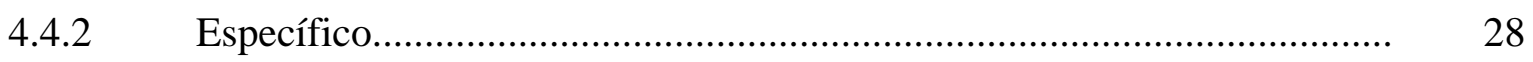

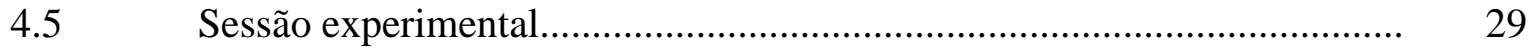

4.5.1 Exercício físico aeróbio agudo.............................................................. 29

4.5.2 Medidas de pressão arterial................................................................. $\quad 30$

4.5.3 Medidas de freqüência cardíaca............................................................. $\quad 30$

4.5.4 Registro da atividade nervosa simpática periférica................................. 30

4.5.5 Avaliação do fluxo sangüíneo do antebraço............................................ 31

4.5.6 Manobra excitatória utilizando o handgrip .............................................. 32

4.5.6.1 Exercício Estático (Isométrico)................................................................ 32

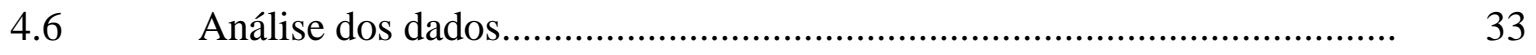

5 RESULTADOS

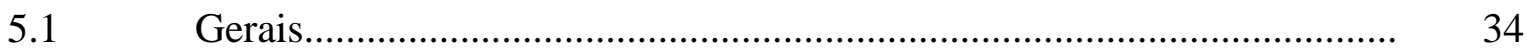

5.2 Efeito do exercício aeróbio prévio nas

respostas hemodinâmicas e neurais....................................................................... 35 


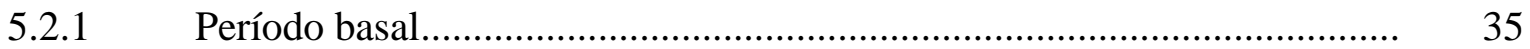

5.2.2 Exercício estático a 30\% da CVM......................................................... 43

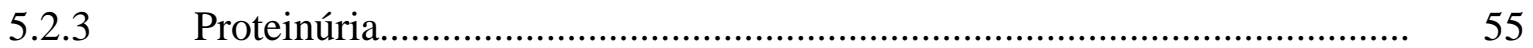

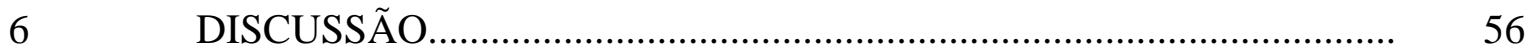

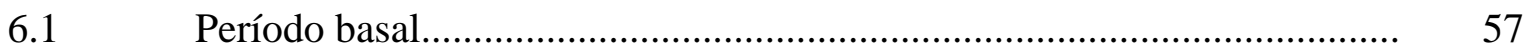

6.2. Exercício estático a 30\% da CVM.......................................................... 61

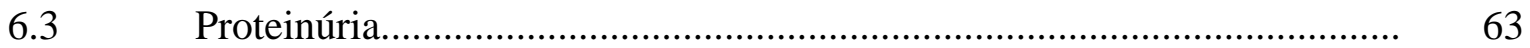

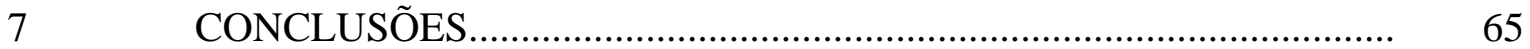

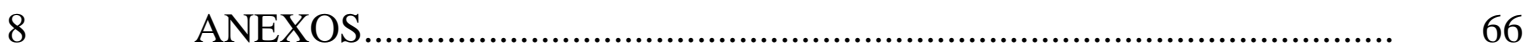

$9 \quad$ REFERÊNCIAS BIBLIOGRÁFICAS.............................................. 106 
Lista de Siglas e Abreviações

$\begin{array}{ll}\text { ADH } & \text { Hormônio antidiurético } \\ \text { ANSP } & \text { Atividade nervosa simpática periférica } \\ \text { ARA } & \text { Antagonista de receptores de angiotensina-II } \\ \text { CVM } & \text { Contração voluntária máxima } \\ \text { DCV } & \text { Doença cardiovascular } \\ \text { DRC } & \text { Doença renal crônica } \\ \text { DRCT } & \text { Doença renal crônica terminal } \\ \text { ECA } & \text { Enzima conversora da angiotensina } \\ \text { EE } & \text { Exercício estático } \\ \text { FC } & \text { Frequencia cardíaca } \\ \text { FSA } & \text { Fluxo sangüíneo do antebraço } \\ \text { HDL } & \text { Lipoproteína de alta densidade } \\ \text { HG } & \text { Handgrip } \\ \text { IMC } & \text { Índice de massa corporal } \\ \text { IRC } & \text { Insuficiência renal crônica } \\ \text { LDL } & \text { Lipoproteína de baixa densidade } \\ \text { PAD } & \text { Pressão arterial diastólica } \\ \text { PAM } & \text { Pressão arterial média } \\ \text { PAS } & \text { Pressão arterial sistólica } \\ \text { RFG } & \text { Ritmo de filtração glomerular } \\ \text { RVP } & \text { Resistência Vascular Periférica } \\ \text { SE } & \text { Sessão exercício } \\ \text { SNA } & \text { Sistema nervoso autônomo } \\ \text { SNS } & \text { Sistema nervoso simpático } \\ \text { SR } & \text { Sessão repouso }\end{array}$


Lista de Figuras

Página

Figura 1 - DRC é fator de risco para DCV e vice-versa...................................... 08

Figura 2 - Exemplos típicos de avaliação da atividade simpática, através da técnica de microneurografia, no nervo fibular...

Figura 3 - PAS dos grupos DRC e CT no período basal, nas sessões controle e exercício

Figura 4 - PAD dos grupos DRC e CT no período basal, nas sessões controle e exercício.

Figura 5 - PAM dos grupos DRC e CT no período basal, nas sessões controle e exercício.

Figura 6 - FC dos grupos DRC e CT no período basal, nas sessões controle e exercício.

Figura 7 - ANSP dos grupos DRC e CT no período basal, nas sessões controle e exercício

Figura 8 - FSA dos grupos DRC e CT no período basal, nas sessões controle e exercício.

Figura 9 - RVP dos grupos DRC e CT no período basal, nas sessões controle e exercício.

Figura 10 - PAS (mm Hg) dos grupos DRC e CT, durante pré-HG, exercício estático a 30\% da CVM, oclusão da circulação e recuperação nas sessões controle e exercício

Figura 11 - PAD (mm Hg) dos grupos DRC e CT, durante pré-HG, exercício estático a 30\% da CVM, oclusão da circulação e recuperação nas sessões controle e exercício

Figura 12 - PAM (mm Hg) dos grupos DRC e CT, durante pré-HG, exercício estático a 30\% da CVM, oclusão da circulação e recuperação nas sessões controle e exercício.

Figura 13 - FC (bpm) dos grupos DRC e CT, durante pré-HG, exercício estático a 30\% da CVM, oclusão da circulação e recuperação nas sessões controle e exercício. 
Figura 14 - ANSP (impulsos/min) dos grupos DRC e CT, durante pré-HG, exercício estático a $30 \%$ da CVM, oclusão da circulação e recuperação nas sessões controle e exercício

Figura 15 - FSA ml(min.100ml) dos grupos DRC e CT, durante pré-HG, exercício estático a $30 \%$ da CVM, oclusão da circulação e recuperação nas sessões controle e exercício.

Figura 16 - RVP (unidades) dos grupos DRC e CT, durante pré-HG, exercício estático a $30 \%$ da CVM, oclusão da circulação e recuperação nas sessões controle e exercício 
Tabela 1 - Estágios da DRC e estimativas do número de pacientes no Brasil.......... 03

Tabela 2 - Definição e estágios da DRC................................................................ 05

Tabela 3 - Estadiamento e classificação da DRC...................................................... 05

Tabela 4 - Fatores de risco cardiovasculares tradicionais vs.

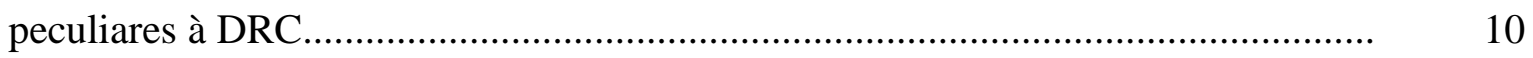

Tabela 5 - Perfil dos voluntários - grupo DRC vs. CT........................................ 34

Tabela 6 - Perfil bioquímico dos voluntários - DRC vs. CT................................. 35

Tabela 7 - Valores médios de todas as variáveis nas sessões repouso e exercício - DRC ................................................................... 35

Tabela 8 - Valores médios de todas as variáveis nas sessões repouso e exercício - CT........................................................................ 36

Tabela 9 - PAS nos grupos DRC e CT......................................................... 37

Tabela 10 - PAD nos grupos DRC e CT......................................................... 37

Tabela 11 - PAM nos grupos DRC e CT........................................................... 38

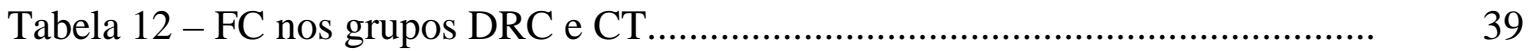

Tabela 13 - FC dos grupos DRC e CT, durante as sessões repouso e exercício....... $\quad 40$

Tabela 14 - ANSP nos grupos DRC e CT ....................................................... 41

Tabela 15 - FSA nos grupos DRC e CT...................................................... 42

Tabela 16 - RVP nos grupos DRC e CT.......................................................... 42

Tabela 17 - PAS nos grupos DRC e CT (EE) ................................................... 44

Tabela 18 - PAS (mm Hg) dos grupos DRC e CT, durante as sessões repouso e exercício.

Tabela 19 - PAS durante pré-HG, exercício estático a 30\% da CVM e recuperação, do grupo DRC 
Tabela 20 - PAS durante pré-HG, exercício estático a 30\% da CVM e recuperação, do grupo CT

Tabela 21 - PAD nos grupos DRC e CT (EE).

Tabela 22 - PAD (mm Hg) dos grupos DRC e CT, durante as sessões repouso e exercício

Tabela 23 - PAD durante pré-HG, exercício estático a 30\% da CVM e recuperação, do grupo DRC.

Tabela 24 - PAD durante pré-HG, exercício estático a 30\% da CVM e recuperação, do grupo CT

Tabela 25 - PAM nos grupos DRC e CT (EE)

Tabela 26 - PAM (mm Hg) dos grupos DRC e CT, durante as sessões repouso e exercício.

Tabela 27 - PAM durante pré-HG, exercício estático a 30\% da CVM e recuperação, do grupo DRC.

Tabela 28 - PAM durante pré-HG, exercício estático a 30\% da CVM e recuperação, do grupo CT

Tabela 29 - FC nos grupos DRC e CT (EE).

Tabela 30 - FC (bpm) dos grupos DRC e CT, durante as sessões repouso e exercício.

Tabela 31 - FC durante pré-HG, exercício estático a 30\% da CVM e recuperação, do grupo DRC.

Tabela 32 - FC durante pré-HG, exercício estático a 30\% da CVM e recuperação, do grupo $\mathrm{CT}$.

Tabela 33 - ANSP nos grupos DRC e CT (EE).

Tabela 34 - ANSP (impulsos/min) dos grupos DRC e CT, durante as sessões repouso e exercício.

Tabela 35 - ANSP durante pré-HG, exercício estático a 30\% da CVM e recuperação, do grupo DRC.

Tabela 36 - ANSP durante pré-HG, exercício estático a 30\% da CVM e recuperação, do grupo CT 
Tabela 38 - FSA ml(min.100ml) dos grupos DRC e CT, durante as sessões repouso e exercício

Tabela 39 - FSA durante pré-HG, exercício estático a 30\% da CVM

e recuperação, do grupo DRC.

Tabela 40 - FSA durante pré-HG, exercício estático a 30\% da CVM

e recuperação, do grupo $\mathrm{CT}$.

Tabela 41 - RVP nos grupos DRC e CT (EE).

Tabela 42 - RVP (unidades) dos grupos DRC e CT, durante as sessões repouso e exercício.

Tabela 43 - RVP durante pré-HG, exercício estático a 30\% da CVM

e recuperação, do grupo DRC.

Tabela 44 - RVP durante pré-HG, exercício estático a 30\% da CVM

e recuperação, do grupo $\mathrm{CT}$.

Tabela 45 - Valores de proteinúria, do grupo DRC 


\section{RESUMO}

Aprile DCB. Efeito agudo do exercício físico aeróbio na atividade nervosa simpática periférica de pacientes portadores de doença renal crônica - estágio III. [dissertação]. São Paulo: Faculdade de Medicina, Universidade de São Paulo; 2009.

A principal causa de mortalidade nos pacientes com doença renal crônica é a doença cardiovascular. A alta prevalência de hipertensão arterial nestes pacientes e sua relação com riscos cardiovasculares são indiscutíveis. A doença renal crônica é caracterizada pela hiperatividade simpática, o que contribui para gênese ou agravo da hipertensão arterial. O exercício aeróbico reduz a pressão arterial e a atividade nervosa simpática em diversas populações, mas seus efeitos não são claros em pacientes com doença renal crônica. O objetivo deste estudo foi avaliar nestes pacientes as respostas hemodinâmicas e neurais ao exercício estático com handgrip após uma sessão de exercício aeróbio. Nove pacientes, portadores de doença renal crônica no estágio III ( $52 \pm 8$ anos) e doze indivíduos saudáveis (50 \pm 5 anos), em ordem aleatória, realizaram uma sessão de exercício aeróbio em ciclo ergômetro (45 minutos a $50 \%$ do $\mathrm{Vo}_{2 \text { pico }}$ ) e uma sessão de repouso (repouso sentado por 45 minutos). Após as sessões, foram registradas no período basal e durante o exercício estático com handgrip (3 minutos a $30 \%$ da contração voluntária máxima): atividade nervosa simpática periférica (microneurografia), pressão arterial, frequiência cardíaca (método oscilométrico - Dixtal no membro inferior), fluxo sangüíneo do antebraço (pletismografia) e calculada a resistência vascular periférica. O teste $t$-studant foi usado para análise de dados no basal e, no período de exercício estático, o ANOVA de dois fatores. Valores de $\mathrm{P} \leq 0,05$ foram considerados estatisticamente significantes. $\mathrm{O}$ exercício físico reduziu a pressão arterial sistólica $(162 \pm 15-152 \pm 23 \mathrm{~mm} \mathrm{Hg})$, a pressão arterial diastólica ( $91 \pm 11$ vs. $85 \pm 14 \mathrm{~mm}$ $\mathrm{Hg}$ ), a atividade nervosa simpática (38 $34-31 \pm 4$ impulsos/min) e a resistência vascular periférica $(59 \pm 29$ - $41 \pm 28$ unidades) e aumentou o fluxo sanguíneo do antebraço $(2,1 \pm 0,8-3,2 \pm 1,3 \mathrm{ml}(\min .100 \mathrm{ml}))$ e a freqüência cardíaca $(62 \pm 9-67 \pm 9 \mathrm{bpm})$ dos pacientes com doença renal crônica. Durante o exercício estático houve atenuação do metabolorreflexo na sessão exercício, de maneira que a atividade simpática, os níveis pressóricos e a resistência vascular periférica foram reduzidos. Não houve alterações significativas na proteinúria pós-exercício aeróbio. Portanto, o exercício físico aeróbio reduziu os níveis tensionais, a atividade nervosa simpática e a resistência vascular periférica. Estas respostas foram observadas agudamente, mas podemos pressupor que estes efeitos também sejam observados com o treinamento físico.

Descritores: Doença renal crônica, exercício, doenças cardiovasculares, hipertensão, sistema nervoso simpático. 


\section{SUMMARY}

Aprile DCB. Acute effectof aerobic exercise in the muscle sympathetic nerve activity in patients with chronic kidney disease - stage III. [tesis]. São Paulo: "Faculdade de Medicina, Universidade de São Paulo"; 2009.

Cardiovascular disease is the major cause of death in chronic kidney disease patients. The high prevalence of hypertension in these patients and its relation with cardiovascular risks are been established. The chronic kidney disease is characterized by a sympathetic overactivity and might contribute to the pathogenesis and worsening of arterial hypertension. The aerobic exercise reduces the blood pressure and sympathetic nerve activity in several populations, but its effects are not fully understood in chronic kidney disease patients. The aim of this study was to evaluate the hemodynamic and neural responses to static handgrip exercise after one session of aerobic exercise in these patients. Nine chronic kidney disease - stage III patients $(50 \pm 8$ years old) and twelve healthy volunteers ( $50 \pm 5$ years old), in random order, realized an aerobic exercise session on cycle ergometer (45 minutes at $50 \%$ of $\mathrm{Vo}_{2 \text { peak }}$ ) and a rest session (45 minutes of seated rest). After the sessions, during basal period and static handgrip exercise ( 3 minutes at $30 \%$ of maximal voluntary contraction force) were registered: muscle sympathetic nerve activity (microneurography), blood pressure and heart rate (by the oscilometric method - Dixtal in lower limb), forearm blood flow (pletismography) and peripheral vascular resistance was calculated. For data analysis in the basal period, a t-student test was used and a two way ANOVA during handgrip exercise period. Values of $\mathrm{P} \leq 0,05$ were considered to be statistically significant. The aerobic exercise reduced systolic blood pressure $(162 \pm 15-152 \pm 23 \mathrm{~mm} \mathrm{Hg})$, diastolic blood pressure $(91 \pm 11$ vs. $85 \pm 14 \mathrm{~mm} \mathrm{Hg}$ ), sympathetic nerve activity (38 $\pm 4-31 \pm 4$ bursts/min) and peripheral vascular resistance $(59 \pm 29-41 \pm 28 \mathrm{U})$, and increased the forearm blood flow $(2,1 \pm 0,8-3,2 \pm 1,3 \mathrm{ml}(\mathrm{min} .100 \mathrm{ml}))$ and the heart rate $(62 \pm 9-67 \pm 9$ bpm) in this population. In the exercise session, during the static handgrip exercise, the metabolorreflex was attenuated and blood pressure, sympathetic nerve activity and peripheral vascular resistance were reduced. There were no significant differences in the pos-exercise proteinuria. These responses were observed after a single bout of aerobic exercise, but these effects might be observed in the physical training too.

Descriptors: Chronic kidney disease, exercise, cardiovascular diseases, hypertension, sympathetic nervous system,. 



\section{INTRODUÇÃO}

A Doença Renal Crônica (DRC) é um dos maiores problemas de saúde pública mundial $^{1}$. Sua ocorrência no mundo vem aumentando nos últimos anos ${ }^{2}$, atingindo proporções epidêmicas. O crescimento do número de casos da doença decorre do aumento da prevalência do diabetes mellitus, da obesidade, da maior longevidade do ser humano, concomitantemente aos avanços diagnósticos e terapêuticos da ciência médica $^{3,4}$. Atualmente, a associação de diabetes e hipertensão arterial acomete a maioria dos pacientes portadores de DRC e quase $70 \%$ dos pacientes com Doença Renal Crônica Terminal (DRCT) ${ }^{5,6}$. Segundo estudos realizados nos EUA e Canadá, o número de pacientes que apresenta risco de doença renal e/ou algum grau de disfunção renal, gira em torno de $10 \%$ da população adulta, aproximadamente 20 milhões de indivíduos ${ }^{7,8}$.

A maioria dos pacientes com DRC tem capacidade física abaixo da média populacional $^{9-16}$. Independente do curso da DRC, a capacidade física diminui continuamente com sua progressão, sendo caracterizada por: redução da flexibilidade, distúrbios da coordenação, diminuição da força muscular e da resistência muscular periférica. Muitos pacientes apresentam dificuldade na realização de tarefas diárias simples, principalmente quando a doença se encontra em seu curso terminal ${ }^{11,17-19}$. Em sua maioria, além dos problemas físicos, também apresentam problemas emocionais, como a depressão ${ }^{11,20-22}$. Mas a causa principal de morte entre os pacientes renais crônicos é a doença cardiovascular ${ }^{23-25}$, de maneira que é mais provável que os indivíduos com DRC morram por causa de uma doença cardiovascular ${ }^{26}$ do que venham a desenvolver insuficiência renal crônica e iniciem tratamento dialítico.

Existem evidências de que a DRC é caracterizada por uma elevada atividade do sistema nervoso simpático (SNS) ${ }^{27-34}$. Indivíduos hipertensos com DRC em grau leve 
apresentam hiperatividade simpática quando comparados a pacientes hipertensos com função renal normal ou indivíduos normotensos ${ }^{35}$. A hiperatividade simpática está relacionada à gênese e à manutenção da hipertensão arterial ${ }^{28,36,37}$, sendo também associada à insuficiência cardíaca, arritmia e outras doenças cardiovasculares ${ }^{36}$.

Os benefícios proporcionados pelo exercício físico à saúde da população em geral são inúmeros, de natureza física, mental, emocional e psicossocial ${ }^{9}$. Também estão estabelecidos os benefícios cardiovasculares proporcionados pelo treinamento ${ }^{38}$, de maneira que um programa de atividade física regular é considerado um tratamento padrão para hipertensão arterial, hiperlipidemia, controle da glicemia e prevenção primária e secundária da doença aterosclerótica das coronárias ${ }^{39}$. Além disso, o exercício físico aeróbio reduz a atividade nervosa simpática em diversas populações, assim como a pressão arterial e a resistência vascular periférica ${ }^{40-44}$.

No entanto, ao contrário de outras doenças crônico-degenerativas, ainda não são bem conhecidos os efeitos do exercício físico em pacientes portadores de DRC prédialítica. Desta forma, o objetivo deste estudo é verificar, nestes pacientes, os efeitos de uma única sessão de exercício aeróbico nas respostas hemodinâmicas e neurais, durante exercício estático com handgrip. 


\section{REVISÃO DE LITERATURA}

\subsection{Doença Renal Crônica}

\subsubsection{Definição}

Classicamente, a DRC consiste em lesão renal e perda progressiva e irreversível da função dos rins (glomerular, tubular e endócrina). Em sua fase mais avançada (chamada de fase terminal de insuficiência renal crônica - IRC) ${ }^{45}$ os rins não conseguem mais cumprir suas funções ${ }^{17,45}$ e surge a síndrome clínica de uremia. Isso pode ser o resultado final de um número amplo de diferentes doenças adquiridas (intersticiais e glomerulares), ou congênitas, além de problemas vasculares e uropatias obstrutivas $^{17}$.

De acordo com a National Kidney Foudation ${ }^{1}$, é portador de DRC qualquer indivíduo que, por um período de 3 meses, apresentar filtração glomerular (FG) < 60 $\mathrm{mL} / \mathrm{min} / 1,73 \mathrm{~m}^{2}$, assim como aqueles com $\mathrm{FG}>60 \mathrm{~mL} / \mathrm{min} / 1,73 \mathrm{~m}^{2}$ e alguma evidência de lesão da estrutura renal (como, por exemplo, albuminúria).

\subsubsection{Epidemiologia}

O número de pacientes com algum grau de déficit de função renal não é exatamente conhecido, mas pode ser eventualmente estimado. Estima-se que $25 \%$ da população adulta brasileira tenham hipertensão arterial, ou seja, cerca de 26 milhões de indivíduos. A prevalência de diabetes é de 7,5\% da população adulta. Desta forma, cerca de 7,7 milhões de indivíduos teriam diabetes, sendo que mais de $30 \%$ destes teriam potencial para desenvolver $\mathrm{DRC}^{46}$. 
No Brasil, o número de pacientes em diálise aumentou cerca de 50\%, nos últimos seis $\operatorname{anos}^{47}$, passando de valores de 48 mil pacientes em jan / 2002 para 87 mil, aproximadamente, em jan / 2008, com incidência de cerca de 26 mil casos. A taxa de prevalência em diálise variou nos últimos dois anos de 361 a 470 pacientes por milhão. Nos EUA, houve um contínuo crescimento do número de pacientes portadores de DRC tratados. Atualmente, de acordo com dados de 2006, a incidência de pacientes com IRC chega a aproximadamente 110 mil pacientes e a prevalência em torno de 500 mil pacientes ${ }^{5}$.

Levando-se em conta dados norte-americanos ${ }^{6}$, para cada paciente mantido em programa de diálise crônica existiriam cerca de 20 a 25 pacientes com algum grau de disfunção renal, ou seja, existiriam cerca de 1,2 a 1,5 milhão de brasileiros com DRC (não-dialítica), em $2004^{45}$. Para uma população nacional estimada em 185 milhões em julho de 2006, teríamos uma distribuição semelhante à da tabela $1^{46}$. Atualmente, esse número seria em torno de 1,7 a 2,2 milhões de pacientes ${ }^{45}$.

\begin{tabular}{llll}
\hline FG & Estágio & $\mathbf{N}$ & $\%$ adultos \\
\hline $30-59$ & 3. Moderada & 1,8 milhões & 1,71 \\
$15-29$ & 4. Severa & 94 mil & 0,09 \\
$<15$ & DRCT & 71 mil & 0,07 \\
Total & & 1,960 milhões & 1,87 \\
\hline
\end{tabular}

FG=Filtração Glomerular

Tabela 1 - Estágios da DRC e estimativas do número de pacientes no Brasil (adaptado de Sesso et $\mathrm{al}^{46}$ ).

\subsubsection{Estágios, classificação e progressão da doença}

Os estágios da doença renal crônica são definidos pelo nível de Ritmo de Filtração Glomerular (RFG), com o mais grave estágio representado pelo mais baixo nível de $\mathrm{RFG}^{1}$. A tabela 2 ilustra a classificação de indivíduos baseada na presença ou ausência de marcadores da doença renal e no nível de RFG: 


\begin{tabular}{|c|c|c|c|c|}
\hline \multicolumn{5}{|c|}{ Definição e Estágios da Doença Renal Crônica } \\
\hline \multirow{2}{*}{$\begin{array}{c}R F G \\
\left(\mathrm{~mL} / \mathrm{min} / 1.73 \mathrm{~m}^{2}\right)\end{array}$} & \multicolumn{2}{|c|}{ com lesão renal } & \multicolumn{2}{|c|}{ sem lesão renal } \\
\hline & $H A^{*}$ & sem $H A^{*}$ & $H A^{*}$ & Sem $H A^{*}$ \\
\hline$\geq 90$ & 1 & 1 & Hipertensão & Normal \\
\hline $60-89$ & 2 & 2 & HÁ com $\downarrow$ RFG & $\downarrow \mathrm{RFG}^{* *}$ \\
\hline $30-59$ & 3 & 3 & 3 & 3 \\
\hline $15-29$ & 4 & 4 & 4 & 4 \\
\hline$<15$ (ou diálise) & 5 & 5 & 5 & 5 \\
\hline
\end{tabular}

Tabela 2 - A área sombreada representa a DRC; os números, os estágios da DRC.

* hipertensão arterial, definida como $\geq 140 / 90$ em adultos.

** pode ser normal em crianças e idosos (adaptado de National Kidney Foundation ${ }^{1}$ ).

A classificação da DRC também pode ser de acordo com a severidade da doença. É uma classificação simples e, por causa da imprecisão do cálculo do RFG e da grande variação do mesmo, pode ser difícil distinguir entre os estágios um e dois, como é mostrado na tabela 3 , a seguir ${ }^{45}$.

Estadiamento e classificação da doença renal crônica

\begin{tabular}{c|c|c}
\hline Estágio & $\begin{array}{c}\text { Filtração Glomerular } \\
\text { (ml/min) }\end{array}$ & Grau de Insuficiência Renal \\
\hline $\mathbf{0}$ & $>90$ & $\begin{array}{c}\text { Grupos de Risco para DRC } \\
\text { Ausência de Lesão Renal }\end{array}$ \\
\hline $\mathbf{1}$ & $>90$ & $\begin{array}{c}\text { Lesão Renal com } \\
\text { Função Renal Normal }\end{array}$ \\
\hline $\mathbf{2}$ & $60-89$ & IR Leve ou Funcional \\
\hline $\mathbf{3}$ & $30-59$ & IR Moderada ou Laboratorial \\
\hline $\mathbf{4}$ & $15-29$ & IR Severa ou Clínica \\
\hline $\mathbf{5}$ & $<15$ & IR Terminal ou Dialítica \\
\hline$I R=$ insuficiência renal; $D R C=$ doença renal crônica.
\end{tabular}

Tabela 3 - Estadiamento e classificação da DRC. (Adaptado de Romão ${ }^{45}$ ).

A função renal declina progressivamente na maioria dos pacientes com DRC e seu declínio pode ser estimado pela medida do RFG, clearance de creatinina ou creatinina plasmática. O começo da falência renal, IRC, é definido pelo início de alguma terapia substitutiva, sintomas ou complicações que reduzam mais ainda a função renal $^{1}$. 
Alguns fatores podem causar piora no quadro da lesão e declínio rápido da função renal, após o início da doença, como o nível de proteinúria, hipertensão arterial, controle inadequado da glicemia em diabéticos, anemia, entre outros ${ }^{1}$.

A DRC, inicialmente assintomática, progride para IRC e poderá apresentar sintomas como fraqueza, irritabilidade muscular, cefaléia, anorexia, náuseas, vômitos, prurido, perda de libido, susceptibilidade a infecções ${ }^{17}$. Seu agravamento pode acarretar acidose metabólica, hiperparatireoidismo secundário, hipertensão arterial, hipertrofia ventricular esquerda, anemia, neuropatia periférica, fraqueza muscular, disfunção do sistema nervoso autônomo (SNA), hiperlipidemia ${ }^{48}$.

\subsubsection{Diagnóstico da DRC e marcadores da lesão renal}

A identificação da causa da DRC é uma das metas de sua avaliação. Entretanto, a mesma pode ser detectada e tratada sem o conhecimento de sua causa ${ }^{49}$.

Alguns marcadores da doença podem ser usados para diagnosticá-la, como: diminuição do RFG para valores menores que $60 \mathrm{ml} / \mathrm{min} / 1.73 \mathrm{~m}^{2}$; albuminúria (microalbuminúria ou macroalbuminúria), com níveis de albumina na urina $\geq 30 \mathrm{mg} / \mathrm{l}$; anormalidades nos sedimentos da urina; anormalidades em imagens (rins policísticos, hidronefroses) além de alterações na composição do sangue e urina, que definem “síndromes tubulares"49.

A albumina é a proteína urinária mais frequente. Um aumento da excreção de albumina é uma das mais precoces manifestações da lesão renal por diabetes, doenças glomerulares e nefro-esclerose hipertensiva. A albuminúria pode ocorrer também em doenças intersticiais, rins policísticos e em casos de DRC pós-transplante renal ${ }^{49}$ e é um importante marcador da DRC ${ }^{50}$.

Os níveis de albumina, considerados normais, para um homem adulto, devem ser $<30 \mathrm{mg} / \mathrm{L}^{49}$. Entre 30 e $300 \mathrm{mg} / \mathrm{L}$, nós temos o que pode ser chamado de 
microalbuminúria. Acima de 300mg/L, temos macroalbuminúria. Os níveis de albumina devem ser ajustados de acordo com a raça, idade e gênero.

Há evidências que a incidência de DRC aumenta brusca e linearmente com o grau de proteinúria ${ }^{50}$. Este é um forte e independente fator de risco para o desenvolvimento de DRC e em doenças cardiovasculares $(\mathrm{DCVs})^{50,51}$. A hematúria também se apresentou como um significante fator de risco para DRC, porém menos potente que a proteinúria ${ }^{50}$.

Tanto a microalbuminúria como a proteinúria podem ser fatores de risco de DCVs em pacientes com diabetes ou hipertensão. Também é plausível que estas doenças causem danos tubulares e glomerulares, resultando em microalbuminúria ${ }^{50}$.

A identificação de fatores de risco modificáveis, como hipertensão e proteinúria podem ser um alerta para o risco do desenvolvimento de DRC e estimular a busca de alternativas que possam modificar estilos de vida ou procurar um tratamento para prevenir a $\mathrm{DRC}^{50}$.

\subsubsection{Complicações e fatores de risco associados}

\subsubsection{Doenças cardiovasculares}

DCVs são líderes nas causas de morte em pacientes com DRC ${ }^{8,23-25,52}$. A doença cardiovascular (DCV) é a causa primária de morbidade e mortalidade prematura em DRC, além de ser de alto risco para pacientes com DRC em todos os seus estágios ${ }^{8,24,52}$. A expectativa de vida de indivíduos com DRC é bastante reduzida, principalmente em pacientes que se submetem à diálise. Pode-se considerar que o risco de DCV em um paciente com DRC com 30 anos de idade é similar ao de um paciente com 80 anos sem doença renal estabelecida ${ }^{52}$. Em 2003 a American Heart Association, publicou um relatório de diretrizes onde considerou que pacientes com DRC devem ser incluídos no 
mais alto grupo de risco para $\mathrm{DCV}$ e, portanto devem receber medidas preventivas agressivas na tentativa de reduzir a prevalência e a severidade das manifestações desta doença $^{8}$.

Os portadores de DRC têm risco de doenças cardiovasculares aumentado por razões, como: 1) associação da DRC com o aumento da prevalência de fatores de risco de doenças cardiovasculares tradicionais e não-tradicionais; 2) DRC como fator de risco independente para a $\mathrm{DCV}^{24,51}$ 3) muitos fatores de risco de doenças cardiovasculares também são fatores de risco de DRC e 4) presença de DCV pode ser fator de risco para a DRC. Ou seja, a relação entre DCV e DRC resulta em um ciclo de progressão tanto da DCV como da DRC. Podemos compreender melhor este ciclo, analisando a figura 1.

Foram avaliados os fatores de risco cardiovasculares e alguns marcadores, em um grupo de pacientes estáveis, com DRC moderada. Foi encontrada alta prevalência de: doença nas coronárias (22\%), insuficiência cardíaca (18\%), acidente vascular cerebral $(16 \%)$ e doença vascular periférica $(14 \%)^{23}$.

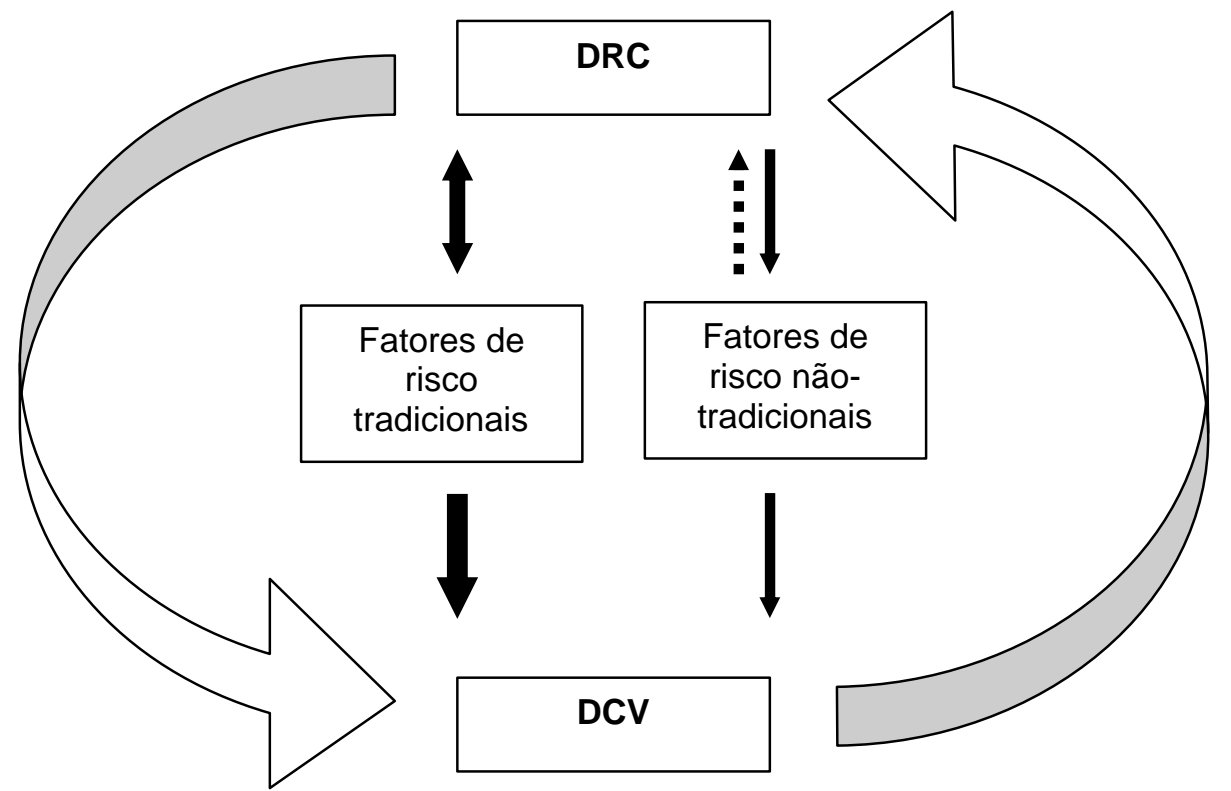

Figura 1 - DRC é fator de risco para DCV e vice-versa (adaptado de Vandana et $\mathrm{al}^{24}$ ). 
As principais causas da alta incidência de mortalidade cardiovascular são: isquemia cardíaca, acidente vascular cerebral, insuficiência cardíaca e morte súbita. Três tipos de fatores exercem importante papel nas lesões vasculares e nas alterações na massa e na função do ventrículo esquerdo, na DRC: 1) fatores de risco tradicionais; 2) fatores peculiares à DRC e 3) fatores de risco emergentes. Outros fatores têm sido identificados recentemente, como alta atividade simpática e a apnéia do sono, entre $\operatorname{outros}^{27}$.

Dentro dos riscos cardiovasculares, fatores tradicionais como hipertensão arterial, dislipidemia e o tabagismo (vasoconstritor e tromboembólico ${ }^{53}$, se destacam como agravantes da $\mathrm{DRC}^{24,27}$. O diabetes e a senilidade também aparecem como um fator de risco tradicional ${ }^{24}$.

A hipertensão arterial talvez seja mais comum entre os pacientes, sendo, desta forma, mais um marcador de várias doenças cardíacas que um fator de risco cardiovascular causador de mortalidade nestes pacientes ${ }^{27}$.

Os níveis plasmáticos de colesterol em pacientes com DRC são muitas vezes mal-interpretados ${ }^{27}$. Estes pacientes, freqüentemente, apresentam problemas nutricionais, como perda de massa magra, aumento dos triglicérides e do colesterolLDL e diminuição do colesterol-HDL. Embora haja pouca evidência sobre o impacto desfavorável da hiperlipidemia na progressão da DRC. Contudo, é importante ressaltar que corrigindo a hiperlipidemia, que se associa à DRC, é possível que se possa corrigir ou amenizar as doenças cardiovasculares, freqüentemente associadas ${ }^{53}$. 


\begin{tabular}{|c|c|}
\hline fatores de risco tradicionais & fatores de risco peculiares à DRC \\
\hline Idade avançada & Tipo de DRC \\
Sexo masculino & Diminuição do RFG \\
Raça branca & Proteinúria \\
Hipertensão & Atividade do sistema renina-angiotensina \\
Colesterol LDL elevado & Sobrecarga no volume do fluido extracelular \\
Colesterol HDL diminuído & Metabolismo anormal de cálcio e fósforo \\
Diabetes mellitus & Dislipidemia \\
Tabagismo & Anemia \\
Inatividade física & Má nutrição \\
Menopausa & Inflamação \\
Estresse & Infecções \\
Histórico familiar & Fatores trombogênicos \\
Obesidade & Estresse oxidativo \\
& Homocisteína elevada \\
& Toxinas urêmicas \\
\hline
\end{tabular}

Tabela 4 - Fatores de risco cardiovasculares tradicionais vs. peculiares à DRC (adaptado de NATIONAL KIDNEY FOUNDATION ${ }^{1}$ ).

Como fatores emergentes, temos os altos valores plasmáticos de homocisteína e de proteína $\mathrm{C}$ reativa (marcador de inflamação em pacientes com DRC), comuns em renais crônicos e associados a altos índices de mortalidade cardiovascular ${ }^{22,33}$.

Os pacientes com DRC freqüentemente sofrem de apnéia do sono ${ }^{28}$. Esta aparece com freqüência de $30 \%$ em pacientes com $\mathrm{DRC}^{27}$ e seus episódios parecem estar relacionados com a hiperatividade simpática, comum nos pacientes com DRC ${ }^{27,28}$.

De maneira geral, a falência renal requer tratamento dialítico ou transplante. Entretanto, as doenças cardiovasculares, frequentemente associadas à DRC, tornam-se extremamente importantes porque é mais provável que os indivíduos com DRC morram por causa de uma DCV, como aterosclerose e insuficiência cardíaca congestiva ${ }^{26}$ do que venham a desenvolver IRC, além do que as doenças cardiovasculares na DRC são tratáveis e podem ser prevenidas ${ }^{8}$.

Dessa forma, a presença do risco elevado de DCV nesta população e suas consequências, desafiam a comunidade cardiológica e nefrológica internacional a buscar 
aprimoramentos diagnósticos e terapêuticos na tentativa de oferecer uma maior e melhor sobrevida a estes indivíduos ${ }^{25}$.

\subsubsection{Hiperatividade do sistema nervoso simpático}

Existem evidências de que a DRC é caracterizada por uma elevada atividade do sistema nervoso simpático $(\mathrm{SNS})^{27-34}$. Isto poderia contribuir para a gênese e manutenção da hipertensão $\operatorname{arterial}^{28,36,37}$, assim como a sobrecarga de volume e a ativação do sistema renina-angiotensina ${ }^{31}$, características destes pacientes. A ANSP é elevada tanto em pacientes dialíticos, como pré-dialíticos ${ }^{33,54}$ e pode afetar prognósticos, independentemente de seus efeitos na pressão $\operatorname{arterial}^{28}$.

O SNS pode ser também importante para determinar o ritmo de progressão da função renal em pacientes com DRC. A liberação das catecolaminas tem efeitos diretos que podem ser relevantes para a lesão renal $^{28}$, já que hormônios vasoativos estão envolvidos na patogenia e na manutenção da hipertensão arterial em pacientes com $\mathrm{DRC}^{33,54}$. A norepinefrina plasmática é usualmente elevada em pacientes com DRC avançada $^{54}$ e o SNS é um potente estímulo para a secreção de renina ${ }^{55}$.

Pacientes hipertensos com insuficiência renal leve apresentam hiperatividade simpática quando comparados a indivíduos normotensos ${ }^{31,35}$ ou pacientes hipertensos, com função renal normal ${ }^{35}$. Assim, temos indícios de que o SNS exerce importante papel nas modificações hemodinâmicas que ocorrem na DRC. 
A hiperatividade simpática também contribui para desenvolvimento de outras formas de lesões teciduais, sendo associada à insuficiência cardíaca, arritmia e outras condições patológicas $^{36}$, como hipertrofia ventricular esquerda ${ }^{28}$. A atividade nervosa simpática pode ser registrada em humanos, pela microneurografia, que podemos observar nos registros abaixo:

(A)

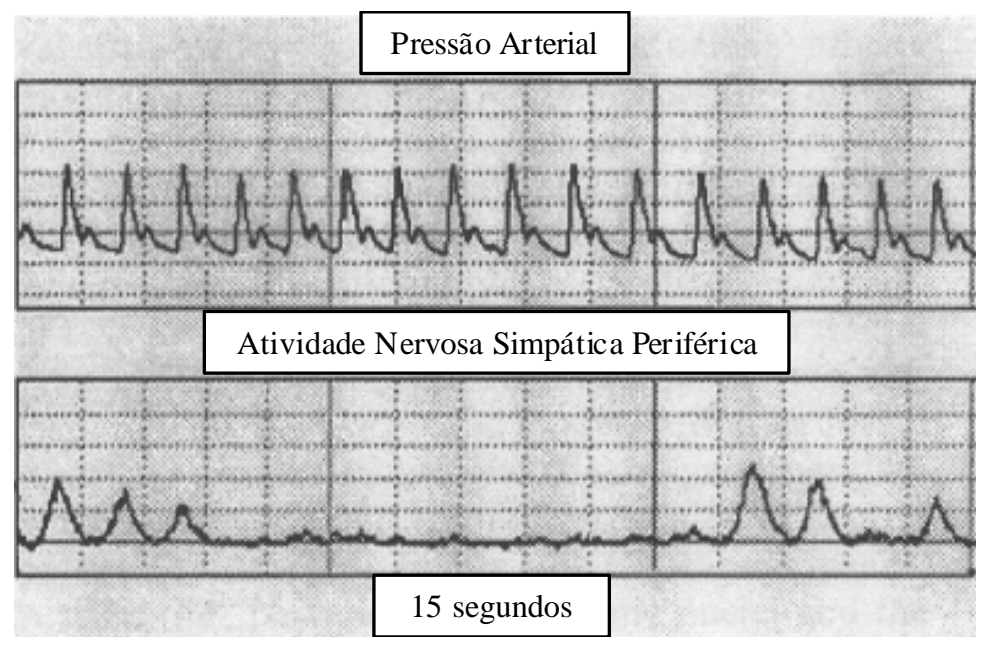

Figura 2 - Exemplos típicos de avaliação da atividade simpática, através da técnica de microneurografia, no nervo fibular. Na figura (A), temos o registro de um indivíduo normal. $\mathrm{Na}$ (B), temos um indivíduo com DRC (adaptado de Neumman et $\mathrm{al}^{28}$ ).

(B)

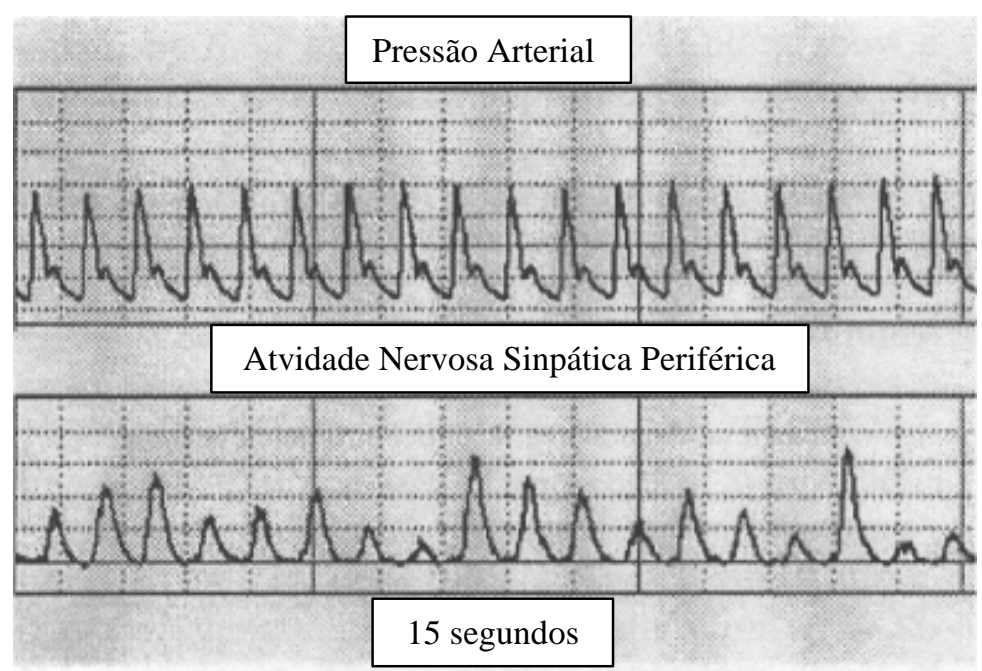




\subsubsection{A inatividade física}

É típico de pacientes com doenças crônicas serem fisicamente inativos, não terem motivação e ainda apresentarem problemas emocionais e sociais ${ }^{9}$. Os pacientes com DRC em seus vários estágios têm capacidade física reduzida ${ }^{9-15}$. Clyne et al $^{16}$, mostrou que pacientes pré-dialíticos jovens e de meia-idade tinham capacidade física máxima de $75 \%$ da expectativa normal. De acordo com Painter ${ }^{19}$, pacientes tratados com diálise têm capacidade física reduzida à cerca de $60 \%$ a $70 \%$ do nível esperado para a idade. A maioria dos pacientes em diálise é sedentária ${ }^{19,56,57}$ e o risco de mortalidade é maior para os pacientes sedentários ${ }^{57}$.

A reduzida tolerância ao exercício físico em pacientes portadores de DRC pode ser atribuída a diversos fatores, como anemia, distúrbios metabólicos, danos no controle autonômico cardíaco, defeitos no metabolismo oxidativo muscular, atrofia dos músculos esqueléticos e disfunções cardíacas ${ }^{17}$.

Além dos hábitos sedentários, disfunções psicológicas como a depressão podem influenciar a capacidade física destes pacientes ${ }^{17}$. A depressão é geralmente o problema psicológico mais comum em pacientes com $\mathrm{DRC}^{11}$.

Portanto, aparentemente, o sedentarismo contribui de forma decisiva para a piora do prognóstico dos pacientes portadores de DRC.

\subsection{O Exercício físico}

Os benefícios proporcionados pelo exercício físico à população, em geral, são bem conhecidos, de natureza física, mental, emocional e psicossocial. O exercício regular melhora o humor, diminui a ansiedade e a depressão, auxilia no controle do estresse e do peso corporal, diminui os fatores de risco cardiovasculares, mantêm saudáveis ossos, músculos e articulações 9 . 
Porém, pacientes com DRC não se beneficiam desses efeitos, de forma sistemática, pois pouco se conhece sobre os efeitos do exercício físico nesses doentes. Mas considerando que as doenças cardiovasculares são a principal causa de morte em

pacientes com $\mathrm{DRC}^{23-25}$ e que já estão bem estabelecidos os benefícios que o exercício físico proporciona a pacientes com DCVs, temos que o exercício físico regular pode ser uma ferramenta não farmacológica na prevenção de riscos cardiovasculares e na manutenção da saúde. Como exemplo, temos que pacientes hipertensos praticantes de atividade física regular mostraram redução nos níveis tensionais, levando à redução da dose ou mesmo da retirada da medicação hipotensora ${ }^{48}$.

\subsubsection{Classificação do exercício físico}

O exercício físico pode ser classificado em relação ao sistema específico de transferência de energia predominantemente ativo. A classificação da atividade em aeróbia e anaeróbia é baseada na intensidade, duração e via energética predominante. Atividades de curta duração e alta intensidade utilizam a via anaeróbia para obtenção de energia, enquanto atividades de baixa intensidade duração prolongada, utilizam a via aeróbia. Dessa forma o treinamento, tanto aeróbio quanto anaeróbio, gera adaptações metabólicas e fisiológicas específicas que consistem em alterações celulares sutis e alterações fisiológicas evidentes ${ }^{58}$.

\subsubsection{Exercício Físico Aeróbio}

O exercício aeróbio (dinâmico) é o tipo de exercício que produz maior benefício cardiovascular. Segundo o American College of Sports Medicine ${ }^{59}$ esses exercícios são $^{2}$ caracterizados por atividades realizadas com movimentos cíclicos, envolvendo grandes grupos musculares, com intensidade leve a moderada (50\% a $80 \%$ do $\mathrm{VO}_{2}$ máx.) e com 
duração longa (20 a 60 minutos). Tanto sua prática aguda (uma única sessão) quanto crônica (treinamento estruturado) produz efeitos cardiovasculares.

\subsubsection{Efeitos agudos do exercício físico aeróbio}

Durante o exercício aeróbico agudo ocorre uma série de alterações neurais, metabólicas e hemodinâmicas para os devidos ajustes e manutenção do fluxo sanguíneo adequado aos músculos. O fluxo sangüíneo para os tecidos específicos em geral é regulado em proporção com a atividade metabólica. Isto significa que durante o exercício, a maior parte do débito cardíaco, bem como uma quantidade significativa de sangue dos rins e das regiões esplâncnicas, sejam desviados para os músculos $\operatorname{ativos}^{41,58}$.

Também ocorre um aumento na atividade nervosa simpática, na freqüência cardíaca, no débito cardíaco, no volume de ejeção, com dilatação simultânea da malha vascular periférica, resultando em uma redução na resistência vascular sistêmica. O aumento do débito cardíaco leva a um progressivo aumento da pressão arterial sistólica, ao passo que a vasodilatação permite que a pressão arterial diastólica permaneça inalterada ou diminua ${ }^{41,60}$.

Acredita-se que a vasodilatação da musculatura exercitada permaneça após o termino do exercício em decorrência de fatores, como: atuação dos metabólitos locais produzidos durante o exercício; vasodilatação da pele; liberação de opióides endógenos; redução da atividade nervosa simpática periférica; diminuição da sensibilidade alfaadrenérgica. Essa manutenção da vasodilatação e conseqüente redução da resistência vascular periférica, leva à diminuição dos valores pressóricos pós-exercício ${ }^{41,61}$. 


\subsection{Controle neural da atividade cardiovascular no exercício}

Além de seu efeito sobre as paredes musculares lisas da árvore vascular arterial, os nervos simpáticos terminam na porção medular das glândulas supra-renais. Durante o exercício físico, em resposta à ativação simpática, esse tecido glandular secreta grande quantidade de adrenalina e uma quantidade menor de noradrenalina, que são lançadas na corrente sanguínea. Esses hormônios agem como mensageiros químicos, capazes de gerar uma resposta constritora generalizada, exceto nos vasos sangüíneos do coração e dos músculos esqueléticos. Durante o exercício, esse controle hormonal do fluxo sangüíneo regional é relativamente pequeno, em comparação ao impulso neural simpático, que é mais rápido e intenso ${ }^{37,58}$.

As modificações cardiovasculares observadas imediatamente antes e no início do exercício são induzidas pelo centro de comando neural, acima da região bulbar. $\mathrm{O}$ comando central é um termo designado para o comando motor de sinais originados de neurônios sub-talâmicos, envolvidos na locomoção. Estes sinais ativam, em paralelo, tanto o sistema cardiovascular como o músculo-esquelético, durante o exercício ${ }^{37,62}$.

Esse feedback suprime a ativação parassimpática e exacerba o fluxo simpático, de forma a aumentar a freqüência cardíaca e a contratilidade miocárdica ${ }^{58}$, aumentando assim o débito cardíaco e a pressão arterial, imediatamente no início do exercício, através de uma rápida retirada vagal $^{37,62}$. Ao mesmo tempo, ocorrem alterações previsíveis no fluxo sangüíneo regional, que são proporcionais à intensidade do exercício. Esses ajustes de dilatação e constrição aprimoram o fluxo sangüíneo para áreas com uma maior necessidade, ao mesmo tempo em que mantêm a pressão por todo sistema $\operatorname{arterial}^{58}$.

À medida que o exercício continua, o feedback para o bulbo, a partir de receptores mecânicos e químicos periféricos existentes no tecido ativo, torna possível fazer uma avaliação da atividade metabólica local e das necessidades circulatórias. 
Fatores metabólicos também agem diretamente sobre os vasos sangüíneos acarretando dilatação dos vasos nos músculos ativos. A redução da resistência periférica permite que as áreas ativas acomodem maior fluxo sangüíneo. Ajustes constritores adicionais, de mediação central, ocorrem nos tecidos menos ativos (pele, rins, região esplâncnica e músculos inativos), garantindo boa pressão de perfusão, mesmo com grande dilatação da árvore vascular dos músculos. Dessa forma é possível a distribuição adequada do sangue, de acordo com as necessidades metabólicas ${ }^{37,58,63}$.

\subsubsection{O controle reflexo da circulação durante o exercício}

O controle circulatório durante o exercício é exercido via comando central, centro de modulação da função autonômica induzida pelo esforço ${ }^{64}$, o qual estabelece moldes básicos de atividade efetora cardiovascular, bem como pelas vias aferentes (reflexo pressor do exercício), moduladas pelo barorreflexo (mecanorreceptores arteriais) e pelo quimiorreflexo (metabolorreflexo) e mecanorreflexo do músculo $\operatorname{ativo~}^{62,65}$.

No início do exercício, ocorre a retirada vagal (via comando central) ${ }^{62}$, com a ativação do barorreflexo e o erro primário corrigido pelo sistema nervoso simpático corresponde a uma alteração mecânica, na parede do vaso. A correção de erros metabólicos é secundária e ocorre em mais altos níveis de exercício ${ }^{65}$.

\subsubsection{Barorreflexo arterial}

O barorreflexo arterial opera, com a mesma sensibilidade, durante o descanso ou exercício, mostrando-se um controlador ativo da pressão $\operatorname{arterial}^{62,66}$.

O barorreflexo arterial, durante o exercício, corrige continuamente os chamados “erros de pressão"62. Este reflexo sempre será ativado quando a elevação do débito cardíaco não for rápida suficiente para aumentar a pressão arterial imediatamente para 
um ponto de operação mais alto do barorreflexo. Quando isso ocorre, a atividade do SNS precisa aumentar para tentar minimizar esses "erros de pressão"65.

O barorreflexo arterial é essencial para elevação normal da atividade do SNS e da pressão arterial no início do exercício, pois o quimiorreflexo ainda não foi ativado, devido às baixas taxas de trabalho. $\mathrm{O}$ mesmo também ajuda a manter a atividade simpática tônica, prevenindo a hipotensão arterial, durante o exercício submáximo, através do controle da vasodilatação muscular, causada pelo quimiorreflexo ${ }^{66}$.

\subsubsection{Quimiorreflexo muscular}

O quimiorreflexo muscular, também conhecido como metabolorreflexo, é ativado sempre que o fluxo sangüíneo muscular diminui até atingir um nível crítico, abaixo do necessário para se manter uma demanda de oxigênio muscular adequada ${ }^{65,66}$.

A liberação de ácido láctico muscular, por exemplo, é um sinal para o início deste reflexo ${ }^{62}$. Então, podemos observar que no início do exercício e durante o exercício leve ou moderado, este reflexo não está ativo, pois os metabólitos acumulados ainda não atingiram o limiar para ativação do quimiorreflexo.

\subsubsection{O Mecanorreflexo muscular}

Existem receptores sensoriais especializados, musculares e tendíneos, sensíveis à pressão, à distensão e à tensão. Estes, conhecidos como proprioceptores, retransmitem rapidamente a informação sobre a dinâmica muscular e do movimento dos membros para as porções conscientes e inconscientes do sistema nervoso central, o que permite registrar continuamente todas as seqüências de movimentos corporais e programar o comportamento motor subseqüente ${ }^{58,63}$.

Os principais proprioceptores musculares são: 
Fusos musculares: fornecem informações sobre alterações no comprimento e na tensão das fibras musculares. Responde à tensão muscular por meio de ação reflexa, baseando-se nas mudanças no comprimento das fibras musculares extrafusais. Fundamental para a regulação do movimento e postura.

Órgãos tendinosos de Golgi: detectam diferenças muito mais na tensão gerada pelo músculo ativo que no comprimento do músculo. Quando estimulados por uma tensão excessiva, os receptores de Golgi conduzem seus sinais rapidamente, a fim de desencadear inibição reflexa dos músculos por eles inervados. A função básica destes receptores consiste em proteger o músculo e seu envoltório de tecido conjuntivo contra possíveis lesões induzidas por uma sobrecarga excessiva.

Corpúsculos de Pacini: sensíveis ao movimento rápido e à pressão profunda, agem como sensores mecânicos de "adaptação rápida". Identificam mais as mudanças no movimento ou na pressão que a quantidade de movimento que ocorreu ou a quantidade de pressão que foi aplicada ${ }^{58}$.

\subsection{A função renal e o exercício físico}

Os efeitos do exercício físico sobre a função renal ainda não estão completamente elucidados. Sabe-se que a função renal é muito importante para a manutenção da homeostase durante o exercício ${ }^{67}$ e que este induz profundas mudanças na hemodinâmica renal e na excreção de eletrólitos.

O fluxo plasmático renal é reduzido durante o exercício ${ }^{58,67}$ chegando a valores de até $25 \%$ do valor de repouso, quando um exercício intenso é realizado. O sangue é desviado dos rins para os músculos, pela combinação da liberação de catecolaminas e por uma maior atividade do $\mathrm{SNS}^{67}$. 
Dessa forma, ocorre constrição dos vasos sangüíneos que se dirigem aos rins. Com a diminuição do fluxo sangüíneo renal, os rins são estimulados a lançar o hormônio renina no sangue. $\mathrm{O}$ aumento da concentração de renina leva à produção de angiotensina e esta, por sua vez estimula a secreção de aldosterona pelo córtex das supra-renais. Este mecanismo é sempre ativado quando ocorre uma redução brusca do fluxo sangüíneo renal, seja pelo exercício físico ou por alguma estimulação simpática anormal, em repouso ${ }^{58,63}$. Outros fatores como a restrição de sódio ou a administração de soluções de eletrólitos (sódio-potássio) também podem alterar esse mecanismo ${ }^{67}$.

A secreção de aldosterona aumenta progressivamente durante o exercício. Sua atividade é fundamental para o controle da concentração total de sódio, assim como o volume do líquido extracelular. A aldosterona age regulando a reabsorção de sódio nos túbulos distais dos néfrons ${ }^{58,63,67}$.

Quando são secretadas grandes quantidades de aldosterona, os íons sódio que penetram nos túbulos são reabsorvidos e retornam ao sangue, junto com o líquido. Conseqüentemente, são eliminados pouco sódio e líquido na urina ${ }^{58,63}$. Ocorre redução tanto do fluxo de urina quanto da excreção de sódio, durante o esforço ${ }^{67}$. O aumento do volume plasmático pelo aumento da secreção de aldosterona também é acompanhado por um aumento do débito cardíaco e por uma elevação da pressão arterial ${ }^{58,63}$.

Além disso, junto à redução do fluxo plasmático renal, está a redução do RFG e do fluxo urinário ${ }^{38,55,67}$. O grau de hidratação é uma importante influência, pois o aumento da hidratação durante o exercício diminui a queda do $\mathrm{RFG}^{58}$. O declínio do RFG e do fluxo plasmático renal efetivo não é máximo depois de $1 \mathrm{~h}$ de exercício leve em indivíduos saudáveis. O RFG continua diminuindo durante a segunda hora ${ }^{55}$.

De acordo com Taverner et $\mathrm{al}^{38}$, os pacientes com DRC moderada não podem manter a função excretora nem conservar água como os indivíduos com função renal normal, durante o exercício, o que sugere uma maior atenção na hidratação antes e 
durante o exercício prolongado. A queda do fluxo plasmático renal efetivo foi similar, durante o exercício, entre sujeitos normais e com DRC. Indivíduos com RFG reduzido podem ter um defeito no mecanismo intra-renal que mantém a filtração glomerular durante o estresse e pequenas mudanças na pressão de perfusão, pelo menos durante o exercício $^{38}$.

Temos ainda redução do fluxo urinário que aparece dependente do RFG, da reabsorção tubular de água, da secreção de solutos e dos níveis circulantes do hormônio antidiurético $(\mathrm{ADH})$. A principal função do $\mathrm{ADH}$ consiste em controlar a excreção de água pelos rins, através do estímulo da reabsorção de água pelos túbulos renais ${ }^{58}$. Durante o exercício, a produção de ADH é estimulada. Isso explica a maior retenção de água pelos rins, durante e após o exercício intenso ${ }^{58,63,67}$.

Clinicamente, a urina coletada em humanos saudáveis, em situação de repouso, é desprovida de proteínas ${ }^{67}$. Algumas variáveis causam um aumento fisiológico da excreção de proteínas, especialmente albumina como: exercício ${ }^{1,67,68}$, postura vertical, gravidez e febre ${ }^{1}$. Existe também aumento na taxa de excreção urinária de proteínas, na maioria dos pacientes com proteinúria, causada por diversos tipos de doenças glomerulares, tanto na postura vertical como na atividade física ${ }^{69}$.

A proteinúria pós-exercício é classificada como fisiológica ${ }^{67}$. O aumento da albumina induzido pelo exercício em indivíduos saudáveis é variável e depende do aumento da filtração glomerular e/ou da diminuição da reabsorção tubular da albumina $^{67,68 .}$ No exercício leve a moderado, o tipo de proteinúria predominante pósexercício é relacionado ao aumento da permeabilidade glomerular ${ }^{70}$. O aumento da permeabilidade glomerular é, possivelmente, provocado pelo efeito das catecolaminas, pelo sistema renina-angiotensina ou por outros fatores hormonais como a intervenção da calicreína, por exemplo ${ }^{67}$. 
A excreção urinária de proteínas varia com a intensidade do exercício, com a duração e com o tipo de atividade. Por exemplo, corredores maratonistas excretam mais proteínas que ciclistas ou nadadores. Este comportamento pode ser muito variável entre os indivíduos ${ }^{67}$.

A severidade da proteinúria e da hematúria pós-exercício depende mais da intensidade que da duração do exercício. E, em longo prazo ${ }^{70}$, considerando os efeitos de adaptação positivos do treinamento ${ }^{67}$, o esforço leve se mostrou inofensivo para a função renal e balanço eletrolítico, bem como para o metabolismo cardíaco, em indivíduos saudáveis ${ }^{70}$.

\subsection{A doença renal crônica e o exercício físico}

Desde 1960, o exercício físico tem se estabelecido como um meio de prolongar a vida, principalmente na prevenção ou no controle de doenças cardiovasculares. A partir de 1980, as aplicações clínicas do exercício físico se expandiram a populações com vários tipos de doenças crônicas, visando mais à qualidade que a quantidade de vida. Possivelmente, então, o maior benefício do exercício físico seria a possibilidade de preservar capacidade funcional, liberdade e independência dos indivíduos ${ }^{48}$.

O exercício físico tem potencial para melhorar desordens cardiovasculares ${ }^{17,38,39}$ e metabólicas, sendo benéfico para o tratamento de muitas doenças crônicas ${ }^{38}$, de maneira que um programa de atividade física regular é considerado um tratamento padrão para hipertensão arterial, hiperlipidemia e controle da glicemia, bem como na prevenção primária e secundária da doença aterosclerótica das coronárias ${ }^{39}$.

O exercício também influencia positivamente problemas como osteoporose ${ }^{17,39}$, doença pulmonar crônica, depressão ${ }^{17}$, fraqueza muscular e outras deteriorações funcionais, que quase sempre ocorrem em pessoas mais idosas ou com alguma 
doença $^{39}$. Há melhora da capacidade funcional e da qualidade de vida, por meio da modificação de fatores de risco ${ }^{17}$.

Quanto à DRC, não estão bem estabelecidos os efeitos do exercício físico. Porém, o exercício físico tem ganhado maior atenção por ser um possível meio de prevenção, redução ou retardo da incapacitação na população dialítica ${ }^{18} \mathrm{e}$, no caso da população com DRC em estágios iniciais, como tratamento de DCVs, causa primária de mortalidade prematura em DRC, em todos os seus estágios ${ }^{8,24,52}$.

Alguns estudos indicam que pacientes com IRC ou DRCT podem se beneficiar da prática regular de exercício físico ${ }^{71,72}$, através de melhora da capacidade cardiorespiratória, da qualidade de vida ${ }^{56,73}$, da força física e do metabolismo de lipídios e de glicose ${ }^{13,74}$. Miller et $\mathrm{al}^{75}$ observaram reduções significativas de até $36 \%$ no uso de medicamentos anti-hipertensivos em pacientes dialíticos, com conseqüente redução de custos, por meio da realização de 17 a 45 minutos de exercício aeróbio, durante a hemodiálise.

Há um crescente número de pesquisas sobre os efeitos do exercício em indivíduos no estágio final da $\mathrm{DRC}^{76}$. Porém, poucos estudos têm relatos dos efeitos do exercício físico em pacientes pré-dialíticos ou com DRC em estágios iniciais ${ }^{17,69,76}$. Fica evidente a necessidade de estudos que demonstrem os efeitos da atividade física no risco cardiovascular de pacientes com DRC no estágio pré-dialítico ${ }^{77}$. Um programa regular de exercícios talvez possa melhorar a capacidade aeróbica e diminuir a pressão arterial destes pacientes.

Não há relatos de danos aos rins de pacientes que participam de programas de exercício. É provável que qualquer método que aumente a atividade física nesta população seja benéfico ${ }^{72}$ Kutner $^{71}$ aponta que perguntar ao paciente sobre a prática regular de atividades físicas poderia ser parte da avaliação de rotina do paciente.

Portanto, não estão claros os efeitos do exercício físico nesta população 


\section{OBJETIVOS}

\subsection{Objetivo Geral}

Avaliar em pacientes com DRC - estágio III (clearance de creatinina entre 30 e $60 \mathrm{~mL} / \mathrm{min} / 1,73 \mathrm{~m}^{2}$ ) e em indivíduos saudáveis as respostas hemodinâmicas e neurais ao exercício estático com handgrip após uma sessão de exercício físico aeróbio.

\subsection{Objetivos Específicos}

Avaliar em pacientes com DRC - estágio III:

1) Efeitos de uma sessão de exercício físico aeróbio na frequiência cardíaca (FC), pressão arterial sistólica (PAS), pressão arterial diastólica (PAD), atividade nervosa simpática periférica (ANSP), fluxo sanguíneo do antebraço (FSA) e resistência vascular periférica (RVP), no repouso e durante exercício estático com handgrip a $30 \%$ da contração voluntária máxima (CVM).

2) Comparar essas variáveis da sessão exercício (SE) com a sessão repouso (SR) entre os pacientes com DRC e comparar os resultados destes pacientes com os resultados do grupo de indivíduos saudáveis (controle).

3) Efeitos de uma sessão de exercício físico aeróbio sobre a proteinúria nos pacientes com DRC. 


\section{METODOLOGIA}

\subsection{Casuística}

Foram estudados nove pacientes, portadores de DRC - estágio III por nefropatia primária ou secundária à hipertensão arterial, selecionados pelo Ambulatório de Nefrologia do Hospital das Clínicas da Faculdade de Medicina da Universidade de São Paulo. Também foram incluídos no trabalho 12 voluntários saudáveis, um grupo controle (CT).

Antes de iniciarem o protocolo, todos foram esclarecidos, em uma breve entrevista, a respeito de todos os procedimentos experimentais, riscos e benefícios envolvidos no estudo. Os voluntários que aceitaram participar assinaram o Termo de Consentimento Livre e Esclarecido, aprovado pelo Comitê de Ética para Análise de Projetos de Pesquisa - CAPPesq - da Diretoria Clínica do Hospital das Clínicas e da Faculdade de Medicina da Universidade de São Paulo (Anexos I e II). O projeto teve auxílio financeiro da FAPESP, processo nº 07/51945-4 (Anexo III).

\subsection{Critérios de inclusão}

Foram incluídos no estudo homens e mulheres:

$\checkmark$ Entre 30 e 60 anos de idade;

Não obesos;

Não diabéticos;

Não portadores de anemia;

Não praticantes de atividade física estruturada;

- Os pacientes do grupo DRC ainda obedeciam aos seguintes critérios:

Apresentavam DRC - estágio III (clearance de creatinina entre 30 e 60 $\mathrm{mL} / \mathrm{min} / 1,73 \mathrm{~m}^{2}$ ); 
Eram hipertensos controlados em uso, preferencialmente, de inibidores de ECA ou ARA. Foram excluídos pacientes que faziam uso de B-bloqueadores e simpatolíticos.

Os pacientes do grupo CT eram normotensos.

\subsection{Exames preliminares}

\subsubsection{Diagnóstico de Hipertensão}

Os voluntários tiveram a pressão arterial aferida três vezes, em ambos os braços, após cinco minutos de repouso na posição sentada, em duas visitas ao laboratório, como sugere o "Joint National Committee on Prevention, Detection, Evaluation, and Treatment of High Blood Pressure"78. A pressão arterial foi aferida pelo método auscultatório, utilizando-se um esfigmomanômetro de coluna de mercúrio e foram consideradas as fases I e $\mathrm{V}$ dos sons de Korotkoff para identificar PAS e PAD, respectivamente. O nível pressórico de cada voluntário foi calculado pela média das seis medidas realizadas. Quando houve variação nos valores pressóricos entre os braços, considerou-se os valores obtidos no braço de pressão mais elevada. Eram considerados hipertensos os indivíduos que apresentavam PAS e PAD superiores a $140 \mathrm{~mm} \mathrm{Hg}$ e 90 mmHg respectivamente. Foram excluídos indivíduos hipertensos em uso de ßbloqueadores e simpatolíticos.

\subsubsection{Diagnóstico de Obesidade}

Os voluntários foram medidos e pesados em balança FILIZOLA ${ }^{\circledR}$, trajando apenas calção e camiseta. O índice de massa corporal (IMC) foi calculado pelo quociente entre massa $(\mathrm{kg})$ e o quadrado da estatura $\left(\mathrm{m}^{2}\right)$. Os indivíduos com IMC $\geq 30$ $\mathrm{kg} / \mathrm{m}^{2}$ foram excluídos do estudo. 


\subsubsection{Exames Laboratoriais}

Os exames realizados nos pacientes, inicialmente, são: Hemoglobina $(\mathrm{Hb})$, glicemia, níveis sangüíneos de uréia, creatinina, proteinúria e clearance de creatinina. Foram excluídos do estudo, de ambos os grupos, os indivíduos que apresentassem os seguintes parâmetros:

$\checkmark \mathrm{Hb} \leq 12 \mathrm{~g} / \mathrm{dl} ;$

$\checkmark$ Glicemia de jejum $\geq 126 \mathrm{mg} / \mathrm{dl}$.

\subsubsection{Avaliação do condicionamento físico (Capacidade aeróbia máxima)}

O condicionamento físico foi avaliado por intermédio de teste ergoespirométrico, realizado num cicloergômetro (Corival Cycle), empregando-se protocolo escalonado com incremento de $30 \mathrm{~W}$ a cada 3 minutos, até a exaustão. Essa avaliação foi precedida por eletrocardiograma de repouso (Cardio Perfect) com registro das 12 derivações padrão (D1, D2, D3, aVL, aVR, aVF, V1, V2, V3, V4, V5, V6). Durante o exercício, a frequiência cardíaca e o eletrocardiograma foram continuamente monitorados e registrados ao final de cada minuto através do registro de 3 derivações simultâneas (MC5, V2M e D2M). A PAS e a PAD foram aferidas pelo método auscultatório, através de um esfigmomanômetro de coluna de mercúrio ao final de cada estágio. Os gases expirados foram coletados e analisados a cada ciclo respiratório pelo analisador de gases computadorizado da Medical Graphics Corporation (CPX/D) durante todo o protocolo de teste. A capacidade aeróbia máxima foi avaliada pelo consumo de oxigênio no final do exercício, $\left(\mathrm{VO}_{2 \text { pico }}\right)$, calculado em médias de 60 segundos. 


\subsection{Protocolo experimental}

\subsubsection{Geral}

Os voluntários que preencheram os critérios de inclusão foram selecionados para realização do teste ergoespirométrico e, de forma aleatória, para a realização das sessões experimentais de exercício ou de repouso.

\subsubsection{Específico}

Após o teste ergoespirométrico, os voluntários realizaram 2 sessões: sessão repouso (SR) e sessão exercício (SE), que foram realizadas em ordem aleatória com intervalo mínimo de 15 dias. O desenho das sessões se encontra no Anexo IV. A sessão controle significava realizar repouso sentado; a sessão exercício, realizar exercício aeróbio em cicloergômetro. Os voluntários do grupo DRC também coletaram uma amostra de urina $24 \mathrm{~h}$ um dia antes das sessões experimentais para dosagem de proteinúria.

Nenhum tipo de atividade física foi realizado nas 48 horas precedentes ao experimento. Logo após a chegada do voluntário ao laboratório, o mesmo era orientado a esvaziar a bexiga e, posteriormente, pesado de bermuda e camiseta. Em seguida era sorteado se o voluntário realizaria a SR ou SE. Posteriormente, era realizado o exercício aeróbio agudo ou repouso na posição sentado. Durante qualquer uma dessas sessões, a pressão arterial e a freqüência cardíaca eram aferidas a cada dez minutos.

Após o exercício ou o repouso o voluntário era novamente orientado a esvaziar a bexiga, pesado pela segunda vez e deitado na maca. Na sequência era realizado o teste de CVM com o handgrip e os equipamentos para registro de FC, PAS, PAD e FSA eram instalados. 
Iniciavam-se, então, os procedimentos de localização do nervo que poderiam ser completados em, no máximo, 45 minutos. Uma vez localizado o sinal nervoso, eram registrados: ANSP, PAS, PAD, PAM, FC e FSA durante 5 minutos, período denominado de basal.

Posteriormente era realizado o exercício estático com o handgrip e, após a finalização desse teste, todos os equipamentos eram retirados do voluntário.

O paciente do grupo DRC era orientado para colher urina nas próximas $24 \mathrm{~h}$, para dosagem de proteinúria. Todos os voluntários eram orientados a retornar ao laboratório num mínimo em 15 dias para a realização da outra sessão experimental.

\subsection{Sessão experimental}

\subsubsection{Exercício físico aeróbio agudo}

As sessões de exercício eram realizadas em cicloergômetro (Corival Cycle) por 45 minutos em $50 \%$ do $\mathrm{VO}_{2}$ pico, mantendo-se uma velocidade de $60 \mathrm{rpm}$. Cada sessão era precedida por 7 minutos de repouso sentado no cicloergômetro e 3 minutos de aquecimento com a potência equivalente a $50 \%$ da que seria usada durante o exercício. Após o exercício, 2 minutos de recuperação ativa era realizada, sendo que no primeiro minuto a potência era reduzida pela metade e no segundo minuto a potência foi zero. $\mathrm{O}$ protocolo era finalizado com 3 minutos de recuperação passiva na posição sentada no cicloergômetro. Para o cálculo da potência necessária para se atingir $50 \%$ do $\mathrm{VO}_{2}$ pico de cada voluntário, foi utilizada a regressão linear dos dados de potência e $\mathrm{VO}_{2}$ obtidos no teste ergoespirométrico máximo realizado anteriormente. 


\subsubsection{Medidas de pressão arterial}

Durante o exercício ou repouso, a medida da pressão arterial foi feita pelo método auscultatório, através de um esfigmomanômetro de coluna de mercúrio. A medida intermitente da pressão arterial (depois que o voluntário deitou-se na maca) foi realizada por um monitor de pressão arterial não-invasivo (Cardioscópio mod. 2010 DIXTAL) que foi posicionado no membro inferior do paciente.

\subsubsection{Medidas de freqüência cardíaca}

A frequiência cardíaca de repouso ou exercício foi aferida pelo método de palpação do pulso radial e durante a coleta dos dados, foi registrada pelo monitor de pressão arterial (Cardioscópio mod. 2010 - DIXTAL) e, simultaneamente, pelo eletrocardiograma, sendo também registrada no polígrafo (GOULD RS 3000).

\subsubsection{Registro da atividade nervosa simpática periférica}

A ANSP foi registrada no nervo fibular, de maneira direta, através da técnica denominada microneurografia, que possibilita o registro dos potenciais de ação das fibras A e C simpáticas em nervos periféricos. A técnica foi realizada conforme o procedimento descrito por Anderson \& Mark $^{79}$. Esta técnica, usada para o registro intraneural da ANSP em humanos ${ }^{27}$, sem anestesia, foi desenvolvida por Hagbarth e Valbo na Suécia, há aproximadamente 30 anos, e tem sido amplamente utilizada nos últimos 20 anos para investigar a regulação simpática cutânea e muscular ${ }^{79}$. O registro intraneural é feito por meio da inserção de microeletrodos de tungstênio, uma haste de $0,2 \mathrm{~mm}$ de espessura inserida, normalmente, em nervos periféricos como o fibular ou o radial, acessando-se a atividade simpática neuromuscular ${ }^{28}$.

Esse método pode ser usado para registrar a atividade simpática de qualquer nervo periférico. No entanto, por razões práticas, a maior parte dos registros é feita no 
nervo fibular, freqüentemente palpável, uma vez que é possível se utilizar da cabeça da

fíbula como referência territorial. É uma técnica bastante segura e as complicações decorrentes dessa técnica são pouco freqüentes e transitórias, vindo a desaparecer no período de uma semana ${ }^{79}$.

De forma sucinta, a técnica se inicia com a estimulação elétrica para mapeamento do trajeto do nervo. Em seguida, um microeletrodo de tungstênio de ponta não isolada (diâmetro 1-5 um) é colocado no local de melhor resposta e a 1-2 cm desse eletrodo é introduzido outro eletrodo para referência. O eletrodo ativo faz estimulação interna de $1 \mathrm{~V}$ a $4 \mathrm{~V}$, até que se obtenha um local onde esse estímulo deflagre contração involuntária no músculo da perna, sem parestesia. O sinal nervoso desse local é amplificado, filtrado e integrado sendo registrado em papel através de um polígrafo GOULD RS 3000. A atividade nervosa simpática é medida contando-se o número de impulsos nervosos por minuto.

\subsubsection{Avaliação do fluxo sanguíneo do antebraço}

O FSA foi medido pela técnica de pletismografia de oclusão venosa a ar. O braço direito do voluntário era mantido acima do nível do coração e dois manguitos eram posicionados, um no punho e outro no braço do voluntário. Um manguito de látex preenchido com ar até uma pressão de $4 \mathrm{~cm}$ de água era colocado no antebraço direito. Para se determinar o fluxo sanguíneo, o manguito do punho era inflado até $200 \mathrm{~mm} \mathrm{Hg}$, interrompendo a circulação sangüínea para a mão e o manguito do braço era inflado (até uma pressão subdiastólica de 40 a $60 \mathrm{~mm} \mathrm{Hg}$ ) e desinflado em intervalos de 7/8 segundos. Esse procedimento provoca oclusão do retorno venoso sem interromper a entrada arterial de sangue no antebraço, ocasionando dilatação nessa região que provoca aumento na pressão interna no manguito de látex, a qual era registrada em um polígrafo. 
O FSA foi calculado por meio da velocidade de incremento da pressão no manguito de látex, sendo medido a cada minuto. A pressão arterial média também era medida a cada minuto durante a mensuração do fluxo sanguíneo, de modo que a resistência vascular periférica foi calculada pela divisão da pressão arterial média pelo fluxo sangüíneo local.

\subsubsection{Manobra excitatória utilizando o handgrip}

A manobra excitatória do sistema nervoso simpático era realizada por meio do exercício estático (EE) com a utilização do handgrip (TBW) a uma intensidade de $30 \%$ da CVM.

O teste de CVM era realizado da seguinte maneira: o handgrip era posicionado na mão esquerda do voluntário e o mesmo era orientado a realizar a preensão manual com o máximo de força que conseguisse, por três vezes consecutivas. Os valores atingidos eram anotados e uma média dos três valores era calculada. Esse valor foi considerado como máximo.

Os valores de ANSP, FC, PAS, PAD, PAM e FSA eram registrados durante três minutos de repouso, seguidos de três minutos da realização do exercício estático com handgrip, seguidos de dois minutos de oclusão da circulação do braço realizada com manguito pneumático a uma pressão de $200 \mathrm{~mm} \mathrm{Hg}$, seguida de três minutos de recuperação.

\subsubsection{Exercício Estático (Isométrico)}

Caracterizado por contração muscular mantida, isto é, sem relaxamento, por tempo pré-estabelecido, a um percentual da força de contração voluntária máxima do indivíduo. 


\subsection{Análise dos dados}

Para verificar o efeito de exercício aeróbio nos parâmetros hemodinâmicos e neurais, no período basal foi aplicado o teste $t$-student, para amostras dependentes, sendo aceito como significante o índice de $\mathrm{P}=0,05$.

Nos períodos de exercício estático, para do comparar o efeito entre as sessões (controle e exercício) e os estágios (repouso, exercício, oclusão e recuperação) foi aplicada análise de variância ANOVA de dois fatores. Foi aceito como significante o índice de $\mathrm{P}=0,05$. Quando necessário foi aplicado o teste de "post-hoc" de Newman Keuls para detectar a diferença significante. 


\section{RESULTADOS}

\subsection{Gerais}

Inicialmente 25 indivíduos foram avaliados, sendo 13 portadores de DRC estágio III e 12 indivíduos saudáveis, o grupo controle (CT). Destes últimos, todos completaram as duas sessões experimentais. Porém, do grupo DRC apenas 9 pacientes completaram as duas sessões experimentais . O perfil dos voluntários dos DRC e CT se encontra nas tabelas 5 e 6 . Dados individuais de cada voluntário se encontram nos Anexos V e VII.

Tabela 5 - Perfil dos voluntários - grupo DRC vs. CT.

\begin{tabular}{lcc}
\hline características & DRC & CT \\
\hline idade (anos) & $52 \pm 8$ & $50 \pm 5$ \\
massa corporal $(\mathrm{kg})$ & $74,8 \pm 12$ & $70 \pm 13$ \\
IMC $\left(\mathrm{kg} / \mathrm{m}^{2}\right)$ & $27 \pm 3$ & $26,2 \pm 3$ \\
PAM (consultório) & $105 \pm 13$ & $90 \pm 6 \#$ \\
Cargas exercício & $45 \pm 13,4$ & $42,3 \pm 14$ \\
\hline \multicolumn{2}{|l}{ Médias \pm dp } \\
\#diferença entre os grupos $(\mathrm{P}<0,01)$ \\
\hline
\end{tabular}

As variáveis idade, massa corporal, IMC e carga utilizada na sessão exercício, não apresentaram diferenças significativas entre os grupos $(\mathrm{P}>0,05)$. Isso demonstra que a amostra foi semelhante. A PAM, porém, apresentou diferença significativa entre os grupos, sendo $\mathrm{P}<0,01$. A tabela 6 demonstra o perfil bioquímico dos voluntários. Não houve diferença significativa nos valores de glicemia ou hemoglobina entre os grupos. Os índices que avaliam a função renal, porém, apresentaram diferenças significativas $(\mathrm{P}<0,01)$. Os resultados laboratoriais individuais se encontram no Anexo VI. 
Tabela 6 - Perfil bioquímico dos voluntários - DRC vs. CT.

\begin{tabular}{lcc}
\hline características & DRC & CT \\
\hline clearance de creatinina $(\mathrm{ml} / \mathrm{min})$ & $52 \pm 9$ & $99 \pm 6 \#$ \\
uréia $(\mathrm{mg} / \mathrm{dl})$ & $65 \pm 12$ & $31 \pm 4 \#$ \\
creatinina $(\mathrm{mg} / \mathrm{dl})$ & $1,8 \pm 0,3$ & $0,8 \pm 0,1 \#$ \\
$\mathrm{Hb}(\mathrm{g} / \mathrm{dl})$ & $13,4 \pm 1,4$ & $13,1 \pm 0,9$ \\
$\mathrm{Glicemia}(\mathrm{mg} / \mathrm{dl})$ & $94 \pm 10$ & $94 \pm 11$ \\
\hline \multicolumn{2}{l}{ Médias \pm dp } & \\
\#diferença entre os grupos $(\mathrm{P}<0,05)$ &
\end{tabular}

\subsection{Efeito do exercício aeróbio prévio nas respostas hemodinâmicas e neurais}

\subsubsection{Período basal}

Os dados individuais de cada voluntário no período basal se encontram nos Anexos VII - XXI. As tabelas 7 e 8 apresentam as médias de todas as variáveis analisadas nos voluntários dos grupos DRC e CT, nas sessões repouso (SR) e exercício (SE).

Tabela 7 - Valores médios de todas as variáveis nas sessões repouso e exercício - DRC.

\section{BASAL GRUPO DRC}

\begin{tabular}{lcc}
\hline & SR & SE \\
\hline PAS (mm Hg) & $162 \pm 15$ & $152 \pm 23 *$ \\
PAD (mm Hg) & $91 \pm 11$ & $85 \pm 14 *$ \\
PAM (mm Hg) & $108 \pm 12$ & $102 \pm 13 *$ \\
FC (bpm) & $62 \pm 9$ & $67 \pm 9 *$ \\
ANSP (impulsos/min) & $38 \pm 4$ & $31 \pm 4 *$ \\
FSA ml(min.100ml) & $2,1 \pm 0,8$ & $3,2 \pm 1,3 *$ \\
RVP (unidades) & $59 \pm 29$ & $41 \pm 28 *$ \\
\hline
\end{tabular}

Médias \pm dp

*diferença entre sessões $(\mathrm{P}<0,05)$ 
Tabela 8 - Valores médios de todas as variáveis nas sessões repouso e exercício - CT.

BASAL GRUPO CONTROLE

\begin{tabular}{lcc}
\hline & SR & SE \\
\hline PAS (mm Hg) & $155 \pm 11$ & $145 \pm 16^{*}$ \\
PAD (mm Hg) & $77 \pm 5$ & $71 \pm 10^{*}$ \\
PAM (mm Hg) & $96 \pm 5$ & $90 \pm 9 *$ \\
FC (bpm) & $66 \pm 8$ & $66 \pm 8$ \\
ANSP (impulsos/min) & $34 \pm 2$ & $27 \pm 4 *$ \\
FSA ml(min.100ml) & $2,3 \pm 1,1$ & $2,9 \pm 1$ \\
RVP (unidades) & $45 \pm 20$ & $31 \pm 7$ \\
\hline \multicolumn{2}{|l}{ Médias \pm dp } \\
*diferença entre sessões $(\mathrm{P}<0,05)$ \\
\hline
\end{tabular}

No período basal, as médias da PAS entre os grupos DRC e CT foram semelhantes $(157 \pm 20$ vs $150 \pm 14 \mathrm{~mm} \mathrm{Hg})$, como mostra a tabela 9. Porém, entre as sessões repouso e exercício, houve redução significativa na PAS, tanto no grupo DRC $(162 \pm 15$ vs $152 \pm 23 \mathrm{~mm} \mathrm{Hg})(\mathrm{P}<0,01)$ como no $\mathrm{CT}(155 \pm 11$ vs $145 \pm 16 \mathrm{~mm} \mathrm{Hg})$ $(\mathrm{P}<0,01)$. O comportamento da PAS entre os grupos, durante o período basal, está ilustrado na figura 3.

Tabela 9 - PAS nos grupos DRC e CT.

\begin{tabular}{lcc}
\hline & DRC & CT \\
\hline PAS $(\mathrm{mm} \mathrm{Hg})$ & $157 \pm 20$ & $150 \pm 14$ \\
\hline Médias \pm dp & &
\end{tabular}


Figura 3 - PAS dos grupos DRC e CT no período basal, nas sessões controle e exercício.

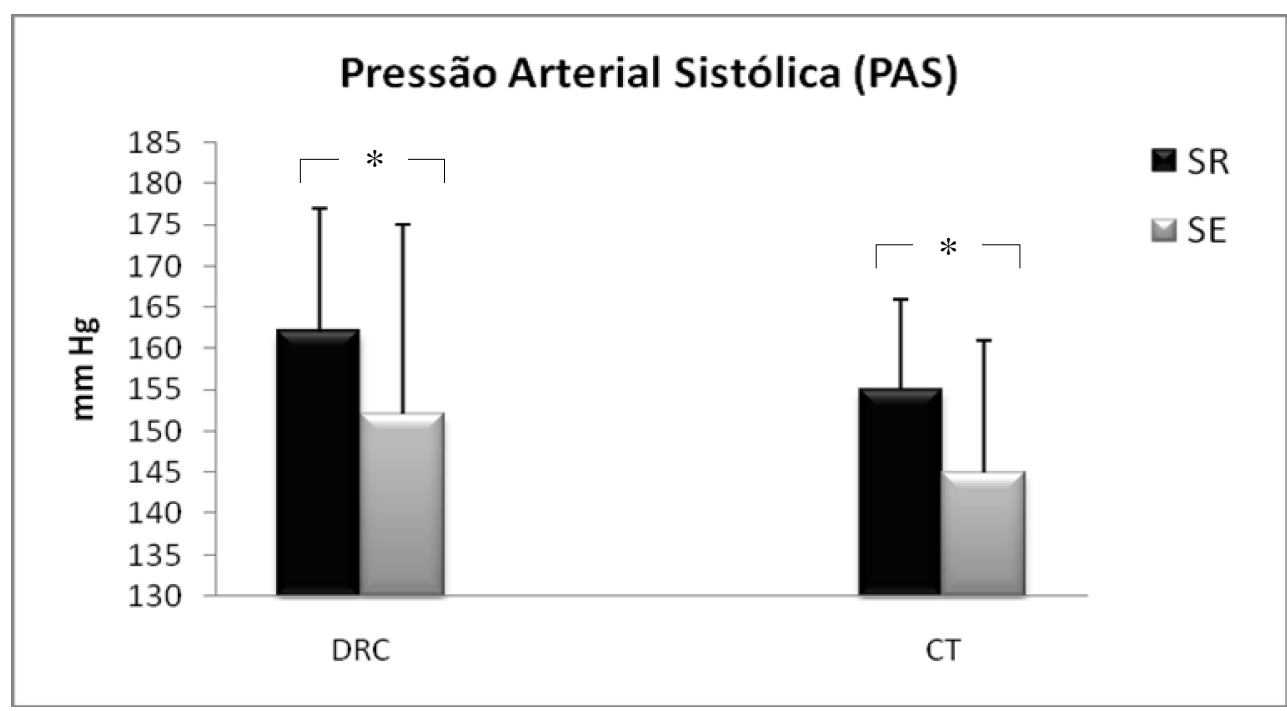

*diferença entre sessões $(\mathrm{P}<0,01)$

Em relação à $\mathrm{PAD}$, no período basal, sua média foi mais alta no grupo DRC que no $\mathrm{CT}$, de maneira significativa $(88 \pm 12$ vs. $74 \pm 7 \mathrm{~mm} \mathrm{Hg})(\mathrm{P}<0,01)$, como mostra a tabela 10. Já nas sessões repouso e exercício, o comportamento da PAD nos grupos foi semelhante, de maneira que na sessão repouso a média da PAD foi maior que na sessão exercício. Houve diferença estatisticamente significante em ambos os grupos $(\mathrm{P}<0,02)$. O comportamento da PAD entre os grupos, no período basal, está ilustrado na figura 4.

Tabela 10 - PAD nos grupos DRC e CT.

\begin{tabular}{lcc}
\hline & DRC & CT \\
\hline PAD $(\mathrm{mm} \mathrm{Hg})$ & $88 \pm 12$ & $74 \pm 7$ \# \\
\hline $\begin{array}{l}\text { Médias } \pm \text { dp } \\
\text { \#diferença entre os grupos }(\mathrm{P}<0,01)\end{array}$
\end{tabular}


Figura 4 - PAD dos grupos DRC e CT no período basal, nas sessões controle e exercício.

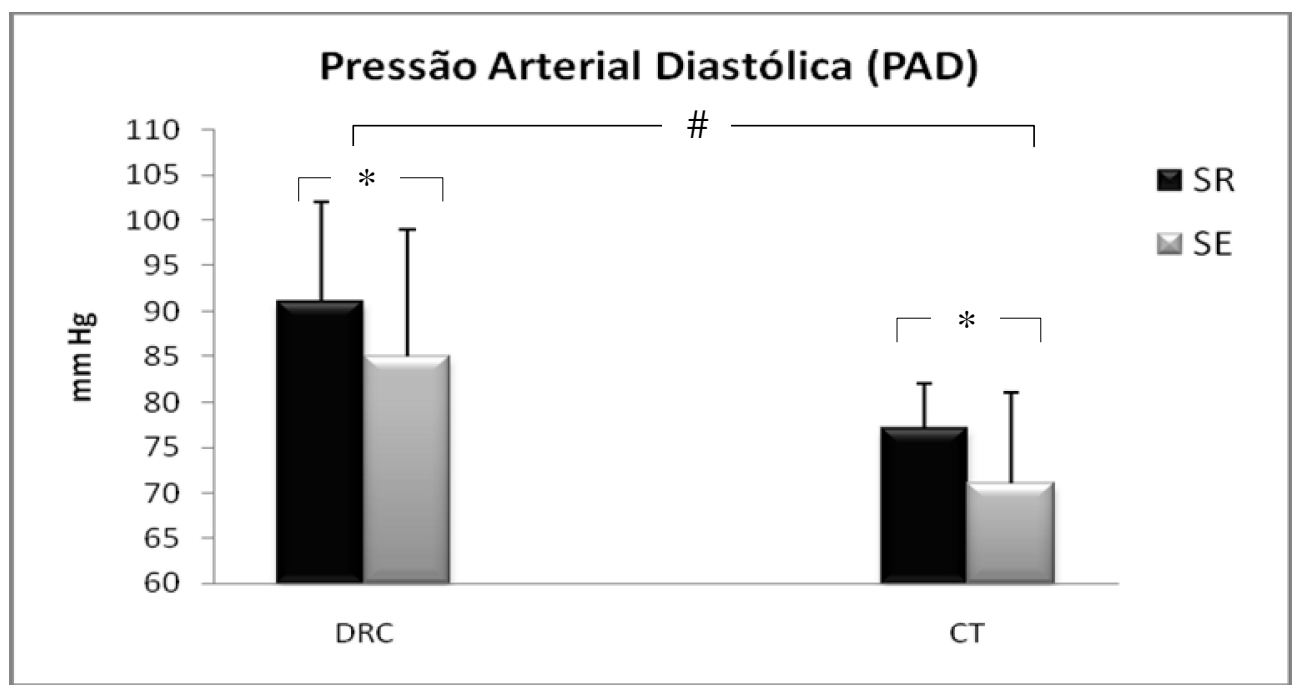

* diferença entre sessões $(\mathrm{P}<0,05)$

\# diferença entre grupos $(\mathrm{P}<0,01)$

O comportamento da PAM foi semelhante ao da PAD, como esperado. No período basal, entre os grupos, a média da pressão arterial diastólica foi mais alta no grupo DRC que no CT, de maneira significativa $(102 \pm 13$ vs. $93 \pm 8 \mathrm{~mm} \mathrm{Hg})(\mathrm{P}<0,01)$, como mostra a tabela 11. Já nas sessões repouso e exercício, a PAM foi menor na sessão exercício que na sessão repouso de maneira significativa em ambos os grupos $(\mathrm{P}<0,01)$. O comportamento da PAM entre os grupos, durante o período basal, está ilustrado na Figura 5.

Tabela 11 - PAM nos grupos DRC e CT.

\begin{tabular}{|c|c|c|}
\hline & DRC & CT \\
\hline PAM (mm Hg) & $102 \pm 13$ & $93 \pm 8 \#$ \\
\hline $\begin{array}{l}\text { Médias } \pm \text { dp } \\
\text { \#diferença entr }\end{array}$ & upos $(P<0,01)$ & \\
\hline
\end{tabular}


Figura 5 - PAM dos grupos DRC e CT no período basal, nas sessões controle e exercício.

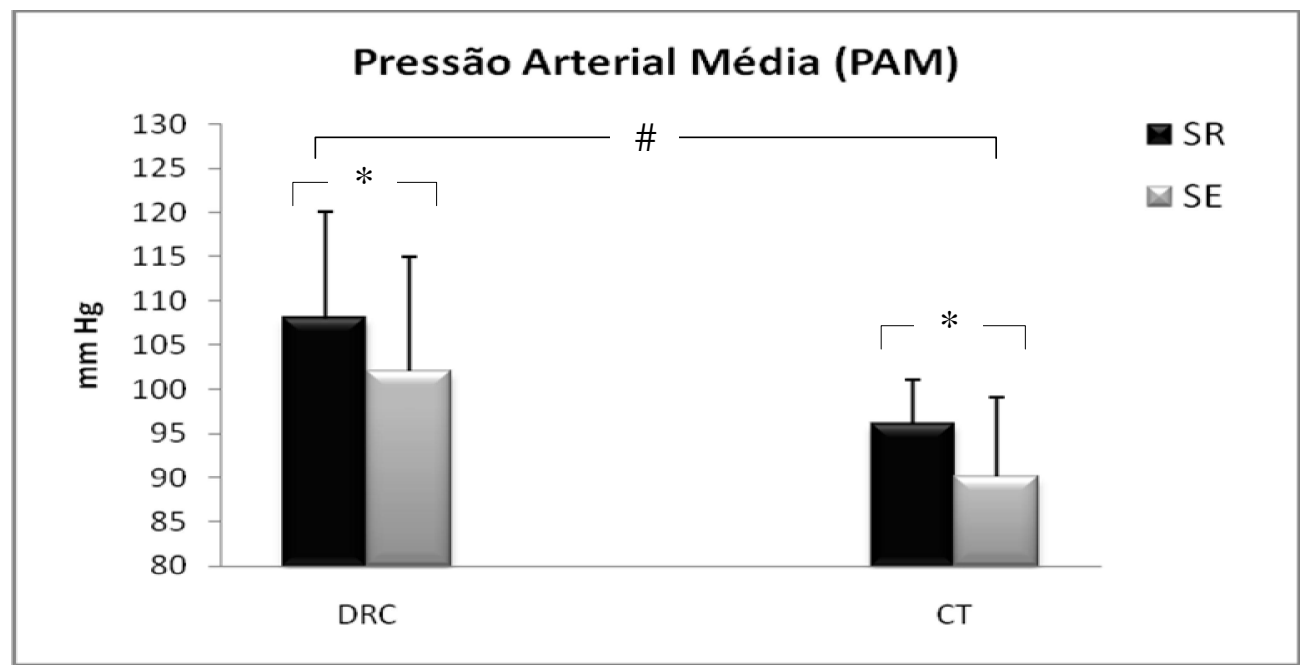

*diferença entre sessões $(\mathrm{P}<0,01)$

\# diferença entre grupos $(\mathrm{P}<0,01)$

No período basal, as médias da FC entre os grupos DRC e CT foram semelhantes ( $65 \pm 9$ vs $66 \pm 8 \mathrm{bpm})$, como mostra a tabela 12. Porém, ao compararmos a FC entre os grupos, observamos que no grupo DRC a FC sofreu um aumento na sessão exercício em relação à sessão repouso de 5 bpm, ao passo que a FC cardíaca se manteve nas sessões repouso e exercício, no grupo CT, como podemos observar na tabela 13. Outro dado interessante foi que a FC na sessão repouso foi significativamente menor no grupo DRC que no CT (62 \pm 9 vs. $66 \pm 8 \mathrm{~mm} \mathrm{Hg})(\mathrm{P}=0,02)$. O comportamento da FC entre os grupos, durante o período basal, está ilustrado na Figura 6.

Tabela 12 - FC nos grupos DRC e CT.

\begin{tabular}{lcc}
\hline & DRC & CT \\
\hline FC $(\mathbf{b p m})$ & $65 \pm 9$ & $66 \pm 8$ \\
\hline Médias \pm dp & &
\end{tabular}


Tabela 13 - FC dos grupos DRC e CT, durante as sessões repouso e exercício.

\begin{tabular}{lcc}
\hline & SR & SE \\
\hline DRC & $62 \pm 9$ & $67 \pm 9 *$ \\
CT & $66 \pm 8$ & $66 \pm 8$ \\
\hline Médias \pm dp & \\
*diferenca entre as sessões $(\mathrm{P}<0.05)$ \\
\hline
\end{tabular}

Figura 6 - FC dos grupos DRC e CT no período basal, nas sessões controle e exercício.

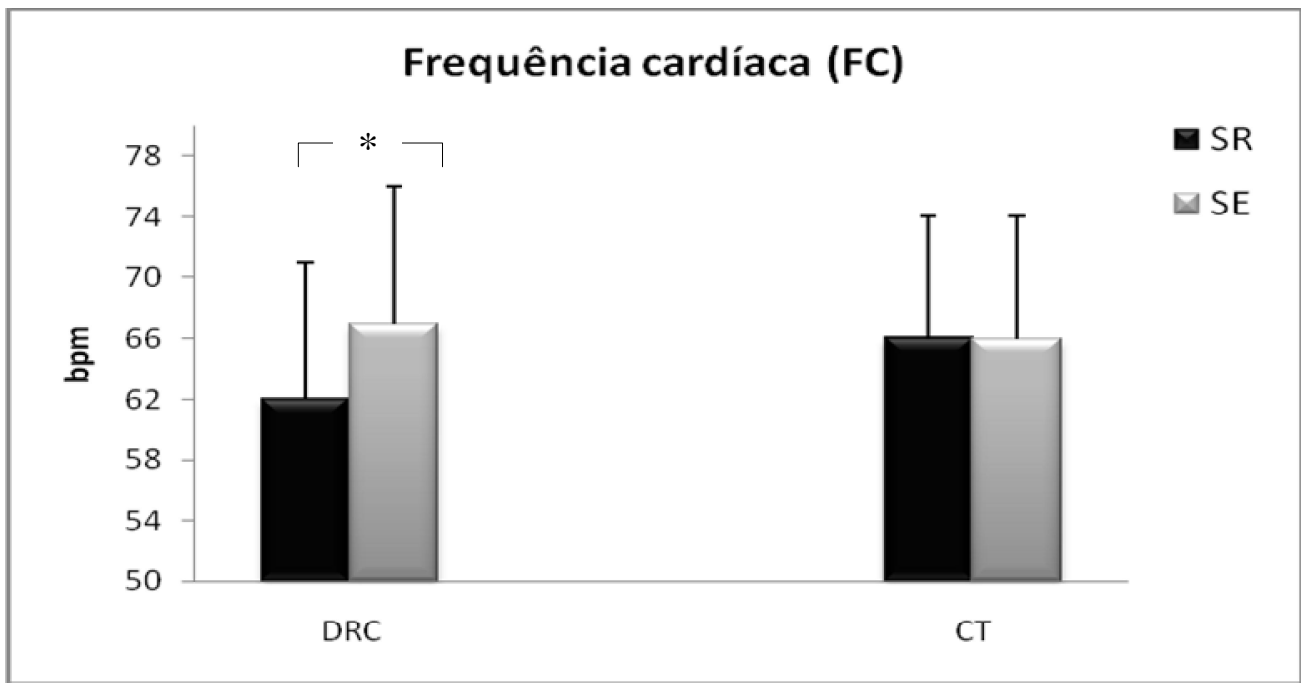

*diferença entre sessões $(\mathrm{P}<0,05)$

Em relação à atividade nervosa simpática periférica (ANSP), o seu comportamento entre os grupos foi diferente no período basal. Sua média foi mais alta no grupo DRC que no CT, de maneira significativa ( $35 \pm 5$ vs. $31 \pm 5$ impulsos/min) $(\mathrm{P}=0,03)$, como mostra a tabela 14 . Já nas sessões repouso e exercício, o comportamento da ANSP nos grupos foi semelhante, de maneira que na sessão exercício houve redução significativa da ANSP em relação à sessão controle, em ambos os grupos $(\mathrm{P}<0,01)$. $\mathrm{O}$ comportamento da ANSP no período basal está ilustrado na figura 7. 
Tabela 14 - ANSP nos grupos DRC e CT.

\begin{tabular}{lcc}
\hline & DRC & CT \\
\hline ANSP & $35 \pm 5$ & $31 \pm 5 \#$ \\
\hline $\begin{array}{l}\text { Médias } \pm \text { dp } \\
\text { \#diferença entre os grupos }(\mathrm{P}<0,05)\end{array}$
\end{tabular}

Figura 7 - ANSP dos grupos DRC e CT no período basal, nas sessões controle e exercício.

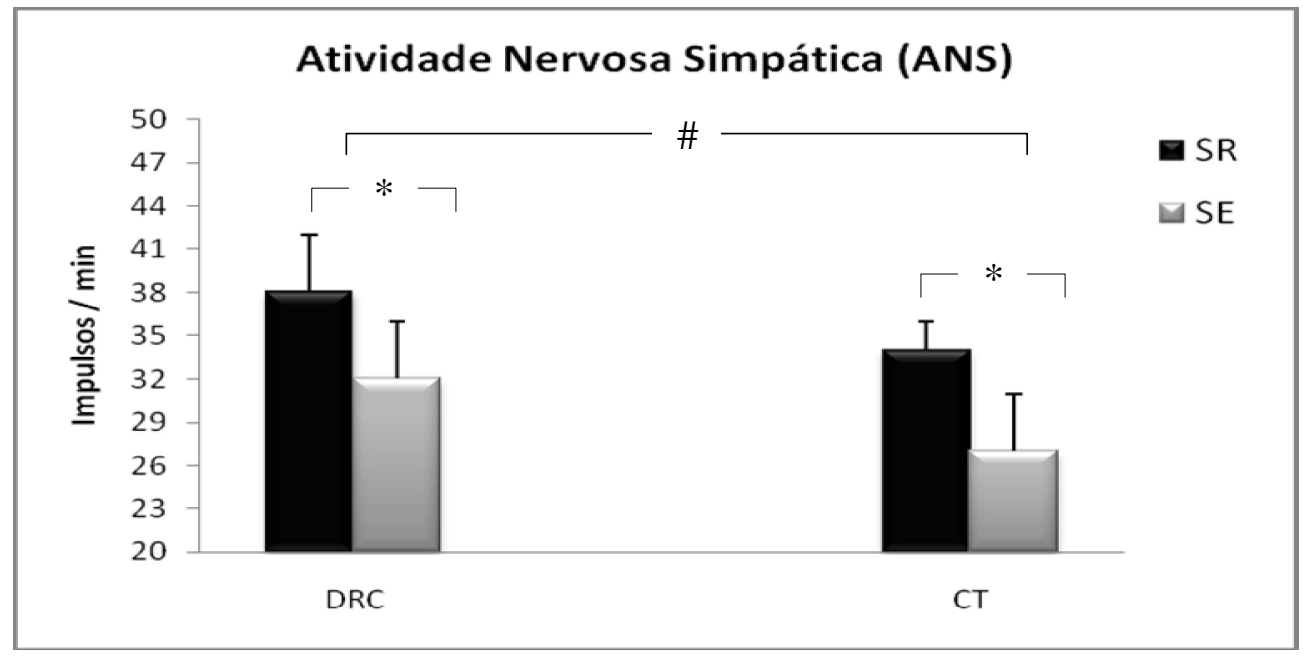

* diferença entre sessões $(\mathrm{P}<0,001)$

\# diferença entre grupos $(\mathrm{P}<0,05)$

No período basal, as médias do fluxo sanguíneo do antebraço (FSA) entre os grupos DRC e CT foram semelhantes $(2,7 \pm 1$ vs $2,6 \pm 1 \mathrm{ml}(\min .100 \mathrm{ml}))$, como mostra a tabela 15. Entre as sessões repouso e exercício, o comportamento do FSA nos grupos também foi semelhante, de maneira que na sessão exercício houve um aumento no FSA em relação à sessão repouso, em ambos os grupos. Este aumento, porém foi significativo apenas no grupo $\mathrm{DRC}(\mathrm{P}=0,01)$. O comportamento do FSA entre os grupos, durante o período basal, está ilustrado na figura 8. 
Tabela 15 - FSA nos grupos DRC e CT.

\begin{tabular}{lcc}
\hline & DRC & CT \\
\hline FSA & $2,7 \pm 1$ & $2,6 \pm 1$ \\
\hline Médias \pm dp & &
\end{tabular}

Figura 8 - FSA dos grupos DRC e CT no período basal, nas sessões controle e exercício.

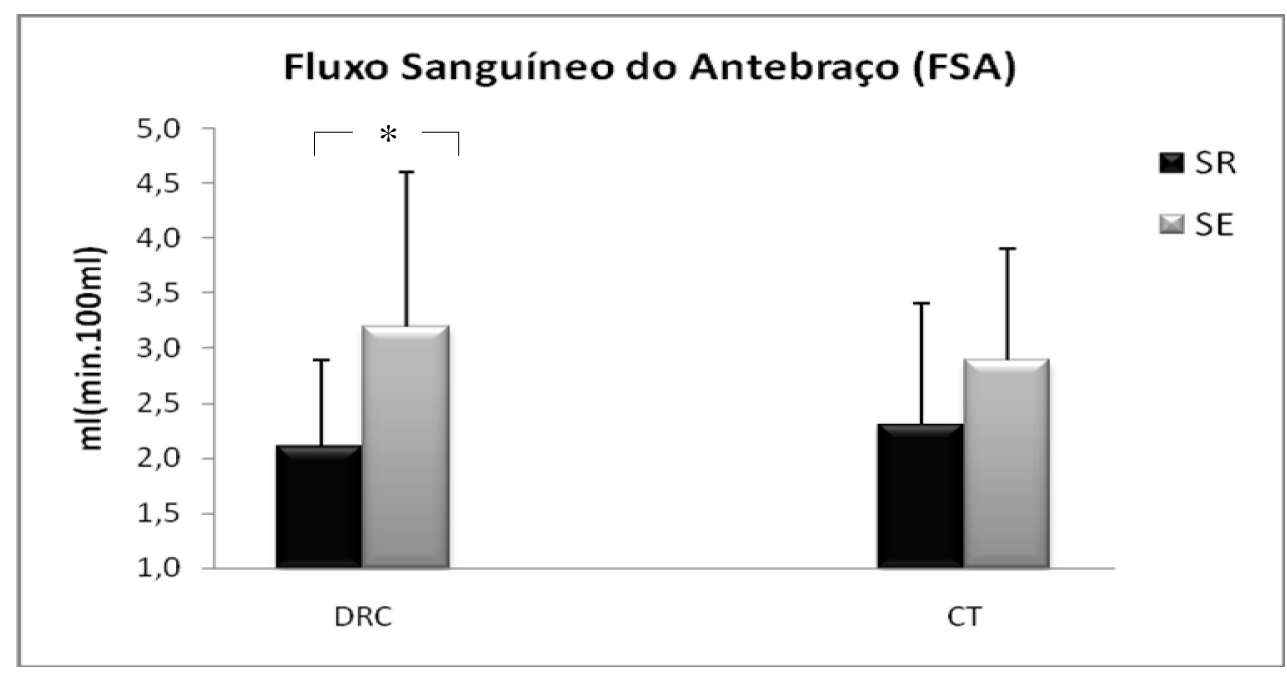

*diferença entre sessões $(\mathrm{P}=0,01)$

Assim como o FSA, no período basal as médias da resistência vascular periférica (RVP) entre os grupos DRC e CT não foram diferentes (50 \pm 25 vs $37 \pm 16$ unidades), como mostra a tabela 16. Entre as sessões repouso e exercício, o comportamento da RVP nos grupos foi semelhante, de maneira que na sessão exercício houve uma redução na RVP em relação à sessão repouso, em ambos os grupos. Esta redução, porém, foi maior e significativa apenas no grupo DRC $(\mathrm{P}<0,01)$. O comportamento da RPV entre os grupos, durante o período basal, está ilustrado na figura 9.

Tabela 16 - RVP nos grupos DRC e CT.

\begin{tabular}{lcc}
\hline & DRC & CT \\
\hline RVP & $50 \pm 25$ & $37 \pm 16$ \\
\hline Médias \pm dp & &
\end{tabular}


Figura 9 - RVP dos grupos DRC e CT no período basal, nas sessões controle e exercício.

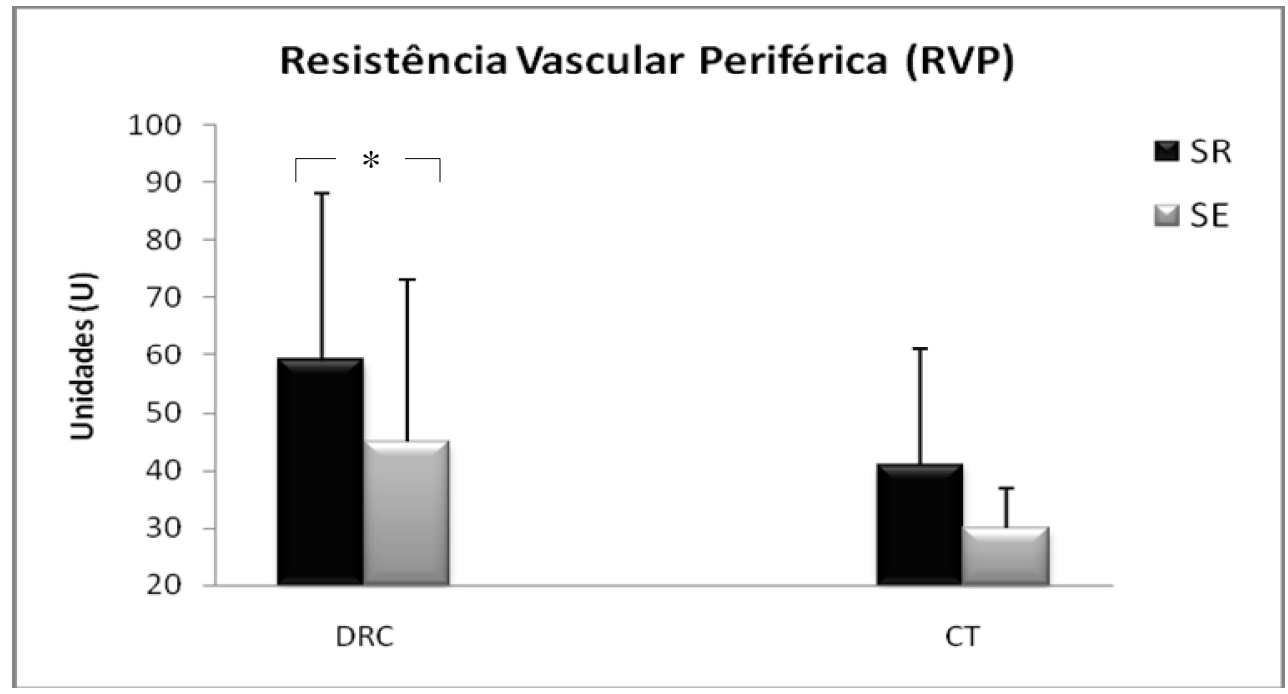

*diferença entre sessões $(\mathrm{P}<0,01)$

\subsubsection{Exercício estático a $30 \%$ da CVM}

Os dados individuais de cada voluntário encontram-se nos Anexos XXII XXXV.

O comportamento da PAS entre os grupos DRC e CT foi semelhante, de maneira que a média geral da PAS entre os grupos não apresentou diferença significativa, como mostra a tabela 17. Porém, entre as sessões repouso e exercício, houve uma redução significativa na PAS em todos os estágios, tanto no grupo DRC como no $\mathrm{CT}(\mathrm{P}<0,01)$, como mostra a tabela 18. O exercício estático (EE) a 30\% da CVM aumentou a PAS, que diminuiu durante a oclusão e sofreu uma redução ainda maior na recuperação. Podemos observar essa variação nos dois grupos, melhor ilustrada na tabelas 19 e 20 e na figura 10. 
Tabela 17 - PAS dos gupos DRC e CT (EE).

\begin{tabular}{lcc}
\hline & DRC & CT \\
\hline PAS $(\mathbf{m m ~ H g})$ & $162 \pm 20$ & $155 \pm 17$ \\
\hline Médias \pm dp & &
\end{tabular}

Tabela 18 - PAS (mm Hg) dos grupos DRC e CT, durante as sessões repouso e exercício.

\begin{tabular}{lcc}
\hline & SR & SE \\
\hline DRC & $168 \pm 15$ & $157 \pm 23 *$ \\
CT & $159 \pm 15$ & $150 \pm 17 *$ \\
\hline
\end{tabular}

Médias \pm dp

*diferença entre as sessões $(\mathrm{P}<0,01)$

Tabela 19 - PAS durante pré-HG, exercício estático a 30\% da CVM e recuperação, do grupo DRC.

\begin{tabular}{c|lcccc}
\hline \multicolumn{7}{c}{ GRUPO DRC } \\
\hline \multicolumn{7}{c}{ Sessões } & Pré-HG & 30\% HG & Oclu & Rec \\
\hline PAS & Repouso & $164 \pm 15$ & $175 \pm 14$ & $170 \pm 14$ & $162 \pm 18$ \\
$($ mm Hg $)$ & Exercício & $152 \pm 24$ & $165 \pm 22$ & $159 \pm 24$ & $152 \pm 25$ \\
\hline Média $\pm d p$ & & & & &
\end{tabular}

Tabela 20 - PAS durante pré-HG, exercício estático a 30\% da CVM e recuperação, do grupo CT.

\begin{tabular}{c|lcccc}
\hline \multicolumn{7}{c}{ GRUPO CONTROLE } \\
\hline \multicolumn{7}{c}{ Sessões } & Pré-HG & 30\% HG & Oclu & Rec \\
\hline PAS & Repouso & $156 \pm 12$ & $168 \pm 11$ & $162 \pm 16$ & $150 \pm 14$ \\
$(\mathbf{m m}$ Hg) & Exercício & $144 \pm 16$ & $162 \pm 18$ & $155 \pm 14$ & $140 \pm 14$ \\
\hline
\end{tabular}

Média \pm dp 
Figura 10 - PAS (mm Hg) dos grupos DRC e CT, durante pré-HG, exercício estático a $30 \%$ da CVM, oclusão da circulação e recuperação nas sessões controle e exercício.

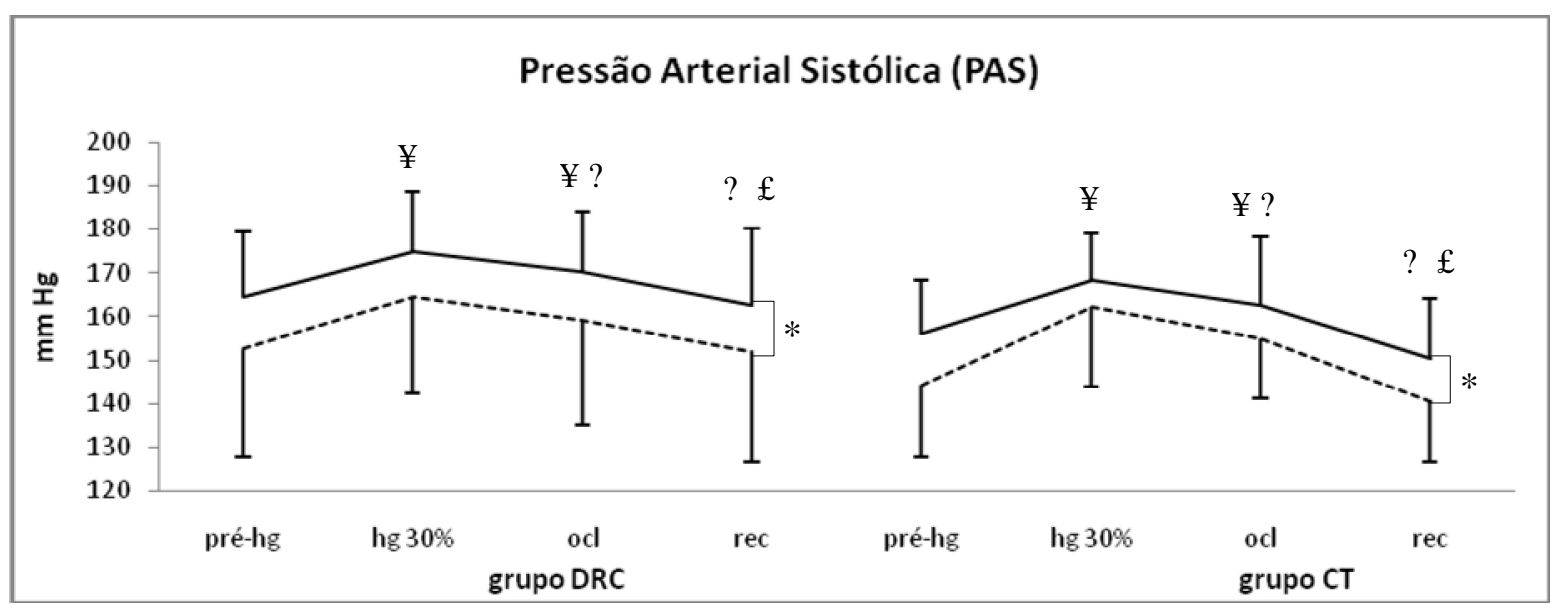

*diferença entre as sessões $(\mathrm{P}<0,01)$

$¥$ diferente do pré-hg / ? diferente do hg / £ diferente da oclusão (SR e SE) - SR $\quad \cdots . . . \mathrm{SE}$

O comportamento da PAD entre os grupos DRC e CT foi diferente da PAS, de maneira que a média geral da PAD foi maior no grupo DRC que no CT tanto na sessão

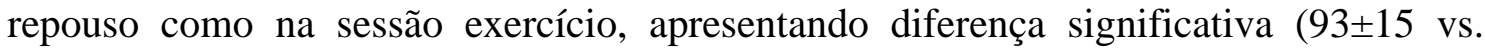
$79 \pm 12 \mathrm{~mm} \mathrm{Hg})(\mathrm{P}<0,01)$, de acordo com a tabela 21. Também houve uma redução significativa na PAD entre as sessões repouso e exercício, em todos os estágios, nos grupos DRC e CT $(\mathrm{P}<0,05)$, conforme a tabela 22. O exercício estático a 30\% da CVM aumentou a PAD, que diminuiu durante a oclusão e sofreu uma redução ainda maior na recuperação. Podemos observar essa variação nas tabelas 23 e 24 e na figura 11.

Tabela 21 - PAD dos gupos DRC e CT (EE).

\begin{tabular}{lcc}
\hline & DRC & CT \\
\hline PAD (mm Hg) & $93 \pm 15$ & $79 \pm 12 \#$ \\
\hline
\end{tabular}

Médias $\pm d p$

\#diferença entre os grupos $(\mathrm{P}<0,01)$ 
Tabela 22 - PAD (mm Hg) dos grupos DRC e CT, durante as sessões repouso e exercício.

\begin{tabular}{lcc}
\hline & SR & SE \\
\hline DRC & $96 \pm 13$ & $90 \pm 17 *$ \\
CT & $82 \pm 10$ & $77 \pm 14 *$ \\
\hline
\end{tabular}

Médias $\pm d p$

*diferença entre as sessões $(\mathrm{P}<0,05)$

Tabela 23 - PAD durante pré-HG, exercício estático a 30\% da CVM e recuperação, do grupo DRC.

\begin{tabular}{c|lcccc}
\hline \multicolumn{7}{c}{ GRUPO DRC } \\
\hline \multicolumn{7}{c}{ Sessões } & Pré-HG & 30\% HG & Oclu & Rec \\
\hline PAD & Repouso & $93 \pm 12$ & $104 \pm 12$ & $95 \pm 8$ & $91 \pm 15$ \\
$($ mm Hg $)$ & Exercício & $85 \pm 17$ & $97 \pm 18$ & $91 \pm 19$ & $85 \pm 14$ \\
\hline Média \pm dp & & & & &
\end{tabular}

Tabela 24 - PAD durante pré-HG, exercício estático a 30\% da CVM e recuperação, do grupo CT.

\begin{tabular}{c|lcccc}
\hline \multicolumn{7}{c}{ GRUPO CONTROLE } \\
\hline \multicolumn{7}{c}{ Sessões } & Pré-HG & 30\% HG & Oclu & Rec \\
\hline PAD & Repouso & $76 \pm 6$ & $91 \pm 9$ & $85 \pm 9$ & $75 \pm 5$ \\
$(\mathbf{m m ~ H g})$ & Exercício & $71 \pm 7$ & $88 \pm 19$ & $79 \pm 12$ & $71 \pm 9$ \\
\hline
\end{tabular}

Média \pm dp

Figura 11 - PAD (mm Hg) dos grupos DRC e CT durante pré-HG, exercício estático a 30\% da CVM, oclusão da circulação e recuperação nas sessões controle e exercício.

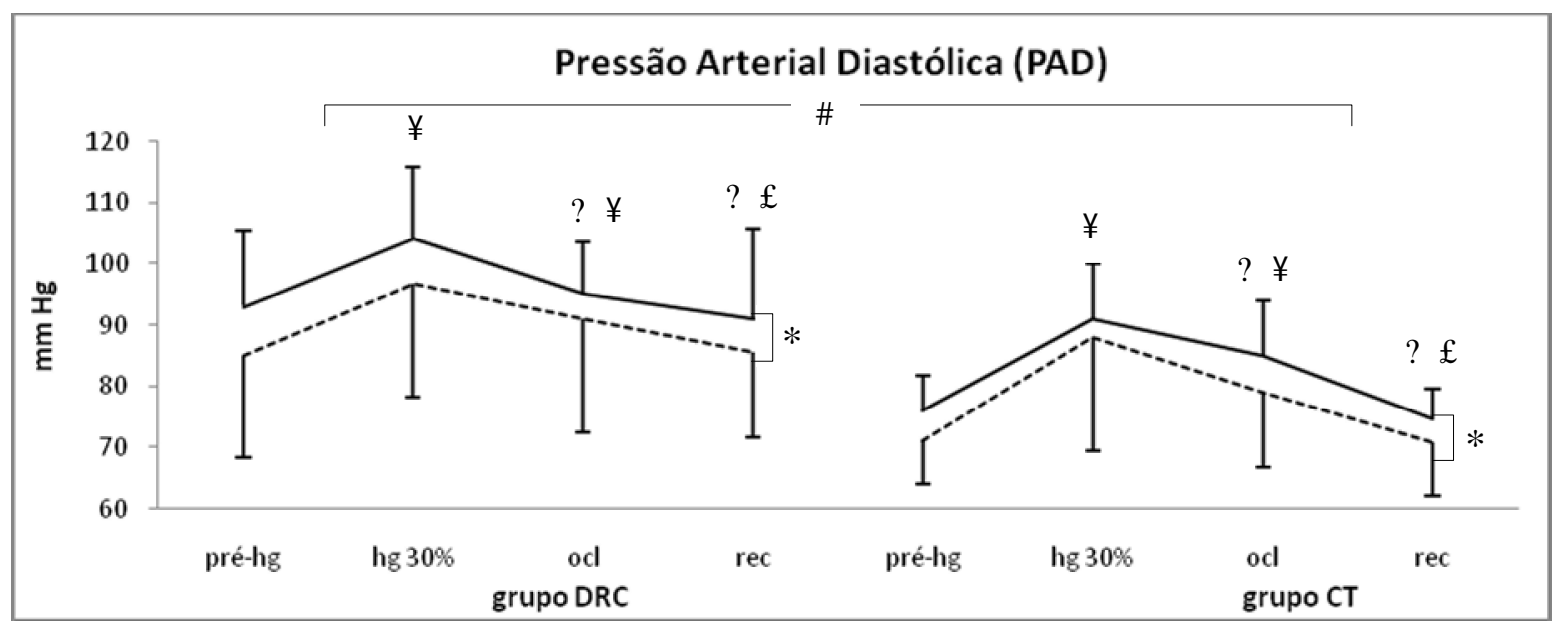

\# diferença entre os grupos $(\mathrm{P}<0,01) / *$ diferença entre as sessões $(\mathrm{P}<0,01)$

$¥$ diferente do pré-hg / ? diferente do hg / £ diferente da oclusão (SR e SE)

$$
\text { - SR } \quad \cdots \cdot \text { SE }
$$


O comportamento da PAM entre os grupos DRC e CT foi semelhante ao da PAD. A média geral da PAM foi maior no grupo DRC que no CT tanto na sessão

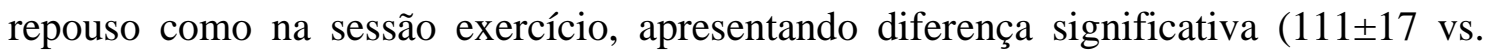
$98 \pm 12 \mathrm{~mm} \mathrm{Hg})(\mathrm{P}=0,02)$, conforme tabela 25. Também houve uma redução significativa na PAM entre as sessões repouso e exercício nos grupos $(\mathrm{P}<0,05)$, conforme a tabela 26. O exercício estático a $30 \%$ da CVM aumentou a PAM, que diminuiu durante a oclusão e sofreu uma redução ainda maior na recuperação. Podemos observar essa variação nas tabelas 27 e 28 e na figura 12 .

Tabela 25 - PAM dos gupos DRC e CT (EE).

\begin{tabular}{lcc}
\hline & DRC & CT \\
\hline PAM (mm Hg) & $111 \pm 17$ & $98 \pm 12$ \# \\
\hline $\begin{array}{l}\text { Médias } \pm \text { dp } \\
\text { \#diferença entre os grupos }(\mathrm{P}<0,05)\end{array}$ \\
\hline
\end{tabular}

Tabela 26 - PAM (mm Hg) dos grupos DRC e CT, durante as sessões repouso e exercício.

\begin{tabular}{lcr}
\hline & SR & SE \\
\hline DRC & $116 \pm 17$ & $106 \pm 17 *$ \\
CT & $100 \pm 10$ & $96 \pm 13 *$ \\
\hline
\end{tabular}

Médias $\pm \mathrm{dp}$

*diferença entre as sessões $(\mathrm{P}<0,05)$

Tabela 27 - PAM durante pré-HG, exercício estático a 30\% da CVM e recuperação, do grupo DRC.

\begin{tabular}{c|lcccc}
\hline \multicolumn{7}{c}{ GRUPO DRC } \\
\hline \multicolumn{7}{c}{ Sessões } & Pré-HG & 30\% HG & Oclu & Rec \\
\hline PAM & Repouso & $113 \pm 17$ & $125 \pm 15$ & $116 \pm 15$ & $111 \pm 18$ \\
$($ mm Hg) & Exercício & $106 \pm 21$ & $113 \pm 15$ & $106 \pm 16$ & $101 \pm 15$ \\
\hline Média \pm dp & & & & &
\end{tabular}


Tabela 28 - PAM durante pré-HG, exercício estático a 30\% da CVM e recuperação, do grupo CT.

\begin{tabular}{c|lcccc}
\hline \multicolumn{7}{c}{ GRUPO CONTROLE } \\
\hline \multicolumn{7}{c}{ Sessões } & Pré-HG & 30\% HG & Oclu & Rec \\
\hline PAM & Repouso & $95 \pm 7$ & $111 \pm 10$ & $103 \pm 9$ & $93 \pm 4$ \\
$(\mathbf{m m ~ H g})$ & Exercício & $91 \pm 8$ & $107 \pm 16$ & $97 \pm 12$ & $89 \pm 9$ \\
\hline
\end{tabular}

Figura 12 - PAM (mm Hg) dos grupos DRC e CT durante pré-HG, exercício estático a 30\% da CVM, oclusão da circulação e recuperação nas sessões controle e exercício.

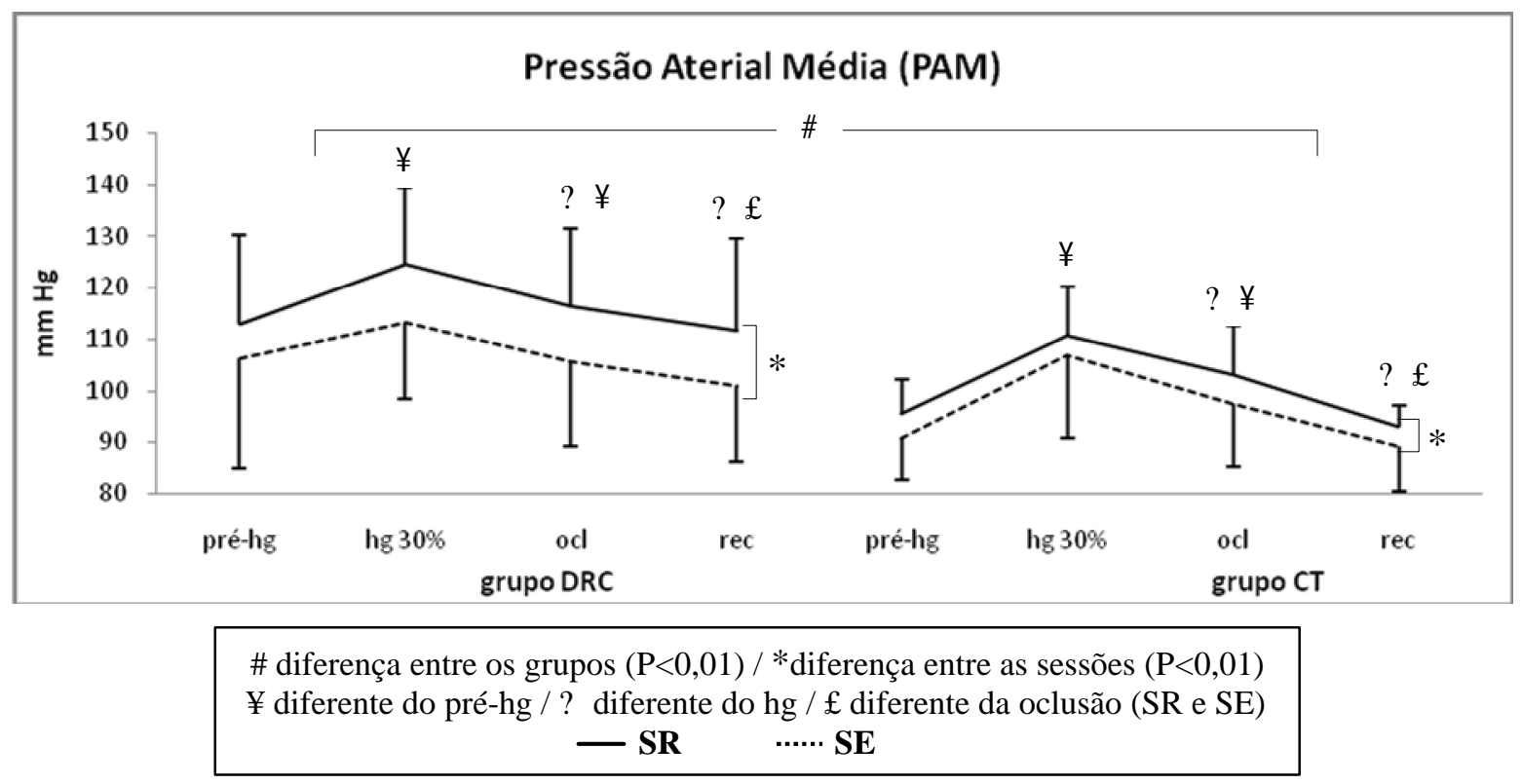

Em relação à $\mathrm{FC}$, os grupos tiveram respostas semelhantes, sem diferença significativa, de maneira que, independente da presença ou não da doença as médias de FC entre DRC e CT não foram diferentes ( $67 \pm 10$ vs. $69 \pm 7 \mathrm{bpm})$, como mostra a tabela 29. Porém, nas sessões, o comportamento dos grupos foi diferente, de maneira que no grupo DRC, a média da FC no repouso foi mais baixa que no exercício, de maneira significativa $(\mathrm{P}=0,04)$ e também foi mais baixa que a $\mathrm{FC}$ de repouso do grupo $\mathrm{CT}$ ( $\mathrm{P}=0,04)$. Já no grupo $\mathrm{CT}$, a média da FC não se modificou durante as sessões repouso e exercício, como pode ser observado na tabela 30. Entre os estágios da manobra excitatória, durante o exercício com handgrip houve um aumento da FC. Esses valores 
sofreram uma redução durante a oclusão a valores semelhantes ao pré-hg, que se mantiveram na recuperação, em ambos os grupos, conforme observamos nas tabelas 31 e 32 e na figura 13.

Tabela 29 - FC dos gupos DRC e CT (EE).

\begin{tabular}{llc}
\hline & DRC & CT \\
\hline FC (bpm) & $67 \pm 10$ & $69 \pm 7$ \\
\hline Média \pm dp & &
\end{tabular}

Tabela 30 - FC (bpm) dos grupos DRC e CT, durante as sessões repouso e exercício.

\begin{tabular}{lcc}
\hline & SR & SE \\
\hline DRC & $65 \pm 10 \propto$ & $69 \pm 9 *$ \\
\hline CT & $70 \pm 7$ & $68 \pm 7$ \\
\hline
\end{tabular}

Médias \pm dp

*diferença entre as sessões $(\mathrm{P}<0,05)$

\# diferença entre grupos na SR $(\mathrm{P}<0,05)$

Tabela 31 - FC durante pré-HG, exercício estático a 30\% da CVM e recuperação, do grupo DRC.

\begin{tabular}{c|lcccc}
\hline \multicolumn{7}{c}{ GRUPO DRC } \\
\hline \multicolumn{7}{c}{ Sessões } & Pré-HG & 30\% HG & Oclu & Rec \\
\hline FC & Repouso & $62 \pm 8$ & $70 \pm 13$ & $64 \pm 10$ & $63 \pm 9$ \\
$($ bpm) & Exercício & $67 \pm 8$ & $72 \pm 11$ & $69 \pm 11$ & $68 \pm 8$ \\
\hline
\end{tabular}

Média \pm dp

Tabela 32 - FC durante pré-HG, exercício estático a 30\% da CVM e recuperação, do grupo CT.

\begin{tabular}{c|ccccc}
\hline \multicolumn{7}{c}{ GRUPO CONTROLE } \\
\hline \multicolumn{7}{c}{ Sessões } & Pré-HG & 30\% HG & Oclu & Rec \\
\hline FC & Repouso & $67 \pm 7$ & $75 \pm 8$ & $67 \pm 7$ & $69 \pm 7$ \\
$($ bpm) & Exercício & $66 \pm 7$ & $73 \pm 6$ & $67 \pm 7$ & $67 \pm 7$ \\
\hline
\end{tabular}

Média $\pm d p$ 
Figura 13 - FC (bpm) dos grupos DRC e CT durante pré-HG, exercício estático a $30 \%$ da CVM, oclusão da circulação e recuperação nas sessões controle e exercício.

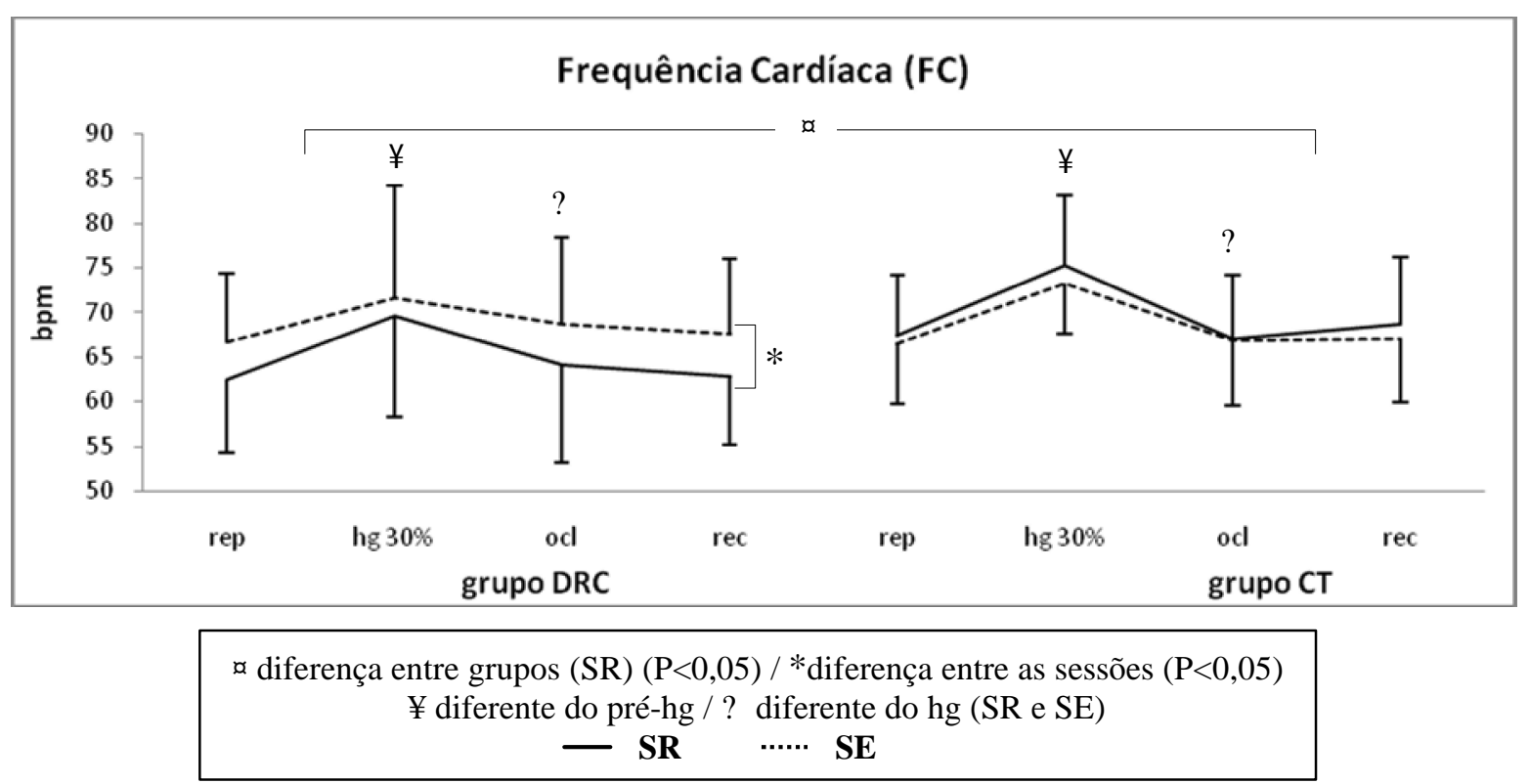

A média geral da ANSP foi maior no grupo DRC que no CT tanto na sessão repouso como na sessão exercício, apresentando diferença significativa (38 \pm 6 vs. $33 \pm 8$ impulsos/min) $(\mathrm{P}=0,02)$, conforme tabela 33. Também houve uma redução significativa na ANSP entre as sessões repouso e exercício, em ambos os grupos $(\mathrm{P}<0,01)$, de acordo com a tabela 34. A média da ANSP entre as sessões repouso e exercício do grupo DRC foi maior que a do grupo $\mathrm{CT}$ em todos os estágios da manobra excitatória $(\mathrm{P} \leq 0,01)$. Entre os estágios, o exercício estático a 30\% da CVM aumentou a ANSP em ambos os grupos. Esta teve uma redução durante a oclusão, sofrendo redução na recuperação, voltando aos valores do repouso. Podemos observar essa variação nas tabelas 35 e 36 e na figura 14.

Tabela 33 - ANSP dos gupos DRC e CT (EE).

\begin{tabular}{llc}
\hline & DRC & CT \\
\hline ANSP (impulsos/min) & $38 \pm 6$ & $33 \pm 8 \#$ \\
\hline $\begin{array}{l}\text { Médias } \pm \text { dp } \\
\text { \#diferença entre os grupos }(\mathrm{P}<0,05)\end{array}$
\end{tabular}


Tabela 34 - ANSP (impulsos/min) dos grupos DRC e CT, durante as sessões repouso e exercício.

\begin{tabular}{l|c|c}
\hline \multicolumn{1}{c}{ SR } & SE \\
\hline DRC & $42 \pm 4$ & $34 \pm 3 *$ \\
\hline CT & $36 \pm 8$ & $30 \pm 7 *$ \\
\hline $\begin{array}{l}\text { Médias } \pm \text { dp } \\
* \text { diferença entre as sessões }(\mathrm{P}<0,01)\end{array}$ \\
\hline
\end{tabular}

Tabela 35 - ANSP durante pré-HG, exercício estático a 30\% da CVM e recuperação, do grupo DRC.

\begin{tabular}{c|lcccc}
\hline \multicolumn{7}{c}{ GRUPO DRC } \\
\hline \multicolumn{7}{c}{ Sessões } & Pré-HG & 30\% HG & Oclu & Rec \\
\hline ANSP & Repouso & $39 \pm 4$ & $49 \pm 4$ & $41 \pm 5$ & $38 \pm 4$ \\
(imp/min) & Exercício & $32 \pm 3$ & $40 \pm 4$ & $34 \pm 3$ & $32 \pm 3$ \\
\hline
\end{tabular}

Média \pm dp

Tabela 36 - ANSP durante pré-HG, exercício estático a 30\% da CVM e recuperação, do grupo CT.

\begin{tabular}{c|lcccc}
\hline \multicolumn{7}{c}{ GRUPO CONTROLE } \\
\hline \multicolumn{7}{c}{ Sessões } & Pré-HG & 30\% HG & Oclu & Rec \\
\hline ANSP & Repouso & $32 \pm 7$ & $38 \pm 9$ & $38 \pm 10$ & $35 \pm 7$ \\
(imp/min) & Exercício & $28 \pm 5$ & $33 \pm 9$ & $31 \pm 8$ & $28 \pm 5$ \\
\hline Média \pm dp &
\end{tabular}

Figura 14 - ANSP (impulsos/min) dos grupos DRC e CT durante pré-HG, exercício estático a $30 \%$ da CVM, oclusão da circulação e recuperação nas sessões controle e exercício.

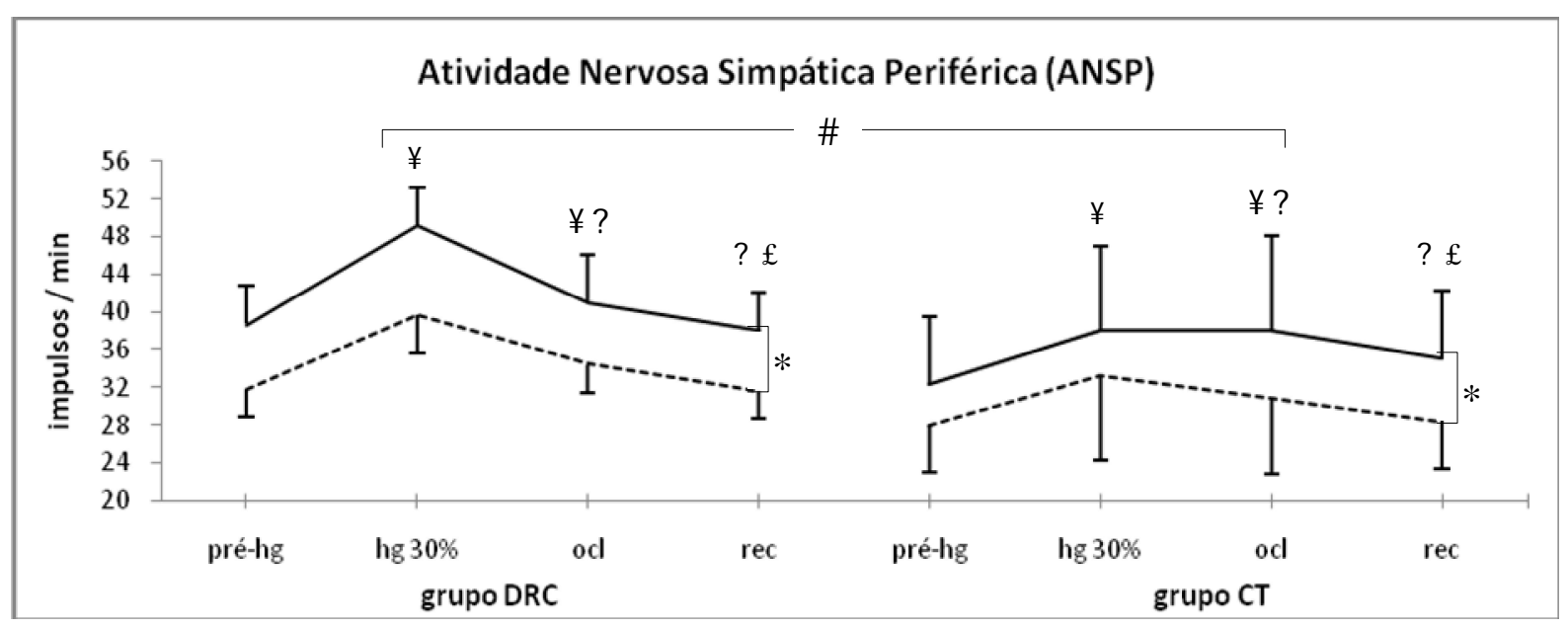

\# diferença entre os grupos $(\mathrm{P}<0,05) / *$ diferença entre as sessões $(\mathrm{P}<0,01)$

$¥$ diferente do pré-hg / ? diferente do hg / £ diferente da oclusão (SR e SE)

- SR $\quad$ S.... SE 
O comportamento do FSA entre os grupos DRC e CT não teve diferença significativa $(3,2 \pm 1,5$ vs. $2,9 \pm 1 \mathrm{ml}(\mathrm{min} .100 \mathrm{ml}))$, de acordo com a tabela 37 . Porém houve um aumento significativo no FSA entre as sessões repouso e exercício, em todos os estágios, em ambos os grupos $(\mathrm{P}=0,02)$, de acordo com as médias na tabela 38. A SE influenciou de maneira significativa a resposta à manobra excitatória, aumentando o FSA em ambos os grupos $(\mathrm{P} \leq 0,01)$. Também houve aumento do FSA no grupo DRC em relação ao $\mathrm{CT}$, em todos os estágios $(\mathrm{P} \leq 0,01)$, na $\mathrm{SE}$. Na SR isso não aconteceu. $\mathrm{O}$ exercício estático a 30\% da CVM aumentou significativamente o FSA, não se alterando de forma significativa durante a oclusão, sofrendo uma redução na recuperação. Podemos observar essa variação, em ambos os grupos, melhor ilustrada nas tabelas 39 e 40 e na figura 15.

Tabela 37 - FSA dos gupos DRC e CT (EE).

\begin{tabular}{lrc}
\hline & DRC & CT \\
\hline FSA ml(min.100ml) & $3,2 \pm 1,5$ & $2,9 \pm 1$ \\
\hline Média \pm dp & &
\end{tabular}

Tabela 38 - FSA ml(min.100ml) dos grupos DRC e CT, durante as sessões repouso e exercício.

\begin{tabular}{lcc}
\hline & SR & SE \\
\hline DRC & $2,6 \pm 0,9$ & $3,9 \pm 1,9 *$ \\
\hline CT & $2,7 \pm 1$ & $3,2 \pm 1 *$ \\
\hline $\begin{array}{l}\text { Médias } \pm \text { dp } \\
\text { *diferença entre as sessões }(\mathrm{P}<0,05)\end{array}$ \\
\hline
\end{tabular}

Tabela 39 - FSA durante pré-HG, exercício estático a 30\% da CVM e recuperação, do grupo DRC.

\begin{tabular}{c|ccccc}
\hline \multicolumn{7}{c}{ GRUPO DRC } \\
\hline \multicolumn{7}{c}{ Sessões } & Pré-HG & 30\% HG & Oclu & Rec \\
\hline FSA & Repouso & $2,4 \pm 0,9$ & $2,8 \pm 0,7$ & $3,0 \pm 1$ & $2,3 \pm 0,8$ \\
ml(min.100ml) & Exercício & $3,5 \pm 1,5$ & $4,1 \pm 1,9$ & $4,6 \pm 2,6$ & $3,3 \pm 1,5$ \\
\hline
\end{tabular}

Média \pm dp 
Tabela 40 - FSA durante pré-HG, exercício estático a 30\% da CVM e recuperação, do grupo CT.

GRUPO CONTROLE

\begin{tabular}{c|lcccc}
\hline \multicolumn{1}{c}{ Sessões } & Pré-HG & 30\% HG & Oclu & Rec \\
\hline FSA & Repouso & $2,6 \pm 1,2$ & $3,0 \pm 1,2$ & $2,8 \pm 1,1$ & $2,5 \pm 1,0$ \\
ml(min.100ml) & Exercício & $3,0 \pm 1,2$ & $3,2 \pm 1,2$ & $3,7 \pm 1,5$ & $2,6 \pm 1,2$ \\
\hline Média \pm dp & & & & &
\end{tabular}

Média \pm dp

Figura 15 - FSA ml(min.100ml) dos grupos DRC e CT durante pré-HG, exercício estático a $30 \%$ da CVM oclusão da circulação e recuperação nas sessões controle e exercício.

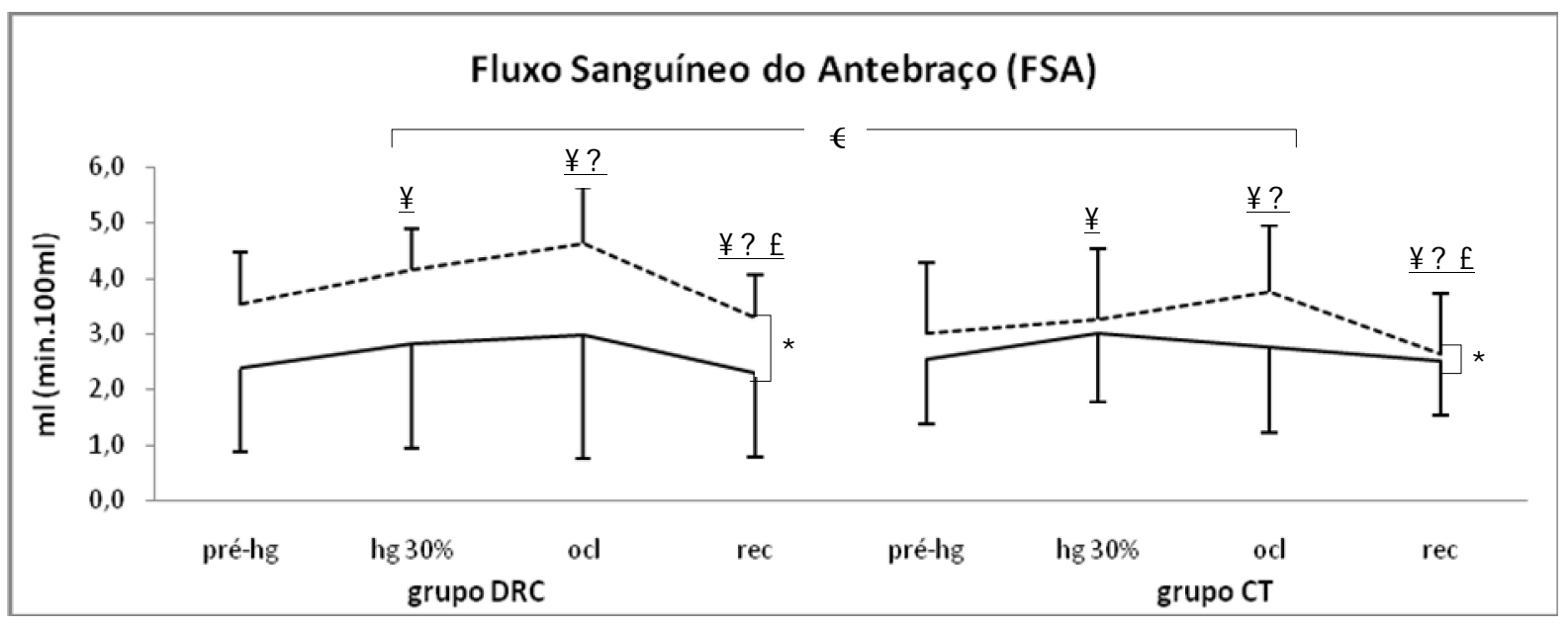

$€$ diferença entre os grupos ( $\mathrm{SE})(\mathrm{P}=0,01) / *$ diferença entre as sessões $(\mathrm{P}<0,05)$ $\underline{¥}$ diferente do pré-hg / ? diferente do hg / $\underline{£}$ diferente da oclusão $\rightarrow$ diferença SE.

- SR ..... SE

O comportamento da RVP entre os grupos DRC e CT não teve diferença significativa ( $44 \pm 24$ vs. $39 \pm 19$ U), de acordo com a tabela 41. Porém houve uma redução estatisticamente significante da RVP na $\mathrm{SE}$ em relação à $\mathrm{SR}$, em ambos os grupos $(\mathrm{P}=0,02)$ conforme a tabela 42. Durante os estágios da manobra excitatória, houve uma redução da RVP, durante a oclusão da circulação, conforme tabelas 43 e 44 .

O comportamento da RVP pode ser observado na figura 16.

Tabela 41 - RVP dos gupos DRC e CT (EE).

\begin{tabular}{ccc}
\hline & DRC & CT \\
\hline RVP (U) & $44 \pm 24$ & $39 \pm 19$ \\
\hline Média \pm dp & &
\end{tabular}


Tabela 42 - RVP (unidades) dos grupos DRC e CT, durante as sessões repouso e exercício.

\begin{tabular}{l|c|c}
\hline \multicolumn{1}{c}{ SR } & SE \\
\hline CT & $44 \pm 24$ & $34 \pm 13 *$ \\
DRC & $53 \pm 25$ & $36 \pm 23 *$ \\
\hline
\end{tabular}

Médias $\pm \mathrm{dp}$

*diferença entre as sessões $(\mathrm{P}<0,05)$

Tabela 43 - RVP durante pré-HG, exercício estático a 30\% da CVM e recuperação, do grupo DRC.

\begin{tabular}{c|lcccc}
\hline \multicolumn{7}{c}{ GRUPO DRC } \\
\hline \multicolumn{7}{c}{ Sessões } & Pré-HG & 30\% HG & Oclu & Rec \\
\hline RVP & Repouso & $58 \pm 30$ & $49 \pm 19$ & $46 \pm 21$ & $57 \pm 27$ \\
(U) & Exercício & $38 \pm 26$ & $34 \pm 22$ & $32 \pm 26$ & $38 \pm 23$ \\
\hline Média $\pm d p$ & & & & &
\end{tabular}

Tabela 44 - RVP durante pré-HG, exercício estático a 30\% da CVM e recuperação, do grupo CT.

\begin{tabular}{c|lcccc}
\hline \multicolumn{7}{c}{ GRUPO CONTROLE } \\
\hline \multicolumn{7}{c}{ Sessões } & Pré-HG & 30\% HG & Oclu & Rec \\
\hline RVP & Repouso & $46 \pm 32$ & $45 \pm 30$ & $45 \pm 25$ & $41 \pm 15$ \\
(U) & Exercício & $33 \pm 14$ & $34 \pm 9$ & $29 \pm 11$ & $40 \pm 18$ \\
\hline Média \pm dp
\end{tabular}

Figura 16 - RVP (unidades) dos grupos DRC e CT durante repouso, exercício estático a 30\% da CVM, oclusão da circulação e recuperação nas sessões controle e exercício.

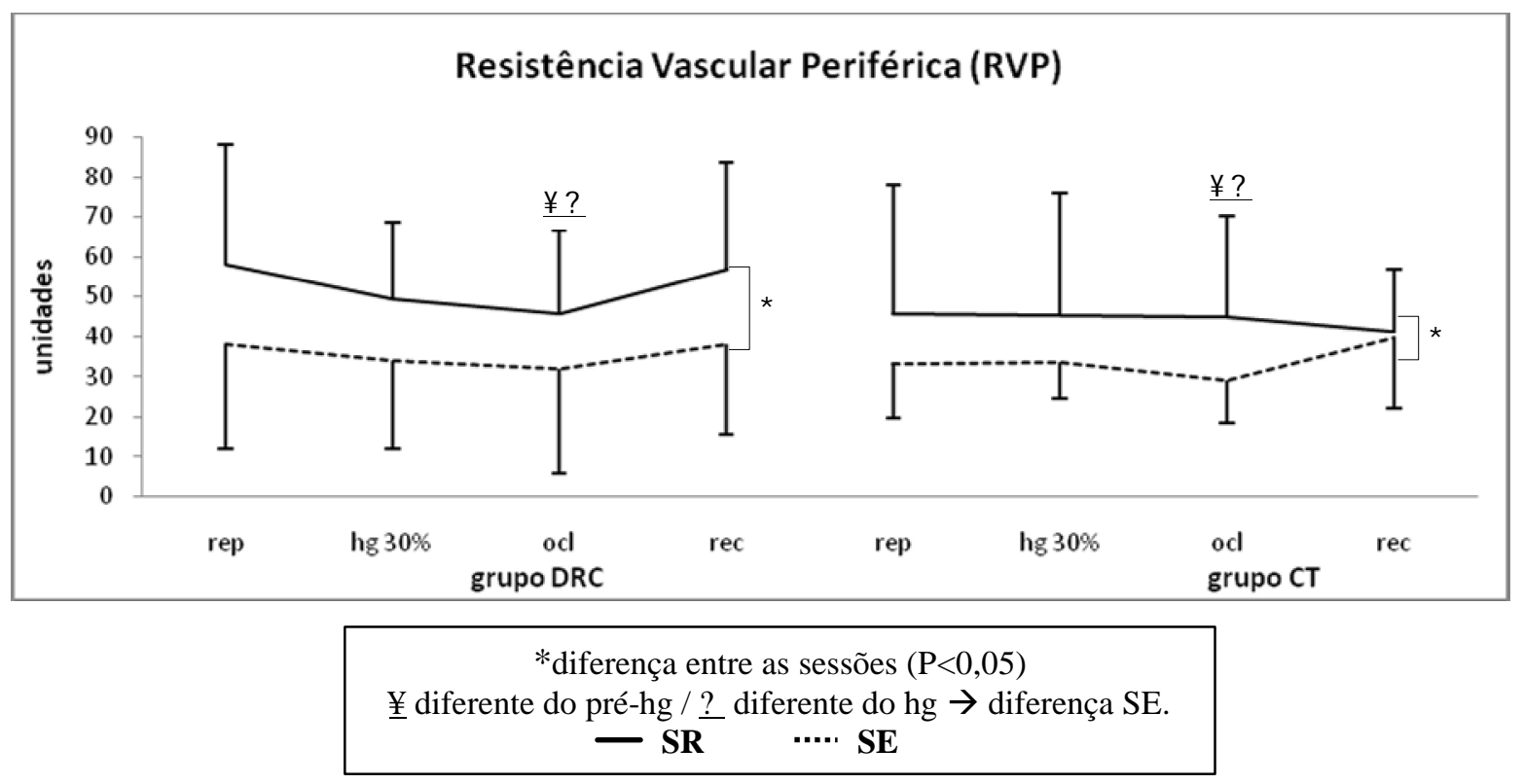




\subsubsection{Proteinúria}

Não foram encontradas diferenças significativas entre as proteinúrias pósexercício e pós-repouso em relação às proteinúrias pré-exercício ou pré-repouso (P>0,1), no grupo DRC, conforme mostra a tabela abaixo:

Tabela 45 - Valores de proteinúria, do grupo DRC.

\begin{tabular}{cccc}
\hline \multicolumn{4}{c}{ PROTEINÚRIA (g/L /24h) } \\
\hline pré-SR & pós-SR & Pré-SE & pós-SE \\
\hline $0,28 \pm 0,24$ & $0,29 \pm 0,22$ & $0,23 \pm 0,25$ & $0,17 \pm 0,16$ \\
\hline & Médias \pm dp & &
\end{tabular}




\section{DISCUSSÃO}

Os principais achados deste estudo foram:

a. Uma única sessão de exercício físico aeróbio a $50 \%$ do $\mathrm{VO}_{2 \text { pico, no }}$ período denominado basal, reduziu a RVP no grupo DRC.

b. O FSA e a FC tiveram um aumento significativo no grupo DRC no período basal.

c. A FC também aumentou no grupo DRC durante o período de manobras excitatórias com handgrip (HG).

d. A ANSP e os níveis pressóricos também foram reduzidos após uma sessão de exercício aeróbio, no período basal, tanto no grupo DRC como no grupo $\mathrm{CT}$.

e. Durante o período de manobra excitatória com o HG, o exercício aeróbio atenuou o metabolorreflexo, de maneira que a atividade simpática foi reduzida em ambos os grupos (DRC e CT), assim como os níveis pressóricos e a RVP.

f. Houve aumento do FSA durante a manobra excitatória com HG em ambos os grupos, apenas na sessão exercício.

g. Não houve alterações significativas na proteinúria pós-exercício aeróbio, a $50 \%$ do $\mathrm{VO}_{2 \text { pico, }}$ nos pacientes portadores de DRC - estágio III.

Os dados obtidos são semelhantes aos encontrados em outras populações. Era esperado que os indivíduos com DRC também pudessem se beneficiar dos efeitos agudos do exercício físico aeróbio, como será discutido a seguir. 


\subsection{Período Basal}

A queda da pressão arterial após a execução de uma única sessão de exercício é denominada hipotensão pós-exercício e tem sido observada em diferentes populações ${ }^{80}$, como em normotensos ${ }^{43,44,81,82}$, hipertensos ${ }^{42,83-85}$, mulheres menopausadas ${ }^{86} \mathrm{e}$ hipertensas ${ }^{85}$, em idosos ${ }^{84}$. Porém, há grande variação na magnitude da hipotenão pósexercício $^{80}$ e alguns trabalhos até mesmo não encontraram queda significativa na PAM de sujeitos normotensos ${ }^{42,83,87}$ ou hipertensos ${ }^{88,89}$. Outros autores encontraram uma queda de até $30 \mathrm{~mm} \mathrm{Hg}$ em normotensos e $40 \mathrm{~mm} \mathrm{Hg} \mathrm{em} \mathrm{hipertensos}{ }^{82}$.

Na população com DRC, porém, não estão claros os efeitos agudos do exercício físico aeróbio em relação à pressão arterial e demais parâmetros hemodinâmicos. Nosso trabalho é pioneiro neste tipo de investigação, nesta população.

Em nosso estudo ocorreu redução da PAS no período basal na SE em relação à SR nos dois grupos (DRC e CT). Essa redução foi, em média, de $10 \mathrm{~mm} \mathrm{Hg}$, em ambos os grupos, o que mostra que 45 minutos de exercício físico aeróbio a $50 \%$ do $\mathrm{VO}_{2 \text { pico }}$ é eficiente na redução da PAS, na mesma magnitude tanto para indivíduos normotensos como para hipertensos portadores de DRC - estágio III. A PAD também foi reduzida na SE, cerca de 6 mm Hg em ambos os grupos. Como já foi demonstrado, houve diferença significativa entre as médias de PAD entre os grupos, de modo que a PAD foi mais alta no grupo DRC que no grupo CT. Em estudos anteriores, a redução média na pressão arterial após uma sessão de exercício em laboratório foi de $15 \mathrm{mmHg}$ para PAS e 4 mmHg para a PAD, em uma população não hipertensa e não portadora de $\mathrm{DRC}^{90}$. Boyce et al $^{76}$ observaram redução da PAS e da PAD em pacientes hipertensos, com DRC pré-dialítica, ao final de um período de treinamento de 4 meses, 3 vezes por semana, numa intensidade que progrediu de 50 a $70 \%$ da freqüência cardíaca de reserva, sendo realizado 30 minutos de caminhada e 30 minutos na bicicleta ergométrica. Pechter et al $^{73}$ também demonstraram redução da PAS e da PAD, 6 e 3,7 mm Hg 
respectivamente, em um grupo de pacientes com DRC grau leve após 12 semanas de treinamento aquático, 2 vezes por semana, $30 \mathrm{~min} / \mathrm{sessão,} \mathrm{com} \mathrm{intensidade} \mathrm{de} \mathrm{40-50 \%}$ do $\mathrm{VO}_{2 \text { pico. }}$ Headley et al $^{91}$ encontraram redução de 6,5 e 2,5 mm Hg na PAS e na PAD, respectivamente, em pacientes com DRC - estágio II a IV, após uma sessão aguda de exercício físico aeróbio (caminhada) a 50-60\% do $\mathrm{VO}_{2 \text { pico, }}$ com duração de 40 minutos. Outros autores não encontraram diferenças significativas na pressão arterial de pacientes com DRC pré-dialítica, após treinamento físico aeróbio ${ }^{13,92}$.

A PAM apresentou o mesmo comportamento que a PAD, sendo sua média maior, no grupo DRC que no CT. Foi observada a redução de $6 \mathrm{~mm} \mathrm{Hg} \mathrm{em} \mathrm{ambos} \mathrm{os}$ grupos. Svarstad et $\mathrm{al}^{55}$, durante a realização de exercício aeróbio de baixa intensidade (25W) e longa duração (2h), observaram um aumento da PAM em pacientes hipertensos, com DRC moderada (clearance 49-66 ml/min) em relação ao controle (sujeitos normotensos).

Klein et $\mathrm{al}^{31}$ mostraram que a PAM é mais elevada em sujeitos portadores de DRC que em sujeitos saudáveis, normotensos. Porém esta comparação não foi relacionada à prática de exercício físico. Apesar de a hipertensão arterial ser prevalente entre pacientes portadores de DRC, existem poucos trabalhos sobre o impacto do exercício físico nas respostas pressóricas nesta população ${ }^{90}$.

No presente estudo, observamos queda da pressão arterial em indivíduos portadores de DRC - estágio III. Como a hipertensão arterial é altamente prevalente nestes pacientes, podemos pressupor que os benefícios do exercício físico também podem ser observados nesses indivíduos, o que justificaria a inclusão de um programa regular de exercício físico aeróbio como parte do tratamento não farmacológico da hipertensão arterial na DRC.

Neste trabalho, os mecanismos envolvidos na queda da pressão arterial estão provavelmente relacionados tanto à diminuição da ANSP como da RVP. Ambos os 
parâmetros foram reduzidos na sessão exercício em relação ao repouso, porém apenas no grupo DRC a queda foi significativa.

A redução da ANSP, bem como da RVP após uma sessão de exercício aeróbio, em diversas populações, já está bem documentada na literatura ${ }^{40-44}$. Sabemos também que a atividade nervosa simpática é elevada em pacientes com DRC ${ }^{27-34}$. Tinucci et $\mathrm{al}^{35}$ comparam a ANSP de pacientes hipertensos com DRC leve com indivíduos hipertensos e normotensos, sem a realização prévia de exercício físico, e relataram aumento da ANSP em na DRC em relação aos hipertensos e destes em relação aos normotensos. Park et $\mathrm{al}^{29}$ também comparam a ANSP pacientes com DRCT com indivíduos normotensos. Os mesmos autores realizam manobras excitatórias do SNS, porém não realizam exercício físico aeróbio antes. Nosso trabalho foi o único a avaliar a ANSP e a RVP em pacientes portadores de DRC após uma sessão de exercício físico aeróbio e compará-la com a ANSP e RVP em um grupo de pacientes normotensos. Outros trabalhos avaliam a ANSP e a RVP pós-exercício aeróbio, mas não em pacientes com DRC. Cléroux et $a^{42}$ observaram a redução da ANSP e da RVP em indivíduos hipertensos, após a realização de 30 minutos de exercício aeróbio em bicicleta ergométrica, a $50 \%$ do $\mathrm{VO}_{2 \text { pico }}$. Floras et al ${ }^{40}$ também observaram a redução da ANSP em indivíduos hipertensos limítrofes, após a realização de 45 minutos de exercício aeróbio em esteira, a 70\% da freqüência cardíaca de repouso.

A diminuição da RVP e consequente diminuição dos valores pressóricos pósexercício pode estar relacionada à vasodilatação mantida após o exercício, principalmente na musculatura que foi exercitada. Como já foi citado anteriormente, acredita-se que a vasodilatação permaneça após o termino do exercício em decorrência de fatores, como $^{41,61}$.

a) redução da atividade nervosa simpática periférica, como de fato ocorreu em nosso trabalho; 
b) atuação de substâncias locais, como opióides endógenos e os metabólitos locais produzidos durante o exercício ${ }^{41,44,61}$, bem como o óxido nítrico ${ }^{41}$;

c) necessidade de vasodilatação da pele para eliminar o calor produzido pelo exercício $^{41,44,61}$

d) diminuição da sensibilidade alfa-adrenérgica ${ }^{41,61}$.

Outros fatores como a diminuição dos níveis das catecolaminas circulantes e dos valores da freqüência cardíaca de repouso também podem estar relacionados à redução dos níveis pressóricos pós-exercício e estão diretamente ligados à redução da atividade nervosa simpática periférica ${ }^{41}$.

O fato de a RVP ter reduzido de maneira significativa apenas no grupo DRC mostra mais uma vez que o exercício físico aeróbio pode ser uma importante ferramenta na redução de riscos cardiovasculares nestes pacientes.

Em relação à FC, seu aumento significativo foi encontrado apenas no grupo DRC, na SE em relação à SR. Taverver et $\mathrm{al}^{38}$ também observaram o aumento na FC em pacientes com DRC pré-dialítica em relação ao controle, após a realização de 30 minutos de exercício aeróbio em bicicleta ergométrica. A intensidade do exercício era determinada quando o indivíduo atingia uma $\mathrm{FC}=110 \mathrm{bpm}$. Os autores observaram que os pacientes atingiam a mesma FC com cargas menores que o grupo controle. Em nosso trabalho, não houve diferença estatisticamente significante entre as cargas nos grupos, o que pode justificar a FC mais elevada em uma mesma intensidade de exercício.

Em nosso trabalho encontramos um aumento significativo do FSA no grupo DRC na SE em relação à SR. O FSA foi registrado no antebraço, mas devemos considerar que as alterações locais refletem as alterações sistêmicas induzidas pelo exercício físico aeróbio, como é o caso do aumento do fluxo sanguíneo nos músculos $\operatorname{ativos}^{37,58,63}$. Cléroux et $\mathrm{al}^{42}$ também observaram o aumento do FSA em sujeitos 
hipertensos, após 30 minutos de exercício aeróbio, a $50 \%$ do $\mathrm{VO}_{2 \text { pico. Não foi }}$ encontrado nenhum trabalho que avalie esta variável em indivíduos com DRC.

A principal causa de mortalidade nos pacientes com DRC é a doença cardiovascular. A alta prevalência de hipertensão arterial nestes pacientes e sua relação com riscos cardiovasculares são indiscutíveis. Como demonstramos, após uma única sessão de exercício físico aeróbio houve queda dos níveis tensionais, redução da ANSP e da RVP. Embora estas respostas tenham sido observadas agudamente, podemos pressupor que estes efeitos também sejam observados com o treinamento físico.

\subsection{Exercício estático a $30 \%$ da CVM}

Existem evidências de que, durante o exercício estático, as respostas autonômicas dependem principalmente de duas vias que interagem entre si: o comando central e o reflexo pressor do exercício ${ }^{62,64,93,94}$. O primeiro atua induzido pela percepção do esforço ${ }^{64}$. Já o reflexo pressor do exercício é mediado pelos quimio e mecanorreflexos ${ }^{64,93,94}$. Atualmente vem se considerando a modulação barorreflexa (barorreflexo arterial) como uma terceira via, já que esta atua tanto no repouso como no início do exercício ${ }^{64,94}$. No exercício isométrico há um aumento da freqüência cardíaca, do débito cardíaco e da pressão arterial $^{93,94}$. O comando central é responsável principalmente pelas respostas de FC e débito cardíaco, por meio da regulação simpática/parassimpática. Logo no início do exercício, no primeiro minuto, há um aumento da FC mediado pelo comando central, reduzindo a ação parassimpática ${ }^{62}$. A ANSP durante o exercício com handgrip, aumenta ${ }^{62,64,94}$ somente após o segundo minuto de contração muscular, pela ação do quimirreflexo, principalmente durante a oclusão venosa, quando há o acúmulo de metabólitos como o ácido láctico muscular ${ }^{62}$. Em seres humanos, é difícil isolar experimentalmente o reflexo pressor do exercício de outros mecanismos neurais, como o comando central e o barorreflexo arterial ${ }^{94}$, mas 
acredita-se que o aumento da ANSP ocorre durante o exercício estático principalmente pelo metabolorreflexo ${ }^{62}$.

No presente estudo, verificamos que a PAS, PAD, PAM e FC aumentam durante o exercício estático com handgrip, provavelmente pelo aumento da $\mathrm{ANSP}^{62,64,94}$, e sofrem uma redução durante a oclusão. Estas respostas ocorrem tanto nas SR como na SE, em ambos os grupos, e demonstram a ação do comando central diminuindo a ação parassimpática e aumentando a FC, e a ação do metabolorreflexo, induzindo aumentos de pressão arterial. Porém, durante a SE, houve redução significativa da PAS, PAD e PAM em todos os estágios, tanto no grupo DRC como no CT. Isso demonstra que uma sessão de exercício aeróbio prévio foi capaz de atenuar a resposta pressórica em condições de "stress" fisiológico, como o exercício estático com handgrip.

Se analisarmos atentamente a magnitude da queda da pressão arterial média dos grupos, em cada estágio, observamos que, apesar de ambos terem redução significativa da pressão arterial em todos os estágios da manobra com o handgrip, esse delta (PAM $\mathrm{PR}_{\mathrm{S}}$ - PAM $\mathrm{SE}_{\mathrm{SE}}$ é maior nos indivíduos portadores de DRC. Isso pode ser encontrado na literatura, sendo observada uma hipotensão pós-exercício de maior magnitude em hipertensos que em normotensos ${ }^{42,83,84}$.

Park et $\mathrm{al}^{29}$ analisaram a resposta pressórica ao exercício estático com handgrip a $30 \%$ da contração voluntária máxima e ao metabolorreflexo (oclusão da circulação do antebraço por 2 minutos) em pacientes com DRCT, sem a realização do exercício físico aeróbio previamente. Foi observado um aumento da PAS durante o exercício estático e durante o metabolorreflexo nos pacientes com DRCT em relação ao controle. A PAD e a FC não apresentaram diferenças significativas entre os grupos. A ANSP também foi maior no grupo com DRCT tanto no exercício estático como na oclusão, em impulsos/minuto. Não foi realizado exercício físico aeróbio antes das manobras. 
Na sessão exercício, em ambos os grupos, o FSA aumentou durante o exercício estático e aumentou ainda mais durante a oclusão, de maneira que a RVP, apesar do aumento da PAM, diminuiu. O aumento do FSA foi maior no grupo DRC que no CT. Cléroux et $\mathrm{al}^{42}$ observaram o aumento do FSA e a redução da RVP em indivíduos hipertensos em relação aos normotensos, após 30 minutos de exercício aeróbio em bicicleta ergométrica, a $50 \%$ do $\mathrm{VO}_{2 \text { pico, }}$ também após o exercício em comparação ao repouso. Halliwill et $\mathrm{al}^{44}$ encontraram a redução na resistência vascular da panturrilha, de sujeitos normotensos, após a realização de 60 minutos de exercício em bicicleta ergométrica, a $60 \%$ do $\mathrm{VO}_{2 \text { pico. }}$

Em relação ao exercício estático com handgrip, observamos que uma sessão de exercício aeróbio prévio foi capaz de atenuar a resposta pressórica, bem como reduzir a ANSP e a RVP, além de aumentar o FSA nos indivíduos com DRC, em condições de "stress" fisiológico. Esse achado tem grande importância, pois podemos observar, mais uma vez, o efeito protetor do exercício físico aeróbio no sistema cardiovascular destes pacientes.

\subsection{Proteinúria}

A incidência de disfunções renais durante o exercício, conforme relato de muitos estudos científicos, oscila entre $11 \%$ e $100 \%$, dependendo do tipo e da intensidade do exercício, bem como do estado de hidratação do atleta. Essas alterações podem incluir proteinúria, hematúria e redução do fluxo sanguíneo renal e do $\mathrm{RFG}^{95}$.

Em nosso trabalho, considerando a realização de exercício aeróbio de baixa

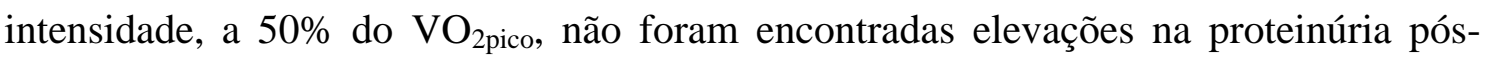
exercício nos pacientes portadores de DRC pré-dialítica, após uma sessão aguda de exercício. Esses dados são coerentes com a literatura, quando consideramos que a severidade da proteinúria e da hematúria pós-exercício depende da intensidade do 
exercício $^{67}$. E, em longo prazo $^{70}$, considerando os efeitos de adaptação positivos do treinamento $^{67}$, o esforço leve se mostrou inofensivo para a função renal e balanço eletrolítico, bem como para o metabolismo cardíaco, em indivíduos saudáveis ${ }^{70}$. Pechter et $\mathrm{al}^{73}$ demonstrou redução da proteinúria à metade do seu valor inicial $(1,0 \pm 0,3$ vs. 0,5 $\pm 0,3 \mathrm{~g} / 24 \mathrm{~h}$ ) em um grupo de pacientes com DRC grau leve após 12 semanas de treinamento aquático, 2 vezes por semana, $30 \mathrm{~min} / \mathrm{sessão,} \mathrm{com} \mathrm{intensidade} \mathrm{de} \mathrm{40-50 \%}$ do $\mathrm{VO}_{2 \text { pico. }}$

É interessante comentar que indivíduos saudáveis que apresentam proteinúria pós-exercício não são susceptíveis de desenvolver doença renal crônica e, portanto, não é necessário reduzir o nível de atividade física ${ }^{95}$. 


\section{CONCLUSÕES}

A hipótese deste estudo era de que uma sessão de exercício físico aeróbio pudesse reduzir a ANSP e os níveis pressóricos na população portadora de DRC-estágio III, assim como ocorre em outras populações.

Isso aconteceu, de maneira que o exercício físico aeróbio a $50 \%$ do $\mathrm{VO}_{2 \text { pico }}$ foi efetivo na melhora de parâmetros cardiovasculares e se mostrou uma possível ferramenta não farmacológica na redução da pressão arterial e da resistência vascular periférica, bem como na prevenção de doenças cardiovasculares - principal causa de mortalidade nesses pacientes.

Como observamos, há poucos estudos realizados em pacientes portadores de DRC no estágio III, no intuito de avaliar os parâmetros hemodinâmicos e neurais, após o exercício físico aeróbio. Na literatura encontramos muitos estudos que demonstram preocupação com a progressão da DRC e com possíveis meios de retardo da mesma, principalmente devido ao crescimento do número de casos de DRCT. Painter ${ }^{96}$ ressalta a possível importância do exercício físico para a população portadora de DRC, mas pontua a necessidade da aquisição de conhecimento científico, especialmente em fisiologia, e de experiência clínica, para documentação do impacto do exercício físico regular, bem como o desenvolvimento de novas diretrizes para realização de exercício para esta população. Desta forma, o exercício físico poderia se tornar prática rotineira no tratamento desses pacientes. Finkelstein et $\mathrm{al}^{97}$ apontam que programas de exercício físico podem ser utilizados como uma estratégia não-farmacológica na melhora da qualidade de vida relacionada à saúde de pacientes com DRC. Por outro lado, grandes níveis de atividade física não foram associados com redução na mortalidade, a longo prazo, em pacientes com DRC em um estudo de Chen et $\mathrm{al}^{98}$.

Painter $^{96}$ justifica a recomendação de exercício físico para pacientes com doenças crônicas, como a DRC, por muitas razões clinicamente relevantes tais como: 
1) O exercício físico pode reduzir fatores de risco cardiovascular e atenuar outras consequiências clínicas da doença e/ou tratamento;

2) O treinamento físico pode atenuar a falta de condicionamento físico dos pacientes e otimizar o tratamento farmacológico ou cirúrgico quando utilizado como terapia adjuvante;

3) Melhorar o funcionamento físico significa melhorar a qualidade de vida / bemestar e, eventualmente, melhorar os resultados globais.

Em nosso trabalho verificamos que uma sessão aguda de exercício físico aeróbio é eficiente na melhora de parâmetros hemodinâmicos e neurais de pacientes portadores de DRC - estágio III. Em relação ao treinamento físico aeróbio, não podemos afirmar categoricamente que os benefícios são os mesmos ou mais duradouros, mas podemos supor. Como já foi demonstrado em alguns estudos, o treinamento físico reduz os níveis pressóricos de pacientes portadores de DRC dialítica ${ }^{75,99,100}$. Portanto, é possível supor que o treinamento físico aeróbio também poderá trazer benefícios para a população portadora de DRC - estágio III.

Se os benefícios do exercício aeróbio e treinamento de força, comprovados em outras populações, forem aplicados a pacientes portadores de DRC, o exercício físico poderá desempenhar papel importante no tratamento, na prevenção e no retardo da progressão da $\mathrm{DRC}^{101}$. Sessões de exercício podem ter um impacto positivo sobre o controle da pressão arterial, como terapia adjuvante para modificar o risco de complicações cardiovasculares $^{91}$.

Ainda não estão claros os efeitos do exercício físico no retardo da progressão da DRC. Porém, seus efeitos na prevenção e controle do risco da doença cardiovascular já estão bastante definidos. Portanto, como a principal causa de morte dos pacientes portadores de DRC é a doença cardiovascular, a inclusão de um programa de exercícios físicos no tratamento não farmacológico desses pacientes seria recomendada. 


\section{ANEXOS}

Anexo I - Aprovação do Comitê de Ética

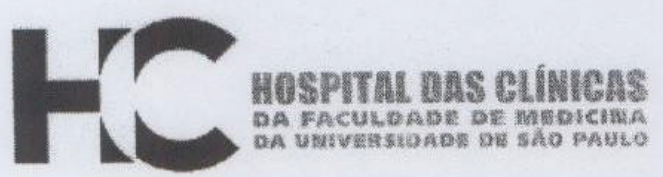

\section{APROVAÇÃO}

A Comissão de Ética para Análise de Projetos de Pesquisa - CAPPesq da Diretoria Clínica do Hospital das Clínicas e da Faculdade de Medicina da Universidade de São Paulo, em sessão de 14/03/2007, APROVOU o Protocolo de Pesquisa $n^{\circ}$ 1133/06, intitulado: "EFEITOS DO EXERCíCIO FísICO AERÓBIO NA ATIVIDADE NERVOSA SIMPÁTICA PERIFÉRICA DE RENAIS CRÔNICOS PRÉ-DIÁLISE" apresentado pelo Departamento de Clínica Médica, inclusive o Termo de Consentimento Livre e Esclarecido.

Cabe ao pesquisador elaborar e apresentar à CAPPesq, os relatórios parciais e final sobre a pesquisa (Resolução do Conselho Nacional de Saúde n 196, de 10.10.1996, inciso IX. 2, letra "c")

Pesquisador(a) Responsável: Dr $^{a}$. Taís Tinucci

\section{Pesquisadores Executantes: Daniele Cristina Bosco}

CAPPesq, 14 de março de 2007.

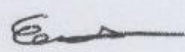

PROF. DR. EDUARDO MASSAD

Presidente da Comissão de Ética para Análise

de Projetos de Pesquisa

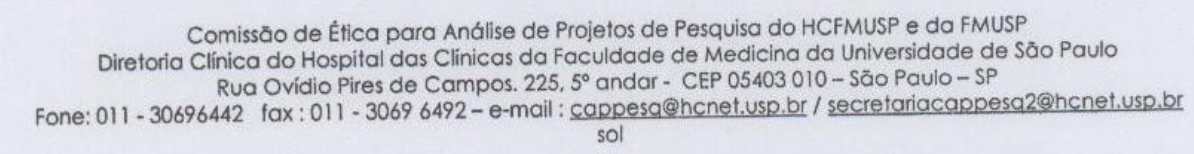


Anexo II

\section{TERMO DE CONSENTIMENTO LIVRE E ESCLARECIDO}

(Instruções para preenchimento no verso)

I - DADOS DE IDENTIFICAÇÃO DO SUJEITO DA PESQUISA OU RESPONSÁVEL LEGAL

1. NOME DO PACIENTE .

DOCUMENTO DE IDENTIDADE № : SEXO : M.....F.....

? DATA NASCIMENTO: $/ \ldots \ldots . . . . . .$.

ENDEREÇO: № APTO:

BAIRRO: CIDADE:

CEP: TELEFONE: DDD (........)

2.RESPONSÁVEL LEGAL

NATUREZA (grau de parentesco, tutor, curador etc.)

DOCUMENTO DE IDENTIDADE № : SEXO : M............?

DATA NASCIMENTO: .........................

ENDEREÇO:

№.

APTO:

BAIRRO:

CIDADE:

CEP:

TELEFONE: DDD (........)

\section{II - DADOS SOBRE A PESQUISA CIENTÍFICA}

1. TÍTULO DO PROTOCOLO DE PESQUISA:

"Efeito do exercício físico aeróbio na atividade nervosa simpática periférica de renais crônicos pré-dialise"

PESQUISADOR: Taís Tinucci

CARGO/FUNÇÃO: Profa. Doutora INSCRIÇÃO CRM № 33514

UNIDADE DO HCFMUSP: Laboratório de Hipertensão da Nefrologia do ICHC

3. AVALIAÇÃO DO RISCO DA PESQUISA:

SEM RISCO ?? RISCO MÍNIMO ?? RISCO MÉDIO ? ?

RISCO BAIXO X RISCO MAIOR ??

(probabilidade de que o indivíduo sofra algum dano como consequência imediata ou tardia do estudo)

4. DURAÇÃO DA PESQUISA : 3 anos

\section{III - REGISTRO DAS EXPLICAÇÕES DO PESQUISADOR AO PACIENTE OU SEU REPRESENTANTE LEGAL SOBRE A PESQUISA CONSIGNANDO:}

\section{Justificativa e os objetivos da pesquisa}

Este estudo tem por objetivo avaliar o efeito de uma única sessão de exercício em biclicleta sobre o controle nervoso da circulação em pacientes com insuficiência renal crônica que ainda não precisam fazer diálise. A importância de se conhecer 
como o exercício pode ajudar na circulação nesses pacientes é porque ele pode melhorar a capacidade física desses doentes, ja que é bastante utilizado no tratamento de cardíacos.

\section{Procedimentos que serão utilizados e propósitos, incluindo a identificação dos procedimentos que são experimentais}

Você será convidado a participar de um estudo que prevê, inicialmente, um teste ergométrico em bicicleta para avaliar a capacidade física atual e detectar um possível problema cardíaco. Este teste será feito no laboratório de hemodinâmica da Escola de Educação Física e Esporte com supervisão médica e será levado até ao ponto que você agüentar.

As sessões experimentais serão realizadas no laboratório de hipertensão do Hospital das Clínicas em ordem aleatória, de maneira que nem você nem eu saberemos em que ordem elas serão realizadas. Em uma delas você pedalará por 45 minutos em uma intensidade que será a metade da que você tiver atingido no teste ergométrico e, na outra sessão, permanecerá sentado na bicicleta em repouso. Essas sessões serão realizadas com um intervalo de 15 dias.

Após cada uma das sessões de exercício e de repouso, faremos um exame que irá analisar como o seu sistema nervoso reagiu a elas. Para tanto, localizaremos um nervoque se localiza ao lado do joelho com uma canetinha que dá uns choquinhos muito leves, que fazem seu pé se mexer. Em seguida será introduzida uma agulhinha, flexível e bem fininha, em seu nervo que medirá os impulsos do seu nervo. Você irá apertar um aparelhinho que se assemelha a uma alça de mala por três minutos sem soltar ou acompanhando o tic-tac de um relógio.

Durante esse exame será medido o fluxo de sangue para o seu braço. Para tanto serão colocados dois manguitos (como os usados no aparelho de medir pressão), um no braço e outro no punho, que serão insuflados durante os exercícios com a alça.

\section{Desconfortos e riscos esperados}

Durante o teste ergométrico você poderá se sentir cansado, com tontura e dores nas pernas. O teste será interrompido assim que você atingir a sua capacidade máxima ou quando não agüentar mais. Não existem riscos maiores para doentes dos rins, sendo que o exame é interronpido quando voce quiser.

Durante o exame do nervo, você poderá sentir dormência, formigamentos ou choques que serão interrompidos, desligando-se o equipamento. Esses sintomas podem ocorrer apenas quando se está procurando o nervo com a canetinha ou quando a agulhinha é introduzida.

Usualmente, esses procedimentos não trazem risco a sua saúde, apenas algum desconforto. Não ha riscos de complicações incuráveis desse exame. Há casos relatados de pacientes que ficaram sentindo dor fraca ou dormência na pele da perna por até uma semana depois do exame. Até onde sabemos, somente dois pacientes sentiram fraqueza na perna em que o exame foi feito, que durou mais ou menos um mês. Depois desse período todos se recuperaram sem sentir mais nada. 


\section{Benefícios que poderão ser obtidos}

É possível que você não seja beneficiado diretamente pelos conhecimentos que serão alcançados com esse estudo. Sabe-se que o exercício físico é muito benéfico para muitos pacientes portadores de doenças crônicas, como você. Porém, são muito pouco conhecidos os efeitos do exercício físico nos pacientes renais que, eventualmente, poderão se beneficiar também.

\section{Procedimentos alternativos que possam ser vantajosos para o indivíduo}

O teste ergométrico será benéfico porque além de avaliar sua capacidade física poderá detectar algum problema cardíaco que ainda não lhe trouxe sintomas, possibilitando o seu tratamento.

O exame do nervo poderá detectar o quanto o seu sistema nervoso interfere na sua pressão arterial e quanto o esforço físico pode alterá-la.

\section{IV - ESCLARECIMENTOS DADOS PELO PESQUISADOR SOBRE GARANTIAS DO SUJEITO DA PESQUISA CONSIGNANDO:}

1. Acesso, a qualquer tempo, às informações sobre procedimentos, riscos e benefícios relacionados à pesquisa, inclusive para dirimir eventuais dúvidas.

Será garantido o acesso, a qualquer tempo, às informações sobre procedimentos, riscos e benefícios relacionados à pesquisa, inclusive para esclarecer eventuais dúvidas.

2. Liberdade de retirar seu consentimento a qualquer momento e de deixar de participar do estudo, sem que isto traga prejuízo à continuidade da assistência.

Será garantida a liberdade de deixar o estudo a qualquer tempo, sem que isso implique em nenhuma interrupção no seu tratamento.

\section{Salvaguarda da confidencialidade, sigilo e privacidade.}

Será garantido o sigilo de todos os procedimentos, não sendo revelada a identidade de nenhum dos participantes do estudo.

4. Disponibilidade de assistência no HCFMUSP, por eventuais danos à saúde, decorrentes da pesquisa.

Será garantida a assistência no HCFMUSP, por eventuais danos à saúde, decorrentes da pesquisa.

5. Viabilidade de indenização por eventuais danos à saúde decorrentes da pesquisa.

Não está prevista, no estudo, indenização por eventuais danos à saúde, decorrentes da pesquisa. 


\section{V - INFORMAÇÕES DE NOMES, ENDEREÇOS E TELEFONES DOS RESPONSÁVEIS PELO ACOMPANHAMENTO DA PESQUISA, PARA CONTATO EM CASO DE INTERCORRÊNCIAS CLÍNICAS E REAÇÕES ADVERSAS.}

Daniele Cristina Bosco

End: Av. Diógenes Ribeiro de Lima, 2000, Bl.33 / ap.11.

Fone: 3477-4375 ou 3069-7686 (laboratório)

Taís Tinucci

End: Av Prof. Mello Moraes, 65.

Fone: 3091-2286

VI - OBSERVAÇÕES COMPLEMENTARES:

\section{VII - CONSENTIMENTO PÓS-ESCLARECIDO}

Declaro que, após convenientemente esclarecido pelo pesquisador e ter entendido o que me foi explicado, consinto em participar do presente Protocolo de Pesquisa

São Paulo, de de $200 \ldots$.

assinatura do sujeito da pesquisa ou responsável legal assinatura do pesquisador (carimbo ou nome Legível) 
Anexo III - Aprovação da FAPESP - Concessão de bolsa

\section{A FAPESP}

FUNDAÇÃO DE AMPARO À PESQUISA DO ESTADO DE SÃO PAULO

\section{COMUNICADO}

IImo.(a) Sr.(a)

DANIELE CRISTINA BOSCO

AV DIOGENES RIBEIRO DE LIMA, 2000

BL 33 - APTO 11

05458-901 SAO PAULO-SP

Comunicamos que o seu pedido de bolsa, em nível de MS-1, foi aprovado para início a partir de 01 set07.

Solicitamos seu comparecimento para assinatura do respectivo termo de outorga e aceitação da bolsa, impreterivelmente até o dia 19 DE OUTUBRO DE 2007 Após essa data, a concessão será automaticamente cancelada.

Conselho Técnico-Administrativo

FAPESP

Obs.: IMPRORROGAVEL

Processo 07/51945-4 
Anexo IV - Fluxograma da Sessão Experimental

\section{PROCEDIMENTOS INICIAIS}

Pesagem ------ Teste de CVM ------ Medidas: FC, PAS e PAD

Sorteio: Sessão Exercício (SE) ou Sessão Repouso (SR)

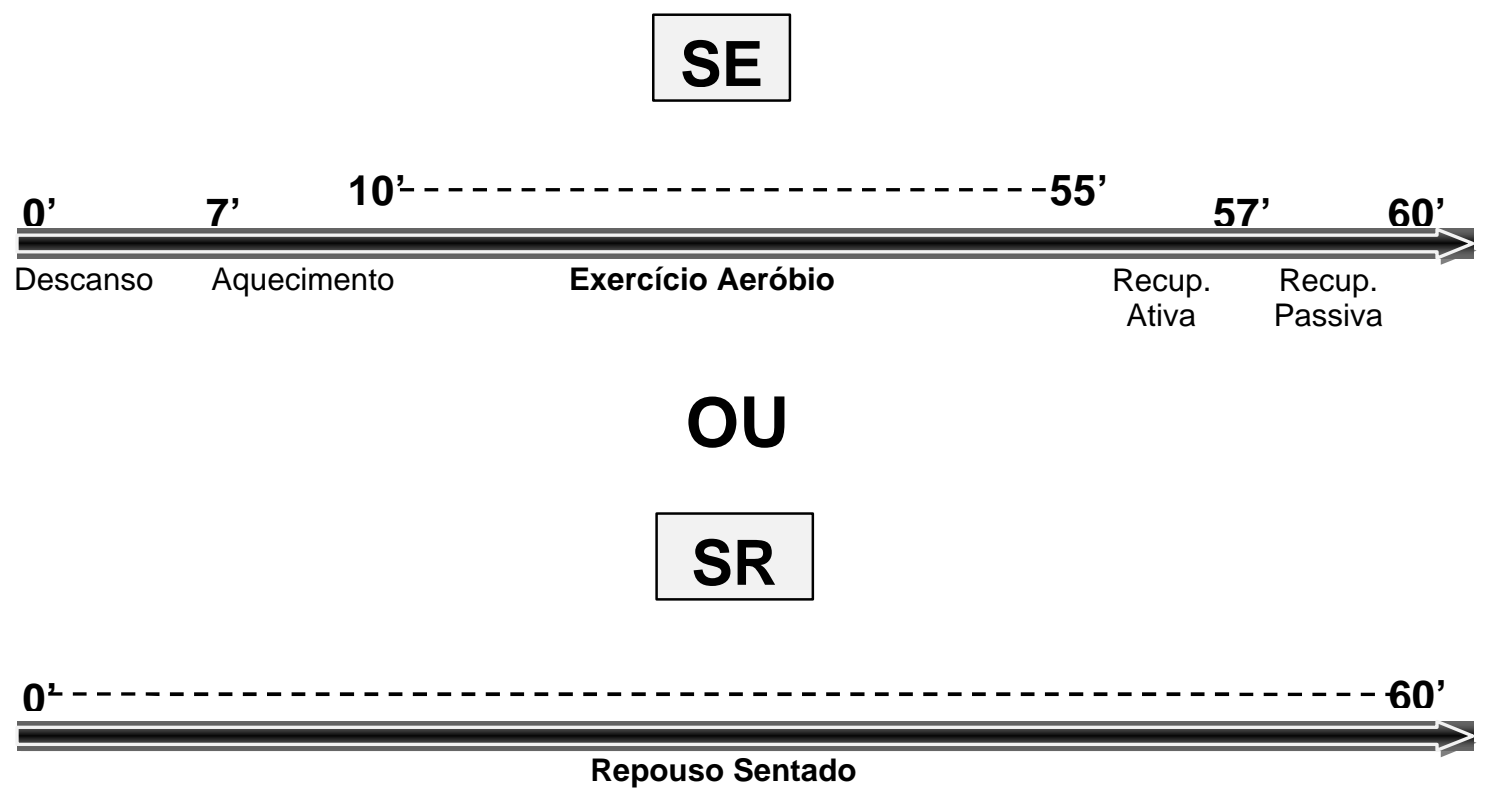

\section{Após SE ou SR:}

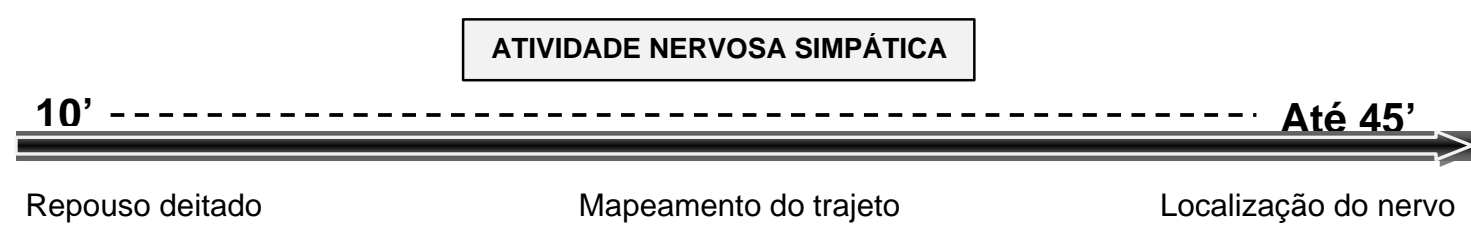

REGISTRO BASAL

$10^{\prime}$

Medidas de PAS, PAD, PAM, FC, ANSP, FSA

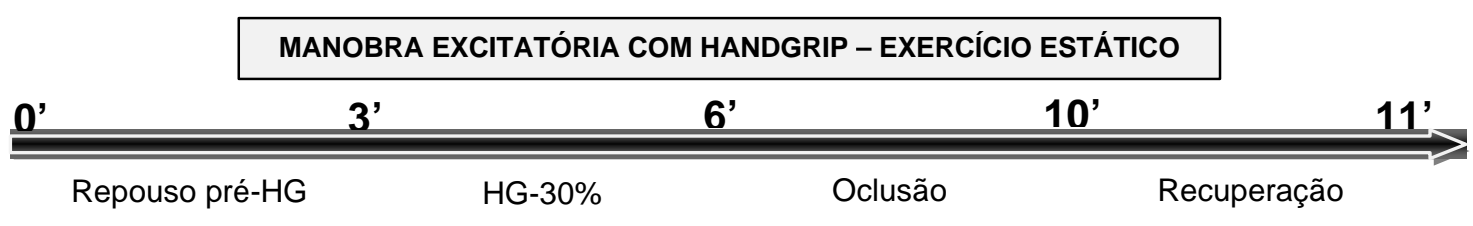

Medidas de PAS, PAD, PAM, FC, ANSP, FSA 
Anexo V - Características gerais da amostra.

Grupo Controle (CT)

\begin{tabular}{|c|c|c|c|c|c|c|c|}
\hline voluntário & idade & sexo & $\begin{array}{c}\text { peso } \\
(\mathbf{k g})\end{array}$ & $\begin{array}{c}\text { altura } \\
(\mathbf{m})\end{array}$ & $\begin{array}{c}\text { PAM } \\
(\mathbf{m m} \mathbf{H g})\end{array}$ & $\begin{array}{c}\text { IMC } \\
\left(\mathbf{k g} / \mathbf{m}^{\mathbf{2}}\right)\end{array}$ & $\begin{array}{c}\text { carga SE } \\
(\mathbf{W})\end{array}$ \\
\hline FCS & 52 & $\mathrm{M}$ & 77,4 & 1,81 & 102 & 23,6 & 63 \\
\hline RS & 48 & $\mathrm{M}$ & 85,8 & 1,83 & 86 & 25,6 & 72 \\
\hline MGB & 39 & $\mathrm{M}$ & 82,8 & 1,78 & 96 & 26,1 & 56 \\
\hline MMC & 48 & $\mathrm{~F}$ & 54,7 & 1,50 & 81 & 24,3 & 34 \\
\hline POS & 56 & $\mathrm{~F}$ & 59,1 & 1,56 & 90 & 24,3 & 30 \\
\hline MARO & 54 & $\mathrm{~F}$ & 69,5 & 1,55 & 94 & 29,0 & 33 \\
\hline EJGV & 47 & $\mathrm{~F}$ & 54,2 & 1,60 & 83 & 21,1 & 33 \\
\hline LMS & 52 & $\mathrm{~F}$ & 80,6 & 1,66 & 88 & 29,3 & 37 \\
\hline MUN & 57 & $\mathrm{~F}$ & 79,7 & 1,63 & 92 & 30,0 & 30 \\
\hline FSP & 51 & $\mathrm{~F}$ & 50,4 & 1,40 & 89 & 25,6 & 36 \\
\hline NPB & 49 & $\mathrm{~F}$ & 83,7 & 1,67 & 84 & 30,0 & 48 \\
\hline MI & 45 & F & 63,4 & 1,59 & 101 & 25,1 & 36 \\
\hline
\end{tabular}

Grupo DRC

\begin{tabular}{|c|c|c|c|c|c|c|c|}
\hline voluntário & idade & sexo & $\begin{array}{c}\text { peso } \\
(\mathbf{k g})\end{array}$ & $\begin{array}{c}\text { altura } \\
(\mathbf{m})\end{array}$ & $\begin{array}{c}\text { PAM } \\
(\mathbf{m m ~ H g})\end{array}$ & $\begin{array}{c}\text { IMC } \\
\left(\mathbf{k g} / \mathbf{m}^{\mathbf{2}}\right)\end{array}$ & $\begin{array}{c}\text { carga SE } \\
(\mathbf{W})\end{array}$ \\
\hline NCMF & 54 & $\mathrm{~F}$ & 73 & 1,61 & 106 & 28,2 & 35 \\
\hline MRP & 59 & $\mathrm{~F}$ & 63,8 & 1,62 & 136 & 24,3 & 42 \\
\hline ELJ & 56 & $\mathrm{~F}$ & 73,2 & 1,57 & 114 & 29,7 & 27 \\
\hline ERS & 52 & $\mathrm{M}$ & 91 & 1,75 & 98 & 29,7 & 66 \\
\hline ACM & 44 & $\mathrm{M}$ & 69 & 1,8 & 107 & 21,3 & 59 \\
\hline LCT & 60 & $\mathrm{M}$ & 71,5 & 1,68 & 100 & 25,3 & 36 \\
\hline CAG & 36 & $\mathrm{~F}$ & 59,1 & 1,49 & 108 & 26,6 & 37 \\
\hline CC & 54 & $\mathrm{M}$ & 94,5 & 1,79 & 96 & 29,5 & 44 \\
\hline ASC & 50 & $\mathrm{M}$ & 78 & 1,65 & 103 & 28,7 & 60 \\
\hline
\end{tabular}


Anexo VI - Resultados dos exames laboratoriais

Grupo Controle (CT)

\begin{tabular}{|c|c|c|c|c|c|}
\hline voluntário & $\begin{array}{c}\text { clearance } \\
(\mathbf{m l} / \mathbf{m i n})\end{array}$ & $\begin{array}{c}\text { uréia } \\
(\mathbf{m g} / \mathbf{d l})\end{array}$ & $\begin{array}{c}\text { creatinina } \\
(\mathbf{m g} / \mathbf{d l})\end{array}$ & $\begin{array}{c}\text { Hb } \\
(\mathbf{m g} / \mathbf{d l})\end{array}$ & $\begin{array}{c}\text { glicemia } \\
(\mathbf{m g} / \mathbf{d l})\end{array}$ \\
\hline FCS & & & & & \\
\hline RS & & & & & \\
\hline MGB & & & & & \\
\hline MMC & 101 & 29 & 0,6 & 13,5 & 78 \\
\hline POS & 99 & 32 & 0,7 & 13,2 & 103 \\
\hline MARO & 95 & 31 & 0,9 & 13,9 & 106 \\
\hline EJGV & 102 & 33 & 0,7 & 11,4 & 83 \\
\hline LMS & 97 & 28 & 0,9 & 14,3 & 92 \\
\hline MUN & 86 & 32 & 1,0 & 13,4 & 108 \\
\hline FSP & 100 & 25 & 0,7 & 13,1 & 93 \\
\hline NPB & 102 & 38 & 0,8 & 12,3 & 85 \\
\hline MI & 106 & 32 & 0,7 & 12,4 & 96 \\
\hline
\end{tabular}

Grupo DRC

\begin{tabular}{|c|c|c|c|c|c|}
\hline voluntário & $\begin{array}{c}\text { clearance } \\
(\mathbf{m l} / \mathbf{m i n})\end{array}$ & $\begin{array}{c}\text { uréia } \\
(\mathbf{m g} / \mathbf{d l})\end{array}$ & $\begin{array}{c}\text { creatinina } \\
(\mathbf{m g} / \mathbf{d l})\end{array}$ & $\begin{array}{c}\text { Hb } \\
(\mathbf{m g} / \mathbf{d l})\end{array}$ & $\begin{array}{c}\text { glicemia } \\
(\mathbf{m g} / \mathbf{d l})\end{array}$ \\
\hline NCMF & 45 & 58 & 1,8 & 12 & 86 \\
\hline MRP & 56 & 65 & 1,6 & 12,8 & 95 \\
\hline ELJ & 54 & 50 & 1,4 & 13,9 & 102 \\
\hline ERS & 64 & 58 & 1,8 & 14,4 & 106 \\
\hline ACM & 64 & 71 & 1,53 & 13,1 & 100 \\
\hline LCT & 51 & 65 & 1,71 & 13,2 & 95 \\
\hline CAG & 35 & 63 & 2,14 & 11,9 & 84 \\
\hline CC & 46 & 92 & 2,27 & 12,6 & 104 \\
\hline ASC & 49 & 62 & 1,58 & 16,5 & 77 \\
\hline
\end{tabular}


atologias de base e medicações em uso pelos pacientes do grupo DRC

\begin{tabular}{c|c}
\hline doença de base & medicações em uso diário \\
\hline Hipertensão + Aterosclerose & Losartana 50mg, Amlodipino 10mg \\
\hline Hipertensão + Aterosclerose & Enalapril 20mg, Hidroclorotiazida 25mg, Amlodipino 10mg \\
\hline Hipertensão Primária & Hidroclorotiazida 25mg, Sinvastatina 10mg, Ranitidina 150mg, Losarta \\
\hline Hipertensão & Enalapril 20mg, Hidroclorotiazida 50mg, Amlodipino 10mg \\
\hline Rins Policísticos & Vasopril 20mg \\
\hline Nefroesclerose & Enalapril 5mg + AAS 100mg \\
\hline ilomerulonefrite rapidamente progressiva & Vasopril 10mg, Hidroclorotiazida 50mg, Amlodipino 5mg \\
\hline dronefrose E + HA + Prot + Hiperuricemia & Alopurinol 100mg + Losartana 50mg + Sinvastatina 10mg \\
\hline Nefrocalcinose & Enalapril 20mg, Hidroclorotiazida 50mg, Citrato de Potássio 101 \\
\hline
\end{tabular}


Anexo VIII - Dados de PAS do período basal nas sessões repouso (SR) e exercício (SE)

Grupo Controle (CT)

\begin{tabular}{|c|c|c|c|c|c|c|}
\hline voluntário & sessão & minuto 1 & minuto 2 & minuto 3 & minuto 4 & minuto 5 \\
\hline FCS & SR & 142 & 161 & 149 & 142 & 143 \\
\hline & SE & 134 & 135 & 126 & 135 & 137 \\
\hline RS & SR & 131 & 133 & 132 & 134 & 134 \\
\hline & SE & 125 & 132 & 121 & 123 & 122 \\
\hline MGB & SR & 150 & 159 & 146 & 140 & 140 \\
\hline & SE & 134 & 128 & 115 & 135 & 133 \\
\hline MMC & SR & 149 & 156 & 158 & 143 & 141 \\
\hline & SE & 127 & 128 & 128 & 128 & 135 \\
\hline POS & SR & 160 & 167 & 160 & 169 & 175 \\
\hline & SE & 168 & 163 & 155 & 162 & 176 \\
\hline MARO & SR & 176 & 180 & 164 & 163 & 163 \\
\hline & SE & 175 & 157 & 169 & 170 & 168 \\
\hline EJGV & SR & 158 & 147 & 155 & 161 & 154 \\
\hline & SE & 147 & 143 & 147 & 155 & 141 \\
\hline LMS & SR & 159 & 160 & 175 & 169 & 169 \\
\hline & SE & 164 & 163 & 170 & 164 & 161 \\
\hline MUN & SR & 176 & 162 & 148 & 156 & 149 \\
\hline & SE & 128 & & 136 & 148 & 155 \\
\hline FSP & SR & 150 & 163 & 145 & 149 & 155 \\
\hline & SE & 131 & 136 & 132 & 127 & 134 \\
\hline NPB & SR & 184 & 170 & 163 & 164 & 163 \\
\hline & SE & 161 & 143 & 150 & 151 & 143 \\
\hline MI & SR & 149 & 149 & 156 & 143 & 149 \\
\hline & SE & 148 & 163 & 163 & 150 & 158 \\
\hline & & & & & & \\
\hline
\end{tabular}


Anexo IX - Dados de PAS do período basal nas sessões repouso (SR) e exercício (SE)

Grupo DRC

\begin{tabular}{|c|c|c|c|c|c|c|}
\hline voluntário & sessão & minuto 1 & minuto 2 & minuto 3 & minuto 4 & minuto 5 \\
\hline NCMF & SR & 155 & 162 & 148 & 164 & 165 \\
\hline & SE & 169 & 160 & 175 & 169 & 169 \\
\hline MRP & SR & 195 & 195 & 199 & 195 & 197 \\
\hline & SE & 189 & 182 & 196 & 199 & 197 \\
\hline ELJ & SR & 174 & 177 & 176 & 156 & 169 \\
\hline & SE & 176 & 163 & 165 & 164 & 164 \\
\hline ERS & SR & 150 & 162 & 170 & 169 & 171 \\
\hline & SE & & 160 & 161 & 169 & 169 \\
\hline ACM & SR & 167 & 157 & 158 & 150 & 158 \\
\hline & SE & 138 & 135 & 114 & 138 & 120 \\
\hline LC & SR & 140 & 144 & 143 & 148 & 151 \\
\hline & SE & 117 & 125 & 119 & 120 & 116 \\
\hline CAG & SR & 159 & 157 & 163 & 156 & 150 \\
\hline & SE & 141 & 149 & 141 & 141 & 136 \\
\hline CC & SR & 162 & 163 & 156 & 155 & 172 \\
\hline & SE & 134 & 140 & 147 & 131 & 157 \\
\hline ASC & SR & 152 & 147 & 156 & 142 & 144 \\
\hline & SE & 142 & 142 & 135 & 141 & 142 \\
\hline
\end{tabular}


Anexo X - Dados de PAD do período basal nas sessões repouso (SR) e exercício (SE)

Grupo Controle (CT)

\begin{tabular}{|c|c|c|c|c|c|c|}
\hline voluntário & sessão & minuto 1 & minuto 2 & minuto 3 & minuto 4 & minuto 5 \\
\hline FCS & SR & 92 & 73 & 85 & 82 & 69 \\
\hline & SE & 66 & 67 & 68 & 67 & 67 \\
\hline RS & SR & 71 & 66 & 63 & 58 & 64 \\
\hline & SE & 67 & 66 & 62 & 60 & 64 \\
\hline MGB & SR & 81 & 79 & 80 & 77 & 78 \\
\hline & SE & 66 & 70 & 62 & 58 & 65 \\
\hline MMC & SR & 72 & 73 & 70 & 72 & 81 \\
\hline & SE & 60 & 63 & 63 & 59 & 60 \\
\hline POS & SR & 79 & 81 & 83 & 82 & 82 \\
\hline & SE & 80 & 81 & 80 & 80 & 80 \\
\hline MARO & SR & 82 & 79 & 80 & 79 & 77 \\
\hline & SE & 73 & 74 & 76 & 69 & 71 \\
\hline EJGV & SR & 84 & 80 & 83 & 73 & 76 \\
\hline & SE & 73 & 91 & 96 & 88 & 98 \\
\hline LMS & SR & 84 & 73 & 72 & 78 & 78 \\
\hline & SE & 74 & 74 & 76 & 77 & 79 \\
\hline MUN & SR & 73 & 74 & 74 & 72 & 78 \\
\hline & SE & 70 & & 68 & 67 & 75 \\
\hline FSP & SR & 74 & 72 & 70 & 71 & 74 \\
\hline & SE & 60 & 60 & 57 & 61 & 55 \\
\hline NPB & SR & 75 & 78 & 81 & 74 & 109 \\
\hline & SE & 63 & 63 & 75 & 71 & 62 \\
\hline MI & SR & 76 & 77 & 79 & 75 & 85 \\
\hline & SE & 86 & 87 & 85 & 82 & 81 \\
\hline & & & & & & \\
\hline
\end{tabular}


Anexo XI - Dados de PAD do período basal nas sessões repouso (SR) e exercício (SE)

Grupo DRC

\begin{tabular}{|c|c|c|c|c|c|c|}
\hline Voluntário & sessão & minuto 1 & minuto 2 & minuto 3 & minuto 4 & minuto 5 \\
\hline NCMF & SR & 96 & 88 & 86 & 94 & 91 \\
\hline & SE & 99 & 95 & 98 & 91 & 93 \\
\hline MRP & SR & 114 & 111 & 111 & 110 & 111 \\
\hline & SE & 109 & 112 & 113 & 113 & 117 \\
\hline ELJ & SR & 102 & 101 & 111 & 95 & 96 \\
\hline & SE & 93 & 96 & 92 & 90 & 93 \\
\hline ERS & SR & 85 & 76 & 82 & 73 & 78 \\
\hline & SE & & 88 & 82 & 77 & 80 \\
\hline ACM & SR & 93 & 92 & 92 & 94 & 89 \\
\hline & SE & 81 & 78 & 73 & 73 & 68 \\
\hline LC & SR & 86 & 80 & 82 & 77 & 79 \\
\hline & SE & 69 & 58 & 61 & 63 & 68 \\
\hline CAG & SR & 99 & 85 & 89 & 87 & 92 \\
\hline & SE & 82 & 89 & 89 & 81 & 87 \\
\hline CC & SR & 82 & 78 & 78 & 74 & 79 \\
\hline & SE & 69 & 71 & 98 & 72 & 71 \\
\hline ASC & SR & 101 & 95 & 89 & 87 & 89 \\
\hline & SE & 86 & 84 & 87 & 85 & 88 \\
\hline
\end{tabular}


Anexo XII - Dados de PAM do período basal nas sessões repouso (SR) e exercício (SE)

Grupo Controle (CT)

\begin{tabular}{|c|c|c|c|c|c|c|}
\hline Voluntário & sessão & minuto 1 & minuto 2 & minuto 3 & minuto 4 & minuto 5 \\
\hline FCS & SR & 111 & 88 & 115 & 111 & 84 \\
\hline & SE & 94 & 90 & 95 & 90 & 86 \\
\hline RS & SR & 82 & 88 & 91 & 76 & 92 \\
\hline & SE & 77 & 76 & 75 & 69 & 71 \\
\hline MGB & SR & 99 & 98 & 95 & 95 & 92 \\
\hline & SE & 77 & 91 & 86 & 85 & 83 \\
\hline MMC & SR & & & & & \\
\hline & SE & & & & & \\
\hline POS & SR & 96 & 95 & 93 & 93 & 112 \\
\hline & SE & 102 & 109 & 88 & 94 & 96 \\
\hline MARO & SR & 100 & 97 & 101 & 94 & 101 \\
\hline & SE & 91 & 106 & 109 & 94 & 102 \\
\hline EJGV & SR & 105 & 94 & 96 & 87 & 95 \\
\hline & SE & 94 & 111 & 96 & 88 & 98 \\
\hline LMS & SR & 116 & 92 & 96 & 95 & 98 \\
\hline & SE & 101 & 88 & 95 & 96 & 92 \\
\hline MUN & SR & 92 & 97 & 91 & 99 & 91 \\
\hline & SE & 99 & & 80 & 82 & 83 \\
\hline FSP & SR & 92 & 83 & 90 & 93 & 95 \\
\hline & SE & 75 & 78 & 86 & 75 & 73 \\
\hline NPB & SR & 95 & 94 & 93 & 87 & 128 \\
\hline & SE & 72 & 89 & 94 & 97 & 75 \\
\hline MI & SR & 88 & 100 & 92 & 96 & 99 \\
\hline & SE & 101 & 103 & 97 & 104 & 96 \\
\hline
\end{tabular}


Anexo XIII - Dados de PAM do período basal nas sessões repouso (SR) e exercício (SE)

Grupo DRC

\begin{tabular}{|c|c|c|c|c|c|c|}
\hline voluntário & sessão & minuto 1 & minuto 2 & minuto 3 & minuto 4 & minuto 5 \\
\hline NCMF & SR & 104 & 104 & 108 & 106 & 107 \\
\hline & SE & 115 & 112 & 113 & 116 & 113 \\
\hline MRP & SR & 126 & 127 & 137 & 145 & 144 \\
\hline & SE & 124 & 126 & 130 & 134 & 135 \\
\hline ELJ & SR & 108 & 110 & 140 & 107 & 105 \\
\hline & SE & 115 & 104 & 97 & 106 & 107 \\
\hline ERS & SR & 104 & 96 & 103 & 95 & 93 \\
\hline & SE & & 103 & 96 & 98 & 96 \\
\hline ACM & SR & 107 & 111 & 103 & 101 & 113 \\
\hline & SE & 109 & 105 & 93 & 95 & 91 \\
\hline LC & SR & 96 & 97 & 108 & 97 & 101 \\
\hline & SE & 87 & 77 & 83 & 78 & 86 \\
\hline CAG & SR & 126 & 107 & 100 & 100 & 105 \\
\hline & SE & 94 & 102 & 102 & 97 & 99 \\
\hline CC & SR & 98 & 104 & 93 & 92 & 94 \\
\hline & SE & 90 & 77 & 111 & 92 & 99 \\
\hline ASC & SR & 112 & 106 & 100 & 102 & 97 \\
\hline & SE & 101 & 101 & 95 & 100 & 102 \\
\hline
\end{tabular}


Anexo XIV - Dados de FC do período basal nas sessões repouso (SR) e exercício (SE)

Grupo Controle (CT)

\begin{tabular}{|c|c|c|c|c|c|c|}
\hline voluntário & sessão & minuto 1 & minuto 2 & minuto 3 & minuto 4 & minuto 5 \\
\hline FCS & SR & 58 & 53 & 53 & 52 & 55 \\
\hline & SE & 59 & 59 & 58 & 55 & 57 \\
\hline RS & SR & 67 & 65 & 66 & 70 & 68 \\
\hline & SE & 63 & 65 & 65 & 66 & 72 \\
\hline MGB & SR & 63 & 58 & 61 & 60 & 60 \\
\hline & SE & 66 & 64 & 68 & 63 & 63 \\
\hline MMC & SR & 72 & 72 & 75 & 72 & 73 \\
\hline & SE & 75 & 78 & & & \\
\hline POS & SR & 57 & 56 & 55 & 56 & 55 \\
\hline & SE & 54 & 55 & 55 & 56 & 58 \\
\hline MARO & SR & 70 & 66 & 70 & 70 & 75 \\
\hline & SE & & 63 & 68 & 62 & 64 \\
\hline EJGV & SR & 61 & 64 & 61 & 60 & 58 \\
\hline & SE & 60 & 60 & 59 & 60 & 60 \\
\hline LMS & SR & & & & & \\
\hline & SE & & & & & \\
\hline MUN & SR & 70 & 70 & 69 & 70 & 77 \\
\hline & SE & 74 & & 73 & 76 & 75 \\
\hline FSP & SR & 78 & 82 & 78 & 82 & 87 \\
\hline & SE & 75 & 73 & 73 & 74 & 73 \\
\hline NPB & SR & 66 & 65 & 64 & 63 & 65 \\
\hline & SE & 59 & 59 & 58 & 61 & 58 \\
\hline MI & SR & 72 & 72 & 70 & 75 & 72 \\
\hline & SE & 73 & 75 & 76 & 78 & 75 \\
\hline & & & & & & \\
\hline
\end{tabular}


Anexo XV - Dados de FC do período basal nas sessões repouso (SR) e exercício (SE)

Grupo DRC

\begin{tabular}{|c|c|c|c|c|c|c|}
\hline voluntário & sessão & minuto 1 & minuto 2 & minuto 3 & minuto 4 & minuto 5 \\
\hline NCMF & SR & 59 & 59 & 58 & 60 & 61 \\
\hline & SE & 61 & 63 & 62 & 65 & 60 \\
\hline MRP & SR & 61 & 61 & 61 & 61 & 61 \\
\hline & SE & 63 & 65 & 68 & 68 & 68 \\
\hline ELJ & SR & 74 & 76 & 85 & 82 & 80 \\
\hline & SE & 78 & 88 & 85 & 87 & 86 \\
\hline ERS & SR & 53 & 54 & 53 & 55 & 53 \\
\hline & SE & & 53 & 51 & 52 & 53 \\
\hline ACM & SR & 51 & 58 & 58 & 60 & 58 \\
\hline & SE & 65 & 63 & 61 & 64 & 61 \\
\hline LC & SR & 55 & 56 & 58 & 56 & 62 \\
\hline & SE & 65 & 68 & 63 & 64 & 61 \\
\hline CAG & SR & 75 & 79 & 75 & 74 & 75 \\
\hline & SE & 74 & 75 & 73 & 72 & 72 \\
\hline CC & SR & 59 & 60 & 61 & 60 & 56 \\
\hline & SE & 65 & 70 & 73 & 72 & 72 \\
\hline ASC & SR & 56 & 58 & 59 & 57 & 57 \\
\hline & SE & 70 & 70 & 68 & 68 & 68 \\
\hline
\end{tabular}


Anexo XVI - Dados de ANSP do período basal nas sessões repouso (SR) e exercício (SE)

Grupo Controle (CT)

\begin{tabular}{|c|c|c|c|c|c|c|}
\hline voluntário & sessão & minuto 1 & minuto 2 & minuto 3 & minuto 4 & minuto 5 \\
\hline \multirow[t]{2}{*}{ FCS } & SR & & & & & \\
\hline & SE & & & & & \\
\hline \multirow[t]{2}{*}{$\mathrm{RS}$} & SR & & & & & \\
\hline & $\mathrm{SE}$ & & & & & \\
\hline \multirow[t]{2}{*}{ MGB } & SR & & & & & \\
\hline & SE & & & & & \\
\hline \multirow[t]{2}{*}{ MMC } & SR & 26 & 31 & 29 & 29 & 37 \\
\hline & SE & 21 & 22 & 23 & 22 & 23 \\
\hline \multirow[t]{2}{*}{ POS } & SR & 39 & 38 & 34 & 32 & 36 \\
\hline & $\mathrm{SE}$ & 36 & 22 & 24 & 24 & 23 \\
\hline \multirow[t]{2}{*}{ MARO } & SR & 37 & 32 & & 30 & 46 \\
\hline & $\mathrm{SE}$ & 25 & 25 & 24 & 25 & 24 \\
\hline \multirow[t]{2}{*}{ EJGV } & SR & 45 & & 30 & 35 & 30 \\
\hline & SE & 27 & 24 & 25 & 27 & 23 \\
\hline \multirow[t]{2}{*}{ LMS } & SR & 35 & 38 & 35 & 37 & 33 \\
\hline & $\mathrm{SE}$ & 24 & 24 & 28 & 26 & 21 \\
\hline \multirow[t]{2}{*}{ MUN } & SR & 33 & 35 & 40 & 35 & 35 \\
\hline & $\mathrm{SE}$ & 33 & 30 & 29 & 32 & 30 \\
\hline \multirow[t]{2}{*}{ FSP } & SR & 32 & 35 & 36 & 32 & 31 \\
\hline & SE & 31 & 32 & 33 & 33 & 31 \\
\hline \multirow[t]{2}{*}{ NPB } & SR & 30 & 32 & 37 & 39 & 30 \\
\hline & $\mathrm{SE}$ & 32 & 30 & 35 & 27 & 34 \\
\hline \multirow[t]{2}{*}{ MI } & SR & & & & & \\
\hline & $\mathrm{SE}$ & & & & & \\
\hline
\end{tabular}


Anexo XVII - Dados de ANSP do período basal nas sessões repouso (SR) e exercício (SE)

Grupo DRC

\begin{tabular}{|c|c|c|c|c|c|c|}
\hline voluntário & sessão & minuto 1 & minuto 2 & minuto 3 & minuto 4 & minuto 5 \\
\hline NCMF & SR & 33 & 35 & 37 & 33 & 30 \\
\hline & SE & 31 & 28 & 29 & 26 & 29 \\
\hline MRP & SR & 38 & 34 & 37 & 36 & 33 \\
\hline & SE & & & 27 & 31 & 26 \\
\hline ELJ & SR & 37 & 39 & 36 & 38 & 38 \\
\hline & SE & 33 & 33 & 32 & 34 & 32 \\
\hline ERS & SR & 38 & 38 & 44 & 40 & 39 \\
\hline & SE & 32 & 31 & 34 & 33 & 33 \\
\hline ACM & SR & 35 & 34 & 33 & 32 & 34 \\
\hline & SE & 26 & 27 & 28 & 28 & 29 \\
\hline LC & SR & 36 & 37 & 34 & & 39 \\
\hline & SE & 32 & 28 & 32 & 30 & 34 \\
\hline CAG & SR & 30 & 31 & 29 & 29 & 27 \\
\hline & SE & & & & & \\
\hline CC & SR & 37 & 39 & 42 & 41 & 40 \\
\hline & SE & 31 & 31 & 30 & 31 & 31 \\
\hline ASC & SR & 49 & 46 & 45 & 48 & 45 \\
\hline & SE & 37 & 39 & 40 & 40 & 39 \\
\hline
\end{tabular}


Anexo XVIII - Dados de FSA do período basal nas sessões repouso (SR) e exercício (SE)

Grupo Controle (CT)

\begin{tabular}{|c|c|c|c|c|c|c|}
\hline voluntário & sessão & minuto 1 & minuto 2 & minuto 3 & minuto 4 & minuto 5 \\
\hline FCS & SR & 2,0 & 2,2 & 1,7 & 1,5 & 1,1 \\
\hline & SE & 2,5 & 2,8 & 2,0 & 2,1 & 3,1 \\
\hline RS & SR & 1,7 & 1,7 & 1,7 & 1,8 & 1,6 \\
\hline & SE & 1,9 & 2,0 & 2,2 & 1,7 & 1,9 \\
\hline MGB & SR & 2,9 & 3,4 & 4,0 & 3,9 & 3,6 \\
\hline & SE & 4,2 & 3,2 & 4,5 & 3,8 & 3,4 \\
\hline MMC & SR & 0,9 & 1,0 & 1,4 & 1,2 & 1,4 \\
\hline & SE & 1,5 & 1,7 & 2,2 & 1,7 & 1,8 \\
\hline POS & SR & & & & & \\
\hline & SE & 1,2 & 1,3 & 1,3 & 1,28 & 1,3 \\
\hline MARO & SR & 1,3 & 1,5 & 1,3 & 1,7 & 1,6 \\
\hline & SE & & & & & \\
\hline EJGV & SR & & 1,6 & & & \\
\hline & SE & & & & & \\
\hline LMS & SR & & & & & \\
\hline & SE & 2,0 & 2,2 & 4,51 & 2,6 & 2,2 \\
\hline MUN & SR & 2,0 & 2,4 & 2,6 & 2,0 & 2,1 \\
\hline & SE & 3,9 & & 6,5 & 4,0 & 4,1 \\
\hline FSP & SR & 3,1 & 3,1 & 2,6 & 3,6 & 3,8 \\
\hline & SE & 2,3 & & 2,5 & 2,6 & 2,6 \\
\hline NPB & SR & 3,2 & 3,7 & 4,1 & 4,2 & 3,9 \\
\hline & SE & 2,0 & & 5,0 & 2,4 & 2,9 \\
\hline MI & SR & 1,1 & 1,0 & 1,0 & 1,8 & 1,0 \\
\hline & SE & 2,6 & 3,1 & 3,8 & 3,2 & 2,6 \\
\hline
\end{tabular}


Anexo XIX - Dados de FSA do período basal nas sessões repouso (SR) e exercício (SE)

Grupo DRC

\begin{tabular}{|c|c|c|c|c|c|c|}
\hline voluntário & sessão & minuto 1 & minuto 2 & minuto 3 & minuto 4 & minuto 5 \\
\hline NCMF & SR & 2,9 & 3,4 & 3,1 & 3,2 & 3,3 \\
\hline & SE & 4,8 & 4,9 & 4,9 & 4,6 & 4,8 \\
\hline MRP & SR & 1,0 & 1,1 & 1,5 & 1,2 & 1,4 \\
\hline & SE & 1,0 & 1,2 & 1,2 & 1,4 & 1,5 \\
\hline ELJ & SR & 2,3 & 1,9 & 3,4 & 2,8 & 2,3 \\
\hline & SE & 5,4 & 5,7 & 4,5 & 4,9 & 4,6 \\
\hline ERS & SR & 1,7 & 1,7 & 1,5 & 1,7 & 1,5 \\
\hline & SE & 2,1 & 1,9 & 1,9 & 1,7 & 2,1 \\
\hline ACM & SR & 1,3 & 1,6 & 1,8 & 1,5 & 1,6 \\
\hline & SE & & & & & \\
\hline LC & SR & 2,3 & 1,7 & 2,6 & 2,7 & 2,5 \\
\hline & SE & 2,9 & 2,6 & 2,6 & 2,8 & 2,9 \\
\hline CAG & SR & 2,8 & 2,6 & 2,3 & 2,5 & 2,4 \\
\hline & SE & & & & & \\
\hline CC & SR & 2,7 & 3,3 & 3,1 & 2,7 & 2,5 \\
\hline & SE & 3,4 & 3,8 & 3,0 & 3,0 & 3,4 \\
\hline ASC & SR & 1,3 & 1,3 & 1,2 & 1,4 & 1,1 \\
\hline & SE & 3,0 & 2,8 & 3,0 & 3,0 & 2,8 \\
\hline
\end{tabular}


Anexo XX - Dados de RVP do período basal nas sessões repouso (SR) e exercício (SE)

Grupo Controle (CT)

\begin{tabular}{|c|c|c|c|c|c|c|}
\hline voluntário & sessão & minuto 1 & minuto 2 & minuto 3 & minuto 4 & minuto 5 \\
\hline FCS & SR & 55 & 40 & 69 & 74 & 73 \\
\hline & SE & 37 & 32 & 48 & 42 & 28 \\
\hline RS & SR & 49 & 51 & 55 & 43 & 58 \\
\hline & SE & 40 & 39 & 33 & 41 & 37 \\
\hline MGB & SR & 34 & 29 & 24 & 24 & 26 \\
\hline & SE & 18 & 29 & 19 & 23 & 24 \\
\hline MMC & SR & & & & & \\
\hline & SE & & & & 47 & \\
\hline POS & SR & & & & & \\
\hline & SE & & & & & \\
\hline MARO & SR & 75 & 63 & 80 & 57 & 63 \\
\hline & SE & & & & & \\
\hline EJGV & SR & & & 58 & & \\
\hline & SE & & & & & \\
\hline LMS & SR & & & & & \\
\hline & SE & 51 & 40 & 21 & 37 & 41 \\
\hline MUN & SR & 46 & 40 & 35 & 50 & 44 \\
\hline & SE & 25 & & 12 & 20 & 20 \\
\hline FSP & SR & 30 & 27 & 35 & 26 & 25 \\
\hline & SE & 33 & & 35 & 29 & 29 \\
\hline NPB & SR & 30 & 25 & 23 & 21 & 33 \\
\hline & SE & 36 & & 19 & 41 & 26 \\
\hline MI & SR & 81 & 97 & 90 & 53 & 96 \\
\hline & SE & 39 & 33 & 26 & 32 & 37 \\
\hline & & & & & \\
\hline
\end{tabular}


Anexo XXI - Dados de RVP do período basal nas sessões repouso (SR) e exercício (SE)

Grupo DRC

\begin{tabular}{|c|c|c|c|c|c|c|}
\hline voluntário & sessão & minuto 1 & minuto 2 & minuto 3 & minuto 4 & minuto 5 \\
\hline NCMF & SR & 35 & 30 & 35 & 34 & 32 \\
\hline & SE & 24 & 23 & 23 & 25 & 24 \\
\hline MRP & SR & 126 & 117 & 94 & 120 & 106 \\
\hline & SE & 122 & 102 & 108 & 97 & 91 \\
\hline ELJ & SR & 47 & 58 & 42 & 39 & 46 \\
\hline & SE & 21 & 18 & 21 & 22 & 23 \\
\hline ERS & SR & 61 & 58 & 67 & 58 & 60 \\
\hline & SE & & 55 & 50 & 56 & 45 \\
\hline ACM & SR & 85 & 71 & 58 & 67 & 69 \\
\hline & SE & & & & & \\
\hline LC & SR & 42 & 58 & 42 & 36 & 40 \\
\hline & SE & 30 & 29 & 32 & 28 & 30 \\
\hline CAG & SR & 46 & 41 & 44 & 40 & 44 \\
\hline & SE & & & & & \\
\hline CC & SR & 37 & 31 & 30 & 34 & 38 \\
\hline & SE & 26 & 20 & 37 & 31 & 29 \\
\hline ASC & SR & 88 & 81 & 86 & 75 & 90 \\
\hline & SE & 34 & 36 & 32 & 33 & 36 \\
\hline
\end{tabular}


Anexo XXII - Médias de PAS durante a manobra excitatória com handgrip nas sessões repouso (SR) e exercício (SE)

Grupo Controle (CT)

\begin{tabular}{|c|c|c|c|c|c|}
\hline voluntário & sessão & pré-HG & HG30\% & oclusão & Recuperação \\
\hline FCS & SR & 142 & 152 & 137 & 135 \\
\hline & SE & 139 & 170 & 156 & 141 \\
\hline RS & SR & 129 & 145 & 137 & 122 \\
\hline & SE & 123 & 133 & 134 & 113 \\
\hline MGB & SR & 149 & 170 & 165 & 135 \\
\hline & SE & 131 & 147 & 153 & 132 \\
\hline MMC & SR & 159 & 175 & 176 & 156 \\
\hline & SE & 131 & 146 & 142 & 131 \\
\hline POS & SR & 168 & 172 & 175 & 159 \\
\hline & SE & 170 & 174 & 175 & 163 \\
\hline MARO & SR & 164 & 177 & 162 & 156 \\
\hline & SE & 164 & 183 & 158 & 146 \\
\hline EJGV & SR & 157 & 164 & 144 & 155 \\
\hline & SE & 137 & 147 & 143 & 137 \\
\hline LMS & SR & 168 & 178 & 164 & 168 \\
\hline & SE & 159 & 181 & 178 & 159 \\
\hline MUN & SR & 156 & 166 & 174 & 153 \\
\hline & SE & 155 & 180 & 158 & 146 \\
\hline FSP & SR & 156 & 177 & 177 & 150 \\
\hline & SE & 126 & 147 & 145 & 132 \\
\hline NPB & SR & 169 & 174 & 177 & 164 \\
\hline & SE & 152 & 175 & 165 & 146 \\
\hline MI & SR & 159 & 168 & 157 & 155 \\
\hline & SE & & & & \\
\hline & & & & & \\
\hline
\end{tabular}


Anexo XXIII - Médias de PAS durante a manobra excitatória com handgrip nas sessões repouso (SR) e exercício (SE)

Grupo DRC

\begin{tabular}{|c|c|c|c|c|c|}
\hline voluntário & sessão & pré-HG & HG30\% & oclusão & recuperação \\
\hline NCMF & SR & 158 & 157 & 157 & 158 \\
\hline & SE & 163 & 171 & 162 & 155 \\
\hline MRP & SR & 194 & 197 & 194 & 197 \\
\hline & SE & 197 & 196 & 197 & 196 \\
\hline ELJ & SR & 174 & 184 & 175 & 173 \\
\hline & SE & 172 & 187 & 184 & 173 \\
\hline ERS & SR & 170 & 182 & 178 & 175 \\
\hline & SE & 167 & 177 & 177 & 170 \\
\hline ACM & SR & 167 & 167 & 168 & 161 \\
\hline & SE & 136 & 147 & 148 & 129 \\
\hline LC & SR & 143 & 156 & 157 & 140 \\
\hline & SE & 114 & 123 & 120 & 114 \\
\hline CAG & SR & 156 & 173 & 153 & 146 \\
\hline & SE & 140 & 165 & 139 & 140 \\
\hline CC & SR & 170 & 187 & 185 & 163 \\
\hline & SE & 141 & 151 & 150 & 146 \\
\hline ASC & SR & 149 & 170 & 166 & 149 \\
\hline & SE & 143 & 166 & 157 & 141 \\
\hline
\end{tabular}


Anexo XXIV- Médias de PAD durante a manobra excitatória com handgrip nas sessões repouso (SR) e exercício (SE)

Grupo Controle (CT)

\begin{tabular}{|c|c|c|c|c|c|}
\hline voluntário & sessão & pré-HG & HG30\% & oclusão & recuperação \\
\hline FCS & SR & 76 & 82 & 78 & 74 \\
\hline & SE & 74 & 83 & 84 & 78 \\
\hline RS & SR & 68 & 73 & 74 & 65 \\
\hline & SE & 69 & 69 & 67 & 64 \\
\hline MGB & SR & 73 & 102 & 89 & 78 \\
\hline & SE & 69 & 81 & 77 & 65 \\
\hline MMC & SR & 89 & 106 & 88 & 69 \\
\hline & SE & 64 & 72 & 62 & 64 \\
\hline POS & SR & 79 & 89 & 84 & 82 \\
\hline & SE & 80 & 94 & 96 & 85 \\
\hline MARO & SR & 80 & 93 & 75 & 76 \\
\hline & SE & 75 & 88 & 71 & 66 \\
\hline EJGV & SR & 74 & 93 & 77 & 77 \\
\hline & SE & 72 & 73 & 89 & 72 \\
\hline LMS & SR & 76 & 88 & 100 & 74 \\
\hline & SE & 80 & 119 & 83 & 81 \\
\hline MUN & SR & 71 & 89 & 99 & 78 \\
\hline & SE & 76 & 107 & 99 & 80 \\
\hline FSP & SR & 70 & 89 & 84 & 75 \\
\hline & SE & 58 & 68 & 69 & 59 \\
\hline NPB & SR & 81 & 97 & 88 & 81 \\
\hline & SE & 66 & 116 & 73 & 67 \\
\hline MI & SR & 82 & 85 & 87 & 82 \\
\hline & SE & & & & \\
\hline & & & & & \\
\hline
\end{tabular}


Anexo XXV - Médias de PAD durante a manobra excitatória com handgrip nas sessões repouso (SR) e exercício (SE)

Grupo DRC

\begin{tabular}{|c|c|c|c|c|c|}
\hline voluntário & sessão & pré-HG & HG30\% & oclusão & recuperação \\
\hline NCMF & SR & 95 & 92 & 95 & 98 \\
\hline & SE & 94 & 92 & 93 & 88 \\
\hline MRP & SR & 119 & 110 & 109 & 123 \\
\hline & SE & 113 & 114 & 127 & 112 \\
\hline ELJ & SR & 103 & 122 & 106 & 98 \\
\hline & SE & 98 & 130 & 108 & 97 \\
\hline ERS & SR & 96 & 118 & 90 & 81 \\
\hline & SE & 91 & 93 & 91 & 91 \\
\hline ACM & SR & 91 & 93 & 87 & 90 \\
\hline & SE & 66 & 89 & 73 & 68 \\
\hline LC & SR & 80 & 89 & 84 & 77 \\
\hline & SE & 61 & 67 & 66 & 69 \\
\hline CAG & SR & 88 & 101 & 92 & 87 \\
\hline & SE & 84 & 93 & 87 & 84 \\
\hline CC & SR & 76 & 106 & 95 & 75 \\
\hline & SE & 70 & 85 & 79 & 77 \\
\hline ASC & SR & 91 & 107 & 100 & 91 \\
\hline & SE & 88 & 108 & 98 & 85 \\
\hline
\end{tabular}


Anexo XXVI - Médias de PAM durante a manobra excitatória com handgrip nas sessões repouso (SR) e exercício (SE)

Grupo Controle (CT)

\begin{tabular}{|c|c|c|c|c|c|}
\hline voluntário & sessão & pré-HG & HG30\% & oclusão & recuperação \\
\hline \multirow[t]{2}{*}{ FCS } & SR & 101 & 107 & 94 & 91 \\
\hline & SE & 98 & 105 & 112 & 101 \\
\hline \multirow[t]{2}{*}{$\mathrm{RS}$} & SR & 87 & 86 & 91 & 82 \\
\hline & $\mathrm{SE}$ & 86 & 93 & 80 & 77 \\
\hline \multirow[t]{2}{*}{ MGB } & SR & 97 & 120 & 111 & 93 \\
\hline & $\mathrm{SE}$ & 88 & 101 & 98 & 86 \\
\hline \multirow[t]{2}{*}{$\mathrm{MMC}$} & SR & 95 & 118 & 114 & 94 \\
\hline & SE & 81 & 94 & 86 & 89 \\
\hline \multirow[t]{2}{*}{ POS } & SR & 95 & 106 & 101 & 95 \\
\hline & SE & 97 & 111 & 105 & 101 \\
\hline \multirow[t]{2}{*}{ MARO } & SR & 101 & 112 & 94 & 90 \\
\hline & $\mathrm{SE}$ & 97 & 112 & 88 & 88 \\
\hline \multirow[t]{2}{*}{ EJGV } & SR & 96 & 123 & 100 & 95 \\
\hline & SE & 90 & 90 & 110 & 91 \\
\hline \multirow[t]{2}{*}{ LMS } & SR & 101 & 110 & 100 & 98 \\
\hline & $\mathrm{SE}$ & 101 & 126 & 101 & 96 \\
\hline \multirow[t]{2}{*}{ MUN } & SR & 82 & 111 & 122 & 96 \\
\hline & $\mathrm{SE}$ & 93 & 131 & 114 & 96 \\
\hline \multirow[t]{2}{*}{ FSP } & SR & 91 & 109 & 100 & 90 \\
\hline & SE & 74 & 85 & 80 & 81 \\
\hline \multirow[t]{2}{*}{ NPB } & SR & 104 & 114 & 108 & 96 \\
\hline & SE & 93 & 127 & 98 & 77 \\
\hline \multirow[t]{2}{*}{$\mathrm{MI}$} & SR & 99 & 102 & 99 & 96 \\
\hline & $\mathrm{SE}$ & & & & \\
\hline
\end{tabular}


Anexo XXVII - Médias de PAM durante a manobra excitatória com handgrip nas

sessões repouso (SR) e exercício (SE)

Grupo DRC

\begin{tabular}{|c|c|c|c|c|c|}
\hline voluntário & sessão & pré-HG & HG30\% & oclusão & recuperação \\
\hline NCMF & SR & 112 & 115 & 116 & 112 \\
\hline & SE & 111 & 113 & 111 & 107 \\
\hline MRP & SR & 155 & 153 & 152 & 156 \\
\hline & SE & 156 & 129 & 127 & 124 \\
\hline ELJ & SR & 117 & 132 & 128 & 118 \\
\hline & SE & 113 & 132 & 124 & 114 \\
\hline ERS & SR & 117 & 142 & 113 & 111 \\
\hline & SE & 112 & 113 & 110 & 109 \\
\hline ACM & SR & 106 & 107 & 102 & 101 \\
\hline & SE & 93 & 114 & 101 & 90 \\
\hline LC & SR & 101 & 111 & 105 & 101 \\
\hline & SE & 81 & 84 & 77 & 79 \\
\hline CAG & SR & 106 & 117 & 108 & 105 \\
\hline & SE & 97 & 106 & 97 & 101 \\
\hline CC & SR & 96 & 122 & 110 & 95 \\
\hline & SE & 90 & 103 & 88 & 83 \\
\hline ASC & SR & 105 & 122 & 113 & 104 \\
\hline & SE & 104 & 125 & 116 & 102 \\
\hline
\end{tabular}


Anexo XXVIII - Médias de FC durante a manobra excitatória com handgrip nas sessões repouso (SR) e exercício (SE)

Grupo Controle (CT)

\begin{tabular}{|c|c|c|c|c|c|}
\hline voluntário & sessão & pré-HG & HG30\% & oclusão & recuperação \\
\hline \multirow[t]{2}{*}{ FCS } & SR & 56 & 62 & 59 & 58 \\
\hline & $\mathrm{SE}$ & 57 & 66 & 60 & 57 \\
\hline \multirow[t]{2}{*}{$\mathrm{RS}$} & SR & 72 & 75 & 72 & 76 \\
\hline & $\mathrm{SE}$ & 67 & 70 & 67 & 68 \\
\hline \multirow[t]{2}{*}{ MGB } & SR & 59 & 70 & 55 & 60 \\
\hline & $\mathrm{SE}$ & 66 & 72 & 67 & 66 \\
\hline \multirow[t]{2}{*}{ MMC } & SR & 74 & 81 & 67 & 76 \\
\hline & $\mathrm{SE}$ & 75 & 79 & 76 & 76 \\
\hline \multirow[t]{2}{*}{ POS } & SR & 55 & 58 & 57 & 56 \\
\hline & $\mathrm{SE}$ & 54 & 61 & & \\
\hline \multirow[t]{2}{*}{ MARO } & $\mathrm{SR}$ & 69 & 76 & 66 & 68 \\
\hline & $\mathrm{SE}$ & 64 & 73 & 63 & 70 \\
\hline \multirow[t]{2}{*}{ EJGV } & SR & 67 & 80 & 66 & 64 \\
\hline & $\mathrm{SE}$ & 65 & 70 & 63 & 65 \\
\hline \multirow[t]{2}{*}{ LMS } & SR & 54 & 63 & 57 & 54 \\
\hline & $\mathrm{SE}$ & & & & \\
\hline \multirow[t]{2}{*}{ MUN } & SR & 68 & 71 & 71 & 69 \\
\hline & $\mathrm{SE}$ & 72 & 84 & 78 & 74 \\
\hline \multirow[t]{2}{*}{ FSP } & SR & 77 & 90 & 80 & 80 \\
\hline & $\mathrm{SE}$ & 74 & 77 & 71 & 72 \\
\hline \multirow[t]{2}{*}{ NPB } & SR & 65 & 73 & 68 & 67 \\
\hline & SE & 57 & 70 & 57 & 56 \\
\hline \multirow[t]{2}{*}{ MI } & SR & 75 & 76 & 78 & 77 \\
\hline & $\mathrm{SE}$ & & & & \\
\hline
\end{tabular}


Anexo XXIX - Médias de FC durante a manobra excitatória com handgrip nas sessões repouso (SR) e exercício (SE)

Grupo DRC

\begin{tabular}{|c|c|c|c|c|c|}
\hline voluntário & sessão & pré-HG & HG30\% & oclusão & recuperação \\
\hline NCMF & SR & 62 & 62 & 64 & 63 \\
\hline & SE & 62 & 70 & 67 & 66 \\
\hline MRP & SR & 60 & 62 & 64 & 60 \\
\hline & SE & 67 & 68 & 66 & 67 \\
\hline ELJ & SR & 79 & 97 & 87 & 81 \\
\hline & SE & 82 & 95 & 95 & 84 \\
\hline ERS & SR & 54 & 65 & 58 & 55 \\
\hline & SE & 52 & 57 & 58 & 54 \\
\hline ACM & SR & 59 & 59 & 58 & 58 \\
\hline & SE & 61 & 61 & 61 & 64 \\
\hline LC & SR & 58 & 63 & 62 & 60 \\
\hline & SE & 65 & 65 & 66 & 68 \\
\hline CAG & SR & 72 & 81 & 72 & 72 \\
\hline & SE & 72 & 79 & 75 & 71 \\
\hline CC & SR & 59 & 76 & 59 & 60 \\
\hline & SE & 70 & 75 & 69 & 68 \\
\hline ASC & SR & 60 & 61 & 57 & 57 \\
\hline & SE & 70 & 75 & 62 & 66 \\
\hline
\end{tabular}


Anexo XXX - Médias de ANSP durante a manobra excitatória com handgrip nas sessões repouso (SR) e exercício (SE)

Grupo Controle (CT)

\begin{tabular}{|c|c|c|c|c|c|}
\hline voluntário & sessão & pré-HG & HG30\% & oclusão & recuperação \\
\hline FCS & SR & & & & \\
\hline & SE & & & & \\
\hline RS & SR & & & & \\
\hline & SE & & & & \\
\hline MGB & SR & & & & \\
\hline MMC & SE & & & & \\
\hline & SR & 20 & 31 & 26 & 27 \\
\hline POS & SR & 22 & 22 & 23 & 22 \\
\hline & SE & 22 & 28 & 27 & 24 \\
\hline MARO & SR & 31 & 39 & 37 & 36 \\
\hline & SE & 32 & 30 & 28 & 24 \\
\hline EJGV & SR & 31 & 30 & 32 & 30 \\
\hline & SE & 27 & 28 & 32 & 28 \\
\hline LMS & SR & 41 & 46 & 55 & 46 \\
\hline & SE & 26 & 29 & 24 & 27 \\
\hline MUN & SR & 40 & 36 & 36 & 35 \\
\hline & SE & 34 & 43 & 36 & 36 \\
\hline FSP & SR & 35 & 56 & 51 & 45 \\
\hline & SE & 28 & 35 & 31 & 31 \\
\hline NPB & SR & 29 & 32 & 33 & 31 \\
\hline & SE & 34 & 50 & 49 & 35 \\
\hline MI & SR & & & & \\
\hline & SE & & & & \\
\hline & & & & & \\
\hline
\end{tabular}


Anexo XXXI - Médias de ANSP durante a manobra excitatória com handgrip nas sessões repouso (SR) e exercício (SE)

Grupo DRC

\begin{tabular}{|c|c|c|c|c|c|}
\hline voluntário & sessão & pré-HG & HG30\% & oclusão & recuperação \\
\hline NCMF & SR & 37 & 47 & 43 & 36 \\
\hline & SE & 28 & 36 & 33 & 27 \\
\hline MRP & SR & 36 & 44 & 38 & 36 \\
\hline & SE & 33 & 39 & 35 & 32 \\
\hline ELJ & SR & 37 & 47 & 37 & 35 \\
\hline & SE & 31 & 42 & 31 & 31 \\
\hline ERS & SR & 41 & 48 & 40 & 39 \\
\hline & SE & 32 & 40 & 37 & 33 \\
\hline ACM & SR & 35 & 47 & 39 & 36 \\
\hline & SE & 29 & 35 & 31 & 28 \\
\hline LC & SR & 38 & 55 & 40 & 37 \\
\hline & SE & 34 & 45 & 38 & 34 \\
\hline CAG & SR & & & & \\
\hline & SE & & & & \\
\hline CC & SR & 39 & 52 & 42 & 40 \\
\hline & SE & 32 & 37 & 35 & 32 \\
\hline ASC & SR & 46 & 53 & 52 & 47 \\
\hline & SE & 37 & 43 & 38 & 35 \\
\hline
\end{tabular}


Anexo XXXII - Médias de FSA durante a manobra excitatória com handgrip nas sessões repouso (SR) e exercício (SE)

Grupo Controle (CT)

\begin{tabular}{|c|c|c|c|c|c|}
\hline voluntário & sessão & pré-HG & HG30\% & oclusão & recuperação \\
\hline FCS & SR & 2,5 & 3,5 & 2,3 & 2,1 \\
\hline & SE & 3,1 & 4,0 & 5,4 & 2,6 \\
\hline RS & SR & 2,1 & 2,8 & 2,5 & 1,8 \\
\hline & SE & 1,9 & 2,2 & 2,4 & 2,1 \\
\hline MGB & SR & 4,8 & 4,5 & 4,1 & 4,0 \\
\hline & SE & 4,8 & 5,2 & 5,6 & 4,1 \\
\hline MMC & SR & 0,8 & 1,1 & 1,1 & 1,4 \\
\hline & SE & 2,0 & 2,1 & 2,3 & 1,3 \\
\hline POS & SR & & & & \\
\hline & SE & 1,2 & 1,3 & 2,3 & 1,3 \\
\hline MARO & SR & 1,1 & 1,0 & 0,9 & 1,0 \\
\hline & SE & & & & \\
\hline EJGV & SR & 2,7 & 2,3 & 2,4 & 2,3 \\
\hline & SE & 1,7 & 2,2 & 2,3 & 1,6 \\
\hline LMS & SR & & & & \\
\hline & SE & 2,5 & 1,7 & 2,5 & 2,1 \\
\hline MUN & SR & 2,1 & 2,9 & 2,7 & 2,1 \\
\hline & SE & 4,1 & 4,2 & 4,8 & 4,2 \\
\hline FSP & SR & 2,8 & 4,2 & 4,3 & 3,9 \\
\hline & SE & 3,4 & 2,8 & 3,3 & 2,4 \\
\hline NPB & SR & & & & \\
\hline & SE & & 3,7 & & 4,0 \\
\hline MI & SR & 1,5 & 2,0 & 0,9 & 0,9 \\
\hline & SE & & & & \\
\hline & & & & \\
\hline
\end{tabular}


Anexo XXXIII - Médias de FSA durante a manobra excitatória com handgrip nas sessões repouso (SR) e exercício (SE)

Grupo DRC

\begin{tabular}{|c|c|c|c|c|c|}
\hline voluntário & sessão & pré-HG & HG30\% & oclusão & recuperação \\
\hline NCMF & SR & 3,4 & 3,5 & 3,4 & 3,1 \\
\hline & SE & 4,7 & 5,4 & 5,6 & 5,0 \\
\hline MRP & SR & 1,5 & 1,9 & 1,8 & 1,5 \\
\hline & SE & 1,6 & 1,6 & 1,4 & 1,4 \\
\hline ELJ & SR & 2,7 & 3,3 & 4,3 & 2,6 \\
\hline & SE & 6,2 & 7,5 & 9,6 & 5,7 \\
\hline ERS & SR & 1,5 & 2,2 & 2,1 & 1,7 \\
\hline & SE & 3,3 & 3,3 & 3,7 & 2,4 \\
\hline ACM & SR & 1,9 & 2,3 & 2,5 & 1,8 \\
\hline & SE & & & & \\
\hline LC & SR & 2,7 & 3,4 & 3,2 & 2,5 \\
\hline & SE & 2,9 & 3,2 & 3,2 & 2,7 \\
\hline CAG & SR & 3,0 & 3,8 & 5,4 & 3,3 \\
\hline & SE & & & & \\
\hline CC & SR & 3,5 & 3,4 & 4,1 & 3,3 \\
\hline & SE & 3,3 & 4,3 & 4,6 & 3,1 \\
\hline ASC & SR & 1,3 & 2,0 & 1,9 & 1,3 \\
\hline & SE & 2,5 & 3,7 & 4,1 & 2,6 \\
\hline
\end{tabular}


Anexo XXXIV - Médias de RVP durante a manobra excitatória com handgrip nas sessões repouso (SR) e exercício (SE)

Grupo Controle (CT)

\begin{tabular}{|c|c|c|c|c|c|}
\hline voluntário & sessão & pré-HG & HG30\% & oclusão & recuperação \\
\hline \multirow[t]{2}{*}{ FCS } & SR & 41 & 31 & 42 & 44 \\
\hline & SE & 31 & 26 & 21 & 39 \\
\hline \multirow[t]{2}{*}{$\mathrm{RS}$} & SR & 41 & 31 & 36 & 45 \\
\hline & $\mathrm{SE}$ & 45 & 41 & 33 & 36 \\
\hline \multirow[t]{2}{*}{ MGB } & SR & 20 & 27 & 27 & 23 \\
\hline & $\mathrm{SE}$ & 18 & 20 & 17 & 21 \\
\hline \multirow[t]{2}{*}{$\mathrm{MMC}$} & SR & 111 & 111 & 99 & 68 \\
\hline & SE & 40 & 44 & 37 & 69 \\
\hline \multirow[t]{2}{*}{ POS } & SR & & & & \\
\hline & SE & 53 & 58 & 45 & 27 \\
\hline \multirow[t]{2}{*}{ MARO } & SR & 94 & 112 & 111 & 96 \\
\hline & $\mathrm{SE}$ & & & & \\
\hline \multirow[t]{2}{*}{ EJGV } & SR & 35 & 54 & 43 & 41 \\
\hline & SE & 54 & 42 & 47 & 57 \\
\hline \multirow[t]{2}{*}{ LMS } & SR & & & & \\
\hline & $\mathrm{SE}$ & & & & \\
\hline \multirow[t]{2}{*}{ MUN } & SR & 38 & 38 & 44 & 45 \\
\hline & SE & 23 & 31 & 24 & 23 \\
\hline \multirow[t]{2}{*}{ FSP } & SR & 33 & 26 & 23 & 23 \\
\hline & SE & 21 & 31 & 24 & 34 \\
\hline \multirow[t]{2}{*}{ NPB } & SR & & & & \\
\hline & $\mathrm{SE}$ & & & & \\
\hline \multirow[t]{2}{*}{$\mathrm{MI}$} & SR & 73 & 102 & 117 & 117 \\
\hline & $\mathrm{SE}$ & & & & \\
\hline
\end{tabular}


Anexo XXXV - Médias de RVP durante a manobra excitatória com handgrip nas sessões repouso (SR) e exercício (SE)

Grupo DRC

\begin{tabular}{|c|c|c|c|c|c|}
\hline voluntário & sessão & pré-HG & HG30\% & oclusão & recuperação \\
\hline NCMF & SR & 33 & 33 & 34 & 36 \\
\hline & SE & 24 & 21 & 20 & 21 \\
\hline MRP & SR & 106 & 82 & 83 & 103 \\
\hline & SE & 95 & 82 & 89 & 85 \\
\hline ELJ & SR & 43 & 40 & 30 & 46 \\
\hline & SE & 18 & 18 & 13 & 20 \\
\hline ERS & SR & 78 & 63 & 54 & 65 \\
\hline & SE & 33 & 34 & 30 & 45 \\
\hline ACM & SR & & & & \\
\hline & SE & & & & \\
\hline LC & SR & 38 & 33 & 33 & 40 \\
\hline & SE & 28 & 26 & 24 & 29 \\
\hline CAG & SR & & & & \\
\hline & SE & & & & \\
\hline CC & SR & 27 & 35 & 27 & 29 \\
\hline & SE & 27 & 24 & 19 & 27 \\
\hline ASC & SR & 80 & 60 & 60 & 78 \\
\hline & SE & 41 & 34 & 28 & 40 \\
\hline
\end{tabular}


Anexo XXXVI - Valores de proteinúria em g / L (24h) pré e pós sessões controle (SC) e exercício (SE)

\begin{tabular}{|c|c|c|c|c|}
\hline voluntário & pré-SR & pós-SR & pré-SE & pós-SE \\
\hline NCMF & 0,027 & 0,05 & 0,03 & 0,08 \\
\hline MRP & 0,146 & 0,46 & 0,15 & 0,3 \\
\hline ELJ & 0,21 & 0,25 & 0,22 & 0,14 \\
\hline ERS & 0 & 0,22 & 0 & 0,081 \\
\hline ACM & 0,3 & 0,38 & & \\
\hline LCT & 0,35 & 0,13 & 0,22 & 0,16 \\
\hline CAG & 0,19 & 0,14 & 0,18 & \\
\hline CC & 0,75 & 0,73 & 0,7 & 0,5 \\
\hline ASC & 0,56 & & 0,55 & \\
\hline
\end{tabular}




\section{REFERÊNCIAS BIBLIOGRÁFICAS}

1. National Kidney Foundation: K/DOQI - Clinical practice guidelines for chronic kidney disease: evaluation, classification and stratification. Am J Kidney Dis. 2002; 39 (suppl.1): S1-S266.

2. Perico N, Codreanu I, Schieppati A, Remuzzi G. Prevention of progression and remission/regression strategies for chronic renal diseases: can we do better now than five years ago. Kidney Int. 2005; 68 (suppl.98): S21-S24.

3. Nwankwo E, Bello Ak, El Nahas Am. Chronic kidney disease: stemming the global tide. Am J Kidney Dis. 2005; 45(1): 201-208.

4. Bastos MG, Carmo WB, Abrita RR, Almeida EC, Mafra D, Costa DMN, Gonçalves JA, Oliveira A Santos FR Paula RB. Doença renal crônica: problemas e soluções. $J$ Bras Nefrol. 2004; 26(4): 202-215.

5. USRDS: U.S. Renal Data System - Annual Data Report 2008. Incidence and prevalence. In: http://www.usrds.org/adr.htm. Última consulta: 25/07/2009.

6. Coresh J, Selvin E, Stevens LA. Prevalence of chronic kidney disease in the United States. JAMA. 2007; 298 (17): 2038-47.

7. Martin LC, Franco RJS. A doença renal como fator de risco cardiovascular. Arq Bras Cardiol. 2005; 85(6): 432-437.

8. Sarnak MJ, Levey AS, Schoolwerth AC, Coresh J, Culleton B, Hamm L, Mccullough P, Kasiske BL, Kelepouris E, Klag MJ, Parfrey P, Pfeffer M, Raij L, Spinosa DJ, Wilson P. Kidney disease as a risk factor for development of cardiovascular disease: a statement from the American Heart Association councils on kidney in cardiovascular disease, high blood pressure research, clinical cardiology, and epidemiology and prevention. Hypertension 2003; 42:1050-1065. 
9. Knap B, Buturovic-Ponikvar J, Ponikvar R, Bren AF. Regular exercise as a part of treatment for patients with end-stage renal disease. Therap Apher Dial. 2005; 9 (3): 211-213.

10. Heiwe S, Tollbäck A, Clyne N. Twelve weeks of exercise training increases muscle function and walking capacity in elderly predialysis patients and healthy subjects. Nephron. 2001; 88: 48-56.

11. Levendoglu F, Altintepe L, Okudan N, Ugurlu H, Gökbel H, Tonbul Z, Güney I, Türk S. A twelve week exercise program improves the psychological status, quality of life and work capacity in hemodialysis patients. J Nephrol. 2004; 17 (6): 826-832.

12. Roger S, Singh MF. Cardiovascular and musculoskeletal rehabilitation in progressive renal insufficiency. Nephrology. 2002; 7: S71-S72.

13. Clyne N, Ekholm J, Jogestrand T, Lins L, Pehrsson S. Effects of exercising training in predialytic uraemic patients. Nephron. 1991; 59: 84-89.

14. Koufaki P, Nash P, Mercer TH. Reproducibility of Exercise Tolerance in Patients with End-Stage Renal Disease. Arch Phys Med Rehabil. 2001; 82: 1421-1424.

15. Sietsema K, Amato A, Adler S, Brass EP. Exercise capacity as a predictor of survival among ambulatory patients with end-stage renal disease. Kidney Int. 2004; 65: 719-724.

16. Clyne N, Jogestrando T, Lins Le, Pehrsson K, Ekelund LG. Factors limiting physical working capacity in predialytic uraemic patients. Acta Mec Scand. 1987; 222: 183-190.

17. Kouidi EJ. Central and peripheral adaptations to physical training in patients with end-stage renal disease. Sports Med. 2001; 31 (9): 651-665.

18. Tawney K, Tawney P, Kovach J. Disablement and rehabilitation in end-stage renal disease. Semin Dialys. 2003; 16 (6): 447-452. 
19. Painter P. Physical functioning in end-stage renal disease patients: update 2005. Hemodialysis Int. 2005; 9: 218-235.

20. Kimmel P, Peterson R, Weihs K, Simmens S, Alleyne S, Cruz I, Veis JH. Multiple measurements of depression predict mortality in a longitudinal study of chronic hemodialysis outpatients". Kidney Int. 2000; 57: 2093-2098.

21. Kimmel PL. Psychosocial factors in dialysis patients. Kidney Int. 2001; 59: 15991613.

22. Lopes A, Bragg J, Young E, Goodkin D, Mapes D, Combe C, Piera L, Held P, Gillespie B, Port FK. Depression as a predictor of mortality and hospitalization among hemodialysis patients in the United States and Europe. Kidney Int. 2002; 62: 199-207.

23. Goicochea M, Vinuesa SG, Gómez-Campderá F, Luño J. Predictive cardiovascular risk factors in patients with chronic kidney disease. Kidney Int. 2005; 67 (suppl. 93): S35-S38.

24. Vandana M, Gul A, Sarnak MJ. Cardiovascular risk factors in chronic kidney disease. Kidney Int. 2005; 68: 1413-1418.

25. Varela AM, Pecoits Filho RFS. Interações entre a doença cardiovascular e a doença renal crônica. J Bras Nefrol. 2006; 28(3 Supl.2): 22-28.

26. Foley R, Murray A, Li S, Herzog CA, Mcbean AM, Eggers P, Collins AJ. Chronic kidney disease and the risk for cardiovascular disease, renal replacement, and death in the United States medicare population, 1998 to 1999. J Am Soc Nephrol. 2005; 16: 489495.

27. Zoccali C, Mallamaci F, Tripepi G. Traditional and emerging cardiovascular risk factors in end-stage renal disease. Kidney Int. 2003; 63 (suppl. 85): S105-S110. 
28. Neumann J, Ligtenberg G, Klein I, Koomans HA, Blankestijn PJ. Sympathetic hyperactivity in chronic kidney disease: pathogenesis, clinical relevance and treatment. Kidney Int. 2004; 65: 1568-1576.

29. Park J, Campese VM, Middlekauff HR. Exercise pressor reflex in humans with endstage renal disease. Am J Physiol Regul Integr Comp Physiol. 2008; 295: 1188-1194.

30. Park J, Campese VM, Nobakht N, Midđlekauff HR. Differential distribution of muscle and skin sympathetic nerve activity in patients with end-stage renal disease. $J$ Appl Physiol. 2008; 105: 1873-1876.

31. Klein IHHT, Ligtenberg G, Neumann J, Oey PL, Koomans HA, Blankestijn PJ. Sympathetic nerve activity is inappropriately increased in chronic kidney disease. $J \mathrm{Am}$ Soc Nephrol. 2003; 14: 3239-3244.

32. Joles JA, Koomans HA. Causes and consequences of increased sympathetic activity in renal disease. Hypertension. 2004; 43: 699-706.

33. Hausberg M, Kosch M, Harmelink P, Barenbrock M, Hohage H, Kisters K, Dietl KH, Rahn KH. Sympathetic nerve activity in end-stage renal disease. Circulation. 2002; 106: 1974-1979.

34. Grassi G, Seravalle G, Arenare F, Buccianti G, Furiani S, Ilardo V, Bolla G, Mancia G. Behaviour of regional adrenergic outflow in mild-to-moderate renal failure. J Hypert. 2009; 27:562-566.

35. Tinucci T, Abrahão SB, Mion Jr D. Mild chronic renal insufficiency induces sympathetic overactivity. J Human Hypert. 2001; 15: 401-406.

36. Julius S. Sympathetic hyperactivity and coronary risk in hypertension. Hypertension. 1993; 21(6, part 2): 886-893. 
37. Irigoyen MC, Consolim-Colombo FM, Krieger EM. Controle cardiovascular: regulação reflexa e papel do sistema nervoso simpatico. Rev Bras Hipertens. 2001; 8(1): 55-62.

38. Taverner D, Craig K, Mackay I, Watson ML. Effects of exercise on renal function in patients with moderate impairment of renal function compared to normal men. Nephron. 1991; 57: 288-292.

39. Copley JB. Resistance training enhances the value of protein restriction in the treatment of chronic kidney disease. Ann Int Med. 2001; 135 (11): 999-1001.

40. Floras JS, Seals DR, Aylward PE, Sinkey C, Thoren P, Mark AL. Postexercise hypotension and sympathoinhibition in borderline hypertensive men. Hypertension. 1986; 14: 28-35.

41. Macdonald JR. Potential causes, mechanisms and implications of post exercise hypotension. J Human Hypert. 2002; 16: 225-236.

42. Cléroux J, Kouame N, Coulombe D, Lacourciere Y. Aftereffects of exercise and systemic hemodynamics in hypertension. Hypertension. 1992; 19: 183-191.

43. Forjaz CLM Matsuidara Y, Rodrigues FB, Nunes N, Negrão CE. Post-exercise changes in blood pressure, heart rate and rate pressure product at different exercise intensities in normotensive humans. Braz J Med Biol Research, 1998; 31(10): 12471255.

44. Halliwill JR, Taylor JA, Eckberg DL. Impaired sympatethic vascular regulations in humans after acute dynamic exercise. J Physiol. 1996; 495(1): 279-288.

45. Romão Jr JE. Doença renal crônica: Definição epidemiologia e classificação. J Bras Nefrol. 2004; 26 (3) Supl 1:1-3.

46. Sesso R, Gordan P. Dados sobre DRC no Brasil. J Bras Nefrol. 2007; 24(1-supl.1): $9-12$. 
47. SBN - Sociedade Brasileira de Nefrologia. In: http://www.sbn.org.br/. Última consulta: 25/07/2009.

48. American College of Sports Medicine - ACSM. Exercise management for persons with chronic diseases and disabilities. 1997, Champaign: Human Kinetics.

49. Levey AS, Eckardt K, Tsukamoto Y, Levin A, Coresh J, Rossert J, Zeeuw D, Hostetter T, Lameire N, Eknoyan G. Definitiơn and classification of kidney disease: a position statement from kidney disease improving global outcomes (KDIGO). Kidney Int. 2005; 67: 2089-2100.

50. Iseki K, Ikemiya Y, Iseki C, Takishita S. Proteinuria and the risk of developing endstage renal disease. Kidney Int. 2003; 63: 1468-74.

51. Atkins RC. The changing patterns of chronic kidney disease: the need to develop strategies for prevention relevant to different regions and countries. Kidney Int. 2005; 68 (suppl.98): S83-S85.

52. Foley RN, Parfrey PS, Sarnak MJ.Cardiovascular disease in chronic renal disease. clinical epidemiology of cardiovascular disease in chronic renal disease. Am J Kidney Dis. 1998; 32: S112-S119.

53. Bastos MG, Carmo WB, Abrita RR, Almeida EC, Mafra D, Costa DMN, Gonçalves JA, Oliveira LA, Santos FR, Paula RB. Doença Renal Crônica: Problemas e Soluções. J Bras Nefrol. 2004; 26(4): 202-215.

54. Converse RL, Jacobsen TN, Toro RD, Jost CMT, Cosentino F, Fouad-Tarazi F, Victor RG. Sympathetic overactivity in patients with chronic renal failure. New Engl J Med. 1992; 327 (27): 1912-1918.

55. Svarstad E, Myking O, Ofstad J, Iversen BM. Effect of light exercise on renal hemodynamics in patients with hypertension and chronic renal disease. Scand J Urol Nephrol. 2002; 36: 464-472. 
56. Painter P, Carlson L, Carey S, Paul SM, Myll J. Physical functioning and health related quality of life changes with exercise training in hemodialysis patients. Am $J$ Kidney Dis. 2000; 35 (3): 482-492.

57. O’hare AM, Tawney K, Bachetti P, Johansen KL. Decreased survival among sedentary patients undergoing dialysis: results from the dialysis morbidity and mortality study wave. Am J Kidney Dis. 2003; 41: 447-454.

58. McArdle WD, Katch FI, Katch VL. Fisiologia do Exercício - Energia, Nutrição e Desempenho Humano. 1996; 4ªed. Rio de Janeiro: Guanabara Koogan S.A.

59. American College of Sports Medicine. ACSM's guidelines for exercise testing and prescription. 2000; 6 ed. Philadelphia: Lippincott Williams \& Wilkins.

60. Martinez-Vea A, Bardají A, Gutierrez C, García C, Peralta C, Marcas L, Oliver JA. Exercise blood pressure, cardiac structure and diastolic function in young normotensive patients with polycystic kidney disease: a Prehypertensive State". Am J Kidney Dis. 2004; 44 (2): 216-223.

61. Forjaz, CLM; Tinucci, T. A medida de pressão arterial no exercício. Rev Bras Hipertens. 2000; 17(1): 79-87.

62. Rowell LB, O'leary DS. "Reflex control of the circulation during exercise: chemoreflexes and mechanoreflexes". J Appl Physiol. 1990; 69 (2): 407-418.

63. Guyton AC, Hall JE. Text Book of Medical Pyisiology.2000; $11^{\text {th }}$ ed. Philadelphia: WB Saunders Company.

64. Williamson JW, Fadel PJ, Mitchel JH. New insights into central cardiovascular control during exercise in humans: a central command update. Exp Physiol. 2005; 91(1): 51-58.

65. Rowell LB. Reflex control of the circulation during exercise". Int J Sports Med. 1992; 13 (suppl.1): S25-S27. 
66. Rowell LB. Neural control of muscle blood flow: importance during dynamic exercise. Clin Exp Pharm Physiol. 1997; 24: 117-125.

67. Poortmans JR. Exercise and renal function. Sports Med. 1984; 1:125-153.

68. Estivi P, Urbino R, Tetta C, Pagano G, Cavallo-Perin P. Urinary protein excretion induced by exercise: effect of a mountain agonistic footrace in healthy subjects. $J$ Sports Med Phys Fitness. 1992; 32: 196-200.

69. Cruz HMM, Cruz J, Castro MCR, Marcondes M. Effect of posture and physical activity on urinary protein excretion by patients with glomerular proteinuria diseases. Braz J Med Biol Res. 1989; 22: 1191-1194.

70. Gerth J, Ott U, Fünfstück R, Bartsch R, Keil E, Schubert K, Hübscher J, Scheucht S, Stein G. The effects of prolonged physical exercise on renal function, electrolyte balance and muscle cell breakdown. Clinic Nephrol. 2002; 57(6): 425-431.

71. Kutner N. How can exercise be incorporated into the routine care of patients on dialysis? Int Urol Nephrol. 2007; 39: 1281-1285.

72. Johansen KL. Exercise in the end-stage renal disease population. J Am Soc Nephrol. 2007; 18: 1845-1854.

73. Pechter U, Maaroos J, Mesikepp S, Veraksits A, Ots M. Regular low-intensity aquatic exercises improves cardio-respiratory functional capacity and reduces proteinuria in chronic renal failure patients. Nephrol Dial Transplant. 2003; 18: 624625 .

74. Kohzuki M, Kamimoto M, Wu XM, Xu H, Kawamura T, Mori N, Nagasaka M, Kurosawa H, Minami N, Kanazawa M, Saito T, Yoshida K. Renal protective effects of chronic exercises and antihypertensive therapy in hypertensive rats with chronic renal failure. J Hypertension. 2001; 19: 1877-1882. 
75. Miller BW, Cress CL, Johnson M, Nichols DH, Schnitzler MA. Exercise during hemodialysis decreases the use of antihypertensive medications. Am J Kidney Dis 2002, 39(4): 828-833.

76. Boyce M, Robergs RA, Avasthi P, Roldan C, Foster A, Montner P, Stark D, Nelson C. Exercise training by individuals with predialysis renal failure: cardiorespiratory endurance, hypertension and renal function. Am J Kidney Dis. 1997; 30(2): 180-192.

77. Mansur HN, Lima JRP, Novaes JS. Nível de atividade física e risco cardiovascular de pacientes com doença renal crônica. J Bras Nefrol. 2007; 29(4):209-4.

78. Joint National High Blood Pressure Education Program Coordinating Committee. The Seventh Report of the Joint National Committee on Prevention, Detection, Evaluation, and Treatment of High Blood Pressure. Hypertension. 2003; 42: 1206.

79. Anderson EA, Mark AL. Microneurographic measurements of sympathetic nerve activity in humans. In: Schneiderman N, Weiss SM, Kaufmann PG. Handbook of research methods in cardiovascular behavioral medicine. Plenum Publishing Corporation. 1989: 112-119.

80. Forjaz CLM, Rezk CC, Santaella DF, Maranhão G, Souza M, Nunes N, Nery S, Bisquolo VAF, Rondon MUPB, Mion Jr D, Negrão CD. Hipotensão pós-exercício: características, determinantes e mecanismos. Rev Soc Cardiol. 2000; 10(3-supl.A): 1624.

81. Macdonald JR, Macdougall JD, Hogben CD. The effects of exercise intensity on post exercise hypotension. J Human Hypert. 1999; 13:527-531.

82. Wilcox R, Benett T, Brown A, Macdonald I. Is exercise good for high blood pressure? Br Med J 1982; 285:767-769.

83. Pescatello L, Fargo A, Leach C, Scherzer H. Short-term effect of dynamic exercise on arterial blood pressure. Circulation. 1991; 83: 1557-1561. 
84. Rondon MUPB, Alves MJNN, Braga AMF, Teixeira OTUN, Barreto ACP, Krieger EM, Negrão CD. Postexercise blood pressure reduction in elderly hypertensive patients. J Am Coll Cardiol. 2002; 39(4): 676-682.

85. Melo CM, Alencar Filho A, Tinucci T, Mion Jr D, Forjaz CLM. Postexercise hypotension induced by low-intensity resistance exercise in hypertensive women receiving captopril. Blood Press Monit. 2006; 11: 183-189.

86. Oneda B. Efeitos da terapia de reposição estrogênica nas respostas hemodinâmicas e neurais ao exercício físico agudo em mulheres no período pós-menopausa [tese]. São Paulo: Faculdade de Medicina USP; 2006.

87. Piepoli M., Isea J , Pannarale G , Adamopoulost S, Sleight P, Coats AJS. Load dependence of changes in forearm and peripheral vascular resistance after acute leg exercise in man. $J$ Physiol. 1994; 478(2): 357-362.

88. Wallace JP, Bogle PG, King B, Krasnoff J, Jastremski CA. The magnitude and duration of ambulatory blood pressure reduction following acute exercise. J Human Hypert. 1999; 13: 361-366.

89. Forjaz CLM, Cardoso Jr CG, Rezk CC, Santaella DF, Tinucci T. Postexercise hypotension and hemodynamics: the role of exercise intensity. J Sports Med Phys Fitness. 2004; 44:54-62.

90. Pescatello LS, Franklin BA, Fagard R, Farquhar W, Kelley G, Ray CA. American College of Sports Medicine position stand. Exercise and hypertension. Med. Sci. Sports Exerc. 2004; 36: 533-53.

91. Headley SA, Germain M, Milch C, Buchholz MP, Coughlin MA, Pescatello LS. Immediate blood pressure-lowering effects of aerobic exercise among patients with chronic kidney disease. Nephrol. 2008; 13: 601-606.

92. Eidemak I, Haaber AB, Feldt-Rasmussen B, Kanstrup I, Strandgaard S. Exercise training and the progression of chronic renal failure. Nephron. 1997; 75(1):36-40. 
93. Ichinose M, Saito M, Wada H, Kitano A, Kondo N, Nishiyasu T. Modulation of arterial baroreflex dynamic response during muscle metaboreflex activation in humans. J Physiol. 2002; 544(3): 939-948.

94. Smith SA, Mitchell JH, Garry MG. The mammalian exercise pressor reflex in health and disease. Exp Physiol. 2005; 91(1): 89-102.

95. Bellinghieri G, Savica V, Santoro D. Rethal alterations during exercise. J Renal Nutr. 2008; 18(1): 158-164.

96. Painter, P. Exercise in chronic disease: physiological research needed. Exerc. Sport Sci. Rev. 2008; 36(2): 83-90.

97. Finkelstein FO, Wuerth D, Finkelstein SH. Health related quality of life and the CKD patient: challenges for the nephrology community. Kidney Int. 2009; 76: 946-952.

98. Chen JL, Lerner D, Ruthazer R, Castaneda-Sceppa C, Levey AS. Association of physical activity with mortality in chronic kidney disease. Nephrol. 2008; 21(2):243-52.

99. Painter P, Nelson-Worel JN, Hill M, Thornbery DR, Shelp W, Harrington A, Weinstein AB. Effects of exercise training during hemodialysis. Nephron. 1986, 43(2):87-92.

100. Goldberg AP, Geltman EM, Hagberg JM, Gavin J, Delmez JA, Carney R, Naumowicz A, Oldfield M, Harter H. Therapeutic benefits of exercise training for hemodialyzed patients. Kidney Int. 1983; 24(suppl.16): 303-309.

101. Moinuddin I, Leehey DJ. A Comparison of Aerobic Exercise and Resistance Training in Patients With and Without Chronic Kidney Disease. Adv Chronic Kidney Dis. 2008; 15(1): 83-96. 